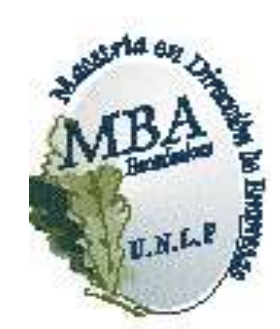

Universidad Nacional de La Plata

Facultad de Ciencias Económicas

MBA - Maestría en Dirección de Empresas

\title{
Satisfacción del Cliente del Servicio de Licencias de Conducir de la Municipalidad de La Plata
}

Trabajo final para optar al título de Magister

Autor: Martín Di Ciano

Director: Gabriela Mollo

La Plata, Diciembre de 2013 


\section{Índice}

1. Planteo del Problema

2. Objetivos de la Investigación __ 2

3. Evaluación del Problema

4. Alcance de la Investigación___ 3

5. Marco Teórico de Referencia ___ 4

5.1 Experiencia internacional y nacional __ 4

5.2. Bases Teóricas___ 7

5.2.1 Marco Jurídico de las Municipalidades __ 7

5.2.2 Excelencia en las organizaciones ___ 9

5.2.3 Calidad__ 11

5.2.4 Calidad Total: $ـ 14$

5.2.5 Expectativas del cliente respecto de la organización ___ 19

5.3 Definición de términos palabras__ 21

6. Metodología de la Investigación __ 22

6.1. Universo y Muestra ___ 22

6.1.1 Universo __ 22

6.1.2 Muestra __ 22

6.2. Tipo de Investigación __ 23

6.3. Técnicas de Recolección de Datos __ 23

6.3.1 Encuestas _ 23

6.3.2 Observación Directa___ 25

6.4. Técnicas de Análisis _ـ 25

7. Resultados de la Investigación___ 27

7.1 Análisis descriptivo de la muestra __ 27

7.2 Frecuencia de utilización del servicio de Licencias de Conducir__ 29

7.3 Dimensión I: Elementos Tangibles: Apariencia de la instalaciones físicas, equipos, personal y materiales de comunicación _ـ 30

7.3.1 Equipos _ 30 
7.3.2 Instalaciones físicas 33

7.3.3 Apariencia física de los empleados 35

7.3.4 Apariencia visual de los elementos materiales de comunicación

7.4 Dimensión II: Confiabilidad. Habilidad para ejecutar el servicio prometido de forma confiable y cuidadosa 39

7.4.1 Los empleados del servicio municipal cumplen lo que prometen 39

7.4.2 Interés que tienen los empleados del servicio municipal por solucionar los problemas 41

7.4.3 Eficacia del servicio de licencias de conducir 43

7.4.4 Tiempo de cumplimiento del trabajo 45

7.4.5 Eficiencia del trabajo del servicio de Licencias de Conducir 47

7.5 Dimensión III: Capacidad de Respuesta - Disposición de los empleados para ayudar al cliente y proporcionar el servicio 49

7.5.1 Nivel de comunicación con los empleados 49

7.5.2 Velocidad del servicio 51

7.5.3 Nivel de disponibilidad de atención 52

7.5.4 Grado de disponibilidad inmediata frente a otras actividades _ 55

7.6 Dimensión IV: Seguridad - Conocimiento y atención mostrados por los empleados y sus habilidades para inspirar credibilidad y confianza.

7.6.1 Confianza que brinda el comportamiento de los empleados 57

7.6.2 Nivel de seguridad que se siente en las transacciones con el servicio de Licencias de Conducir 59

7.6.3 Nivel de amabilidad que muestran los empleados del servicio 61 7.6.4 Grado de conocimiento que tienen los empleados para resolver las inquietudes de los usuarios 63

7.7 Dimensión V: Empatía - Atención individualizada que ofrece la organización a los clientes 64

7.7.1 Nivel de individualización en la atención del servicio 65

7.7.2 Conveniencia de los horarios de trabajo 67

7.7.3 Nivel de personalización en la atención del servicio 69 
7.7.4 Grado de preocupación que tienen los empleados por los intereses del cliente

7.7.5 Grado en que el servicio comprende las necesidades específicas del cliente

7.8 ¿Cuál es la dimensión más importante para el cliente de la Dirección Operativa de Licencias de Conducir? 74

7.9 Calificación global de la percepcion de los usuarios de la Dirección Operativa de Licencias de Conducir 75

7.9 Calificación global de la expectativa de los usuarios de la Dirección Operativa de Licencias de Conducir 75

7.10 Brecha global entre las expectativas y percepciones de los usuarios de la Dirección de Defensa del Consumidor. 76

7.11 Resumen de saldos de respuesta por género 76

7.12 Resumen de saldos de respuesta por edad 78

8. Conclusiones 77

9. Bibliografía 80

10. Referencias y Anexos 82 


\section{Planteo del Problema}

En la actualidad existe un interés creciente por la evaluación de la conducta del sector público en general, y en particular de los municipios, dado su cercanía con la comunidad en su rol de prestador de servicios públicos, de la construcción de las obras que demande el progreso local, de la ordenación del desarrollo de su territorio, de la promoción de la participación comunitaria, el mejoramiento social, cultural y la defensa de los derechos de sus habitantes.

La temática de la Calidad de los Servicios adquiere relevancia toda vez que la población tiene diferentes necesidades y/o requerimientos que deben ser satisfechos a través de la oportuna atención del Estado. Esta presencia estatal y su preocupación en los servicios públicos básicos, proporciona a la ciudadanía confianza en la utilización de los diferentes servicios cuando estos son requeridos, dando además un parámetro de solvencia y oportunidad, frente a la tecnología con la cual se va desarrollando la atención al cliente.

Una de las situaciones más comunes de la institución es que surgen problemas con las personas debido a la falta de comunicación, ya que muchas veces no se escucha al solicitante y por ende existen diversas barreras que impiden que se capte la información correcta, ya que el personal sólo se limita a brindar una opción de solución de la problemática a diversas dudas que posee el cliente, esto representa un serio problema, porque no se brinda un servicio de calidad al cliente y es necesario que el personal posea el conocimiento necesario para tratar con éstos y así ofrecer diferentes soluciones a las expectativas que surgen.

Las organizaciones públicas, como cualquier organización prestadora de servicios, necesita conocer el grado de aceptación de su oferta. Cabe, entonces, preguntarse si los servicios prestados por los municipios alcanzan los valores de calidad requeridos por los usuarios, o si por el contrario existe una diferencia entre la calidad del servicio prestado con el servicio requerido por los vecinos. 


\section{Objetivos de la Investigación}

- Evaluar el nivel de satisfacción de los clientes del servicio de Licencias de Conducir de la Municipalidad de La Plata en relación a:

- La importancia de cada atributo del servicio: en relación a la atención al público, en relación a la infraestructura y equipamiento y en relación a los procesos para la realización de trámites.

- El grado de satisfacción del servicio en general

- Identificar si la calidad del servicio que se presta en la Dirección Operativa de Licencias de Conducir de la Municipalidad de La Plata cumple con las expectativas de los usuarios.

\section{Evaluación del Problema}

Mejorar la calidad en el servicio al cliente implica superar el trabajo con respecto a lo que antes se hacía, para satisfacer las necesidades del cliente, sin olvidarse que el éxito de la mayoría de las instituciones, actualmente, es conocerlos desde el mismo instante en que éstos se ponen en contacto con la institución.

Este nuevo paradigma es el que enfrentan los municipios con ciudadanos más informados de sus derechos y de los deberes de la organización municipal para con la comunidad, así como también con un marcado interés en la transparencia de las decisiones. Esta nueva realidad enfrenta a las organizaciones municipales con un cliente polifacético, que se encuentra en su comunidad, al interior de su organización y en los niveles superiores de Gobierno.

Estas nuevas condiciones demandan de las organizaciones municipales una mayor capacidad para predecir los resultados, una administración más rigurosa de la información de sus procesos, una capacitación más especializada de sus funcionarios, una mejora sustantiva de la administración de la información al 
interior de la organización y la adopción más formal y comprometida de un estilo de administración.

En este contexto los argumentos que justifican un análisis de calidad en el sector público son diversos. Entre ellos se encuentran, la magnitud de su actividad económica en el agregado de la economía, la ausencia de competencia en gran parte de los servicios públicos provistos, la necesidad de justificar resultados en un contexto presupuestario restrictivo, y por sobre todas las cosas, el impacto de los servicios públicos en el crecimiento económico y el bienestar de la población.

Evaluar la percepción de la calidad de los servicios públicos por parte de sus usuarios, es de vital importancia por varias razones entre las que se pueden mencionar:

- Mandato legal

- Compromiso político

- Reducción de costos

- Satisfacción del usuario

- Mejora de los servicios públicos

- Reducción de reclamos y conflictos

- Estabilidad

Se entiende que este trabajo ayudará a los gobiernos municipales a establecer con más precisión los parámetros para evaluar el nivel de satisfacción de los clientes que solicitan sus servicios. Esta información permitirá detectar y corregir errores en la calidad de los servicios y por lo tanto mejorarlos.

\section{Alcance de la Investigación}

Los resultados que se presentan son el producto de un proyecto de investigación del MBA cuyo título es "la competitividad empresarial y su impacto regional", acreditado en el marco del Programa de Incentivos de la Secretaria de Ciencia y Técnica de la UNLP, con un tronco común que luego se 
divide en cada una de las áreas de interés definidas en conjunto entre el MBA y la Municipalidad de La Plata.

La Investigación se realizó para la Municipalidad de La Plata en las áreas: Licencias de conducir, Obras privadas, Defensa del consumidor, Juzgado de faltas y Recaudaciones y cobranzas. Comprendió el segundo semestre 2012.

\section{Marco Teórico de Referencia}

\subsection{Experiencia internacional y nacional}

La mayoría de los estudios sobre calidad apuntan a la calidad "industrial". En esta rama disciplinar es abundante el volumen de bibliografía que se puede encontrar. Sin embargo cuando de calidad aplicada a los servicios se trata las referencias bibliográficas son cada vez menores. Este tipo de estudios son un fenómeno de reciente interés (aunque cada vez más amplio). Este nuevo interés "viene enmarcado sobre todo por el profundo y rápido cambio que se está produciendo en la administración pública y en la relación que establece con los ciudadanos. Hoy los ciudadanos han dejado de ser los "administrados", más o menos conformes con los servicios que les "daba" la administración, y han pasado a ser ciudadanos-clientes, que saben que pagan $y$, en consecuencia, exigen a cambio servicios de calidad $\mathrm{y}$, además, de calidad entendida desde su punto de vista. Así, la administración se convierte en proveedora de servicios para un "mercado" de ciudadanos que le demanda calidad." (Gadea, 2000).

Es importante resaltar que los servicios poseen ciertas características diferenciales a los bienes industriales. Estas diferencias son cruciales al momento de pensar programas de mejora de la calidad. Las mismas son: Intangibilidad, Heterogeneidad e inseparabilidad. Otro aspecto significativo es que los servicios públicos tienen algunos aspectos diferenciales respecto de los que se ofertan en régimen privado y que, en cualquier caso, también deben ser tenidos presentes para el armado de programas de mejora de calidad. Estas diferencias son (según Albert Gadea) 
- El objetivo de los servicios públicos es maximizar el bien público, cosa bastante interpretable, a diferencia de la cuenta de resultados, objetivo final a maximizar en los servicios privados

- Han de garantizar la igualdad/equidad en su prestación

- Frecuentemente se ofertan en régimen de monopolio/oligopolio. Tienen el "mercado" cautivo, sin los mecanismos habituales de competencia (en todo caso, la competencia es por comparación territorial o cronológica)

- Los usuarios (los que hacen uso) de los servicios no coinciden siempre con los clientes (los que los pagan). Sea como sea, unos servicios públicos de calidad han de dar satisfacción tanto a los usuarios como a los clientes

- Se produce un veredicto indirecto sobre su bondad: la reelección o no de sus últimos responsables.

Según las experiencias exitosas estudiadas respecto de gobiernos que buscaban mejorar la calidad de los servicios públicos a través de la modernización de la gestión del Estado (Scott y Shieff-1993; Wisnieswski y Donnelly-1996; Gaster1996; Donnelly y Shiu; Wisniewski-2001; Gutiérrez y Jorge-2008), se puede establecer que no hay una sola forma de asegurar mejores resultados en la calidad de los servicios municipales. Sin embargo, se pueden destacar algunas características presentes en todas las experiencias de éxito analizadas:

- Foco en el ciudadano. Bajo distintas metodologías, todas las experiencias estudiadas han derivado en un cambio de paradigma en la relación entre el ciudadano y el Estado, así como su posterior impacto en las prácticas, procesos y prestaciones.

- Estrategia global. Los proyectos de mejora se enmarcan en una estrategia de gobierno, como parte de una política pública, que busca una nueva y mejor relación con el ciudadano, dándole mayor peso político y social.

- Vocación de servicio público. Los funcionarios comparten una profunda vocación de servicio público y han buscado implementar mejoras a partir del trabajo voluntario de cada uno de sus miembros. En estos casos los recursos económicos no siempre son lo más importante. 
- Procesos participativos e identificación de factores clave. En los casos estudiados se observa el surgimiento de una preocupación colectiva en torno a un problema específico, que se aborda desde muchos frentes distintos. Ese espacio abierto, de alta participación, permite el surgimiento de iniciativas, en un principio marginales, las que un momento crítico cobran importancia. Lo relevante entonces, no es encontrar la fórmula única para replicar e implementar rápidamente, sino descubrir las variables que están en juego, los factores clave que permitan la obtención de resultados, su contexto social y cultural.

- Alineamiento corporativo en torno al objetivo. Uno de los elementos que ha resultado clave para que la implementación de programas de resultados concretos en el mediano plazo es el compromiso del nivel directivo superior con los sistemas de gestión.

- Marketing interno y motivación. En organizaciones grandes es difícil lograr alineamientos y compromisos en forma rápida y la promoción interna es tremendamente necesaria al momento de perseguir resultados.

- Formación permanente. Para mejorar los servicios es necesario que toda la organización participe en un proceso de formación permanente, liderado internamente a partir de la propia experiencia. Esto refuerza conocimientos, aborda nuevas temáticas de acuerdo con los nuevos desafíos que se van presentando y ayuda a comprender que no se mejoran los servicios una vez, se mejoran siempre, en forma permanente y sistemática, instaurando la lógica de la mejora continua.

- Mediciones. Una medición inicial marca el comienzo de un trabajo que nunca termina, y buscará oportunidades de mejora inimaginables a los ojos de hoy. No se puede avanzar en forma segura a un objetivo si se está ciego y sin guía. Nadie mejor que el usuario sabe orientar los esfuerzos para satisfacer sus expectativas de servicio, y las mediciones son el único medio que permite acercarse a ellas.

- Gestión del conocimiento. Una vez iniciado el camino a la excelencia y generadas las condiciones de funcionamiento que permiten la participación de todos, comienzan a surgir proyectos de mejora en distintos ámbitos de la organización. Generalmente sucede que comienzan a surgir planes que pueden compartirse entre los distintos equipos o unidades para ir estimulando tanto la creatividad como su replicabilidad en otros ámbitos. 
Comienza a juntarse una gran cantidad de buenas prácticas que es necesario administrar, premiar y distribuir. Si esta información se encuentra en un solo sitio es posible acceder de mejor manera al conocimiento acumulado, la información del programa, documentos oficiales, archivos tipo, etc.

\subsection{Bases Teóricas}

\subsubsection{Marco Jurídico de las Municipalidades}

La Constitución Nacional establece en su art. 5, capítulo 1, primera parte: "Cada provincia dicta para sí una constitución bajo el sistema representativo republicano, de acuerdo con los principios, declaraciones y garantías de la Constitución Nacional, y que asegure su administración de justicia, su régimen municipal, y la educación primaria. Bajo esta forma el Gobierno Federal, garante a cada provincia el goce y ejercicio de sus instituciones."

El artículo 42 de la Constitución Nacional, establece: "Los consumidores y usuarios de bienes y servicios tienen derecho, en la relación de consumo, a la protección de su salud, seguridad e intereses económicos; a una información adecuada y veraz; a la libertad de elección y a condiciones de trato equitativo y digno.

Las autoridades proveerán a la protección de esos derechos, a la educación para el consumo, a la defensa de la competencia contra toda forma de distorsión de los mercados, al control de los monopolios naturales y legales, al de la calidad y eficiencia de los servicios públicos, y a la constitución de asociaciones de consumidores y de usuarios.

La legislación establecerá procedimientos eficaces para la prevención y solución de conflictos, y los marcos regulatorios de los servicios públicos de competencia nacional, previendo la necesaria participación de las asociaciones de consumidores y usuarios y de las provincias interesadas, en los organismos de control".

Cada provincia, conforme a lo dispuesto por el artículo $5^{\circ}$ debe asegurar la autonomía municipal reglando su alcance y contenido en el orden institucional, político, administrativo, económico y financiero. (art.123; título 2, sección 4). 
Por otra parte, el Decreto-Ley 6769/58-Ley Orgánica de las Municipalidades expresa en el art. $1^{\circ}$ : La Administración local de los Partidos que forman la Provincia estará a cargo de una Municipalidad compuesta de un Departamento Ejecutivo, desempeñado por un ciudadano con el título de Intendente, y un Departamento Deliberativo, desempeñado por ciudadanos con el título de Concejal, y en el Art 25: Las ordenanzas (dictadas exclusivamente por el Concejo Deliberante) deberán responder a los conceptos de ornato, sanidad, asistencia social, seguridad, moralidad, cultura, educación, protección, fomento, conservación y demás estimaciones encuadradas en su competencia constitucional que coordinen con las atribuciones provinciales y nacionales. Las mismas por el Art. $\mathbf{2 7}^{\circ}$ : (Texto según Decreto-Ley 9117/78) dice que corresponde a la función deliberativa municipal reglamentar: 1.- La radicación, habilitación y funcionamiento de los establecimientos comerciales e industriales, en la medida que no se opongan a las normas que al respecto dicte la Provincia y que atribuyan competencia a organismos provinciales... 5.Las obligaciones de los vecinos respecto de los servicios de la Municipalidad y de los escribanos con relación al pago de los tributos municipales en ocasión de los actos notariales de transmisión o gravamen de bienes... 9.- La instalación y el funcionamiento de establecimientos sanitarios y asistenciales; de difusión cultural y de educación física; de servicios públicos y todo otro de interés general en el partido, en la medida que no se opongan a las normas que al respecto dicte la Provincia... 20.- La expedición de licencias de conductor, en las condiciones establecidas por la legislación y reglamentación provincial... 21.- El patentamiento de vehículos que circulen por la vía pública, que no estén comprendidos en regímenes nacionales o provinciales... 28.- $Y$ toda otra materia vinculada a los conceptos y estimaciones contenidas en el artículo $25^{\circ}$.

Asimismo, el Art. $131^{\circ}$ expresa que la ejecución directa de los servicios de la Municipalidad corresponde al Departamento Ejecutivo, quien administrará los establecimientos por medio de empleados a sueldo, comisiones de vecinos $u$ organismos descentralizados. En los convenios, cooperativas o consorcios, será obligatoria su participación en los órganos directivos.

ARTICULO 226 ${ }^{\circ}$ : Constituyen recursos municipales los siguientes impuestos, tasas, derechos, licencias, contribuciones, retribuciones de servicios y rentas: 
$1^{\circ}$ (texto según art. 44 Ley 13154): Alumbrado, limpieza, riego y barrido, con excepción de los casos en que la prestación se haga efectiva sobre inmuebles pertenecientes al dominio de la Provincia, destinados a servicios educativos, de salud, de justicia y de seguridad.... $4^{\circ} \ldots$ permisos de uso de playas y riberas en jurisdicción municipal, $\ldots 7^{\circ}$ Edificación, refecciones, delineación, nivelación y construcción de cercos y aceras, ...10 $10^{\circ}$ Patentes de vehículos automotores, para el transporte de pasajeros y carga.

ARTICULO $227^{\circ}$ : La denominación "Impuestos" es genérica y comprende todas las contribuciones, tasas, derechos y demás obligaciones que el municipio imponga al vecindario en sus ordenanzas, respetando los límites establecidos en esta ley y los principios generales de la Constitución.

ARTICULO 228 : La percepción de impuestos municipales es legítima en virtud de la satisfacción de las necesidades colectivas que con ella se procura. Los órganos del gobierno municipal tienen por lo tanto amplias atribuciones para especificar los gastos que deban pagarse con el producto de aquellos impuestos, sin más limitaciones que las que resultan de la aplicación de los mismos a la atención de las aludidas necesidades colectivas. En esta materia, las facultades del gobierno municipal son irrenunciables e intransferibles y en consecuencia, ninguna autoridad podrá imponer a las comunas gastos que ellas mismas no hayan autorizado, ni privarlas del derecho de invertir sus recursos en la forma que dispongan sus poderes legalmente constituidos.

\subsubsection{Excelencia en las organizaciones:}

Desde la aparición de la globalización, se han provocado profundos cambios en todo el mundo y en todas las organizaciones, generando particularmente un gran impacto en las estructuras políticas y administrativas del Estado, que le exigen modernizaciones y significativos progresos en materia de comunicación, transparencia, eficiencia y coordinación (ILPES 1995). Las exigencias anteriores están estrechamente relacionadas con los cambios estructurales y con el nuevo estilo de gestión pública que demandan estas nuevas estructuras. Por otra parte, el impacto de la globalización en las organizaciones privadas ha cambiado significativamente las estrategias de competencia, dando una atención preferencial al paradigma del cliente (Ivancevich et al. 1996). Esto 
también genera una nueva actitud del ciudadano, que observa a los gobiernos con renovada visión y demanda de ellos servicios eficientes y responsables, reducción del déficit y control del gasto público.

La mayoría de los modelos de excelencia desarrollados en el mundo han sido creados en el marco del desarrollo económico. Objetivos declarados para la implantación de modelos de excelencia suelen ser: mejorar la competitividad de las organizaciones; provocar efectividad de las organizaciones en la creación de valor para todos sus grupos de interés, especialmente para sus clientes y mercados; promover, desarrollar y difundir procesos y sistemas destinados al mejoramiento continuo de la calidad en los productos y en los servicios a fin de apoyar la modernización y competitividad de esas organizaciones; promover la comprensión de los factores y elementos que tiene una influencia decisiva en la obtención de niveles superiores de calidad. Si bien los modelos de excelencia nacen para ser implementados en organizaciones privadas o sin fines de lucro, rápidamente su aplicación se ha extendido exitosamente en instituciones del sector público.

Esta creciente realidad, exige de sus gobiernos locales, fundamentalmente las municipalidades, como órgano jurídico y político - nuevos roles y nuevos estilos de gestión, que respondan a las demandas de comunicación, transparencia, eficiencia y coordinación, exigidas también a los gobiernos provinciales y nacionales.

Los nuevos estilos de gestión de las organizaciones municipales, requieren el uso de herramientas modernas que apoyen categóricamente el mejoramiento y el cambio que estas organizaciones demandan para asumir sus nuevos roles.

El modelo de gestión tradicional del Sector Público se caracteriza por un alto nivel de burocratización, en el cual las conductas se rigen por medio de reglas y normas de las cuales no es posible apartarse. En esta línea, entonces, el control de gestión tiende a centrarse sobre los procedimientos, a fin de asegurar que la normativa sea respetada. 
La gestión de una municipalidad en Argentina tiene asociada una serie de características que la hacen distintiva respecto a otros tipos de organizaciones. Dentro de las principales características se encuentran:

- El líder de la organización, el intendente o intendenta, así como su Concejo, son elegidos democráticamente por los ciudadanos de la comuna cada cuatro años.

- El actuar de la municipalidad está geográficamente determinado por los límites comunales.

- Cada comuna está inserta en una realidad única y singular.

\subsubsection{Calidad}

Para hacer referencia a la calidad en la prestación de servicios públicos, primeramente hay que definir lo que se entiende por calidad.

La más clásica definición la defiende el experto en TQM (Calidad Total), Philips B. Crosby: "Es la conformidad con los requerimientos."

Se define como calidad de diseño el grado con el que el producto cumple con las expectativas del cliente.

La calidad es el conjunto de propiedades y características de un servicio, producto o proceso, que satisface las necesidades y expectativas establecidas por el usuario, el ciudadano o el cliente de los mismos.

El concepto anterior involucra explícitamente los siguientes términos:

Producto:

Es el resultado de todo proceso. Este resultado puede ser para el caso municipal de información o la prestación de un servicio administrativo (extensión de certificaciones, licencias, etc.) o un servicio público (agua, drenajes, infraestructura, mercados, cementerios, rastros, etc.). Por lo tanto, cuando se habla de producto, no sólo se refiere a un bien tangible, sino también a servicios e información que son los procesos habituales en el ámbito de los servicios municipales.

Cliente:

Es quien recibe el producto. Pague directamente por el mismo o no. Sea miembro de la misma organización, o no. Por lo que existe el cliente interno, que es cuando el receptor es un miembro de la organización y cliente externo, 
en el caso de que el receptor no pertenezca a la organización que produce el producto. La denominación de cliente externo en la administración pública refuerza la visión del ciudadano como un usuario con derecho a exigir y que sus demandas sean atendidas. Dentro del ámbito municipal, se puede definir que el cliente interno lo constituyen los funcionarios y trabajadores de la municipalidad y el cliente externo son básicamente todos los vecinos del municipio, así como los transeúntes que son las personas que se encuentran accidentalmente en una jurisdicción municipal, teniendo su vecindad en otra, y que pudiera realizar alguna gestión en la municipalidad.

Características del producto:

Propiedades del producto (información o servicios) con las que se espera satisfacer las necesidades del cliente, pueden ser de distinto tipo: técnicas, físicas y económicas, según la naturaleza del producto y de las necesidades que se desean satisfacer.

Necesidades del cliente:

Necesidad es algo requerido por la persona que solicita la información o servicio y que le motiva a la acción para su satisfacción. Las características del producto o servicio son las que deben satisfacer las necesidades del cliente.

Satisfacción del Cliente:

Philip Kotler (Marketing en el sector público. 2006, Págs. 40, 41), define la satisfacción del cliente como “... el nivel del estado de ánimo de una persona que resulta de comparar el rendimiento percibido de un producto o servicio con sus expectativas".

\section{Expectativas:}

Lo que el cliente espera de la información, producto o servicio.

Como puede observarse, en las definiciones anteriores queda suficientemente claro que el cliente es el protagonista. El cliente se convierte en el objetivo de una organización que desea brindar información y servicios con calidad, en el centro de sus actividades y procesos, y la evaluación de su satisfacción se convierte en un elemento primordial que permite obtener la retroalimentación esencial para mejorar la calidad. 


\section{Servicios}

En economía y en marketing (mercadotecnia) un servicio es un conjunto de actividades que buscan responder a una o más necesidades de un cliente. Se define un marco en donde las actividades se desarrollarán con la idea de fijar una expectativa en el resultado de éstas. Es el equivalente no material de un bien. La presentación de un servicio no resulta en posesión, y así es como un servicio se diferencia de proveer un bien físico.

Entre las características propias de un servicio que permiten diferenciarlo de un producto aparecen la intangibilidad (un servicio no puede verse, probarse, sentirse, oírse ni olerse antes de la compra), la heterogeneidad (dos servicios similares nunca serán idénticos o iguales), la inseparabilidad (la producción y el consumo son parcial o totalmente simultáneos), la perecibilidad (un servicio no se puede almacenar por la simultaneidad entre producción y consumo) y la ausencia de propiedad (los compradores de un servicio adquieren el derecho a recibir una prestación, uso, acceso o arriendo de algo, pero no la propiedad del mismo).

Servicios Públicos:

Son las actividades de las entidades u órganos públicos o privados con personalidad jurídica creados por Constitución o por ley, para dar satisfacción en forma regular y continua a cierta categoría de necesidades de interés general, bien en forma directa, mediante concesionario o a través de cualquier otro medio legal con sujeción a un régimen de Derecho Público o Privado, según corresponda.

Características:

a) Todo servicio público debe suministrarse con un criterio técnico gerencial y con cuidadosa consideración a las funciones del proceso administrativo científico: planificación, coordinación, dirección, control y evaluación, tanto en su concepción orgánica como en el sentido material y operativo.

b) Debe funcionar de manera permanente, es decir, de manera regular y continua para que pueda satisfacer necesidades de las comunidades por sobre los intereses de quienes los prestan.

c) La prestación del servicio público no debe perseguir principalmente fines de lucro; se antepone el interés de la comunidad a los fines del beneficio 
económico de personas, organismos o entidades públicas o privadas que los proporcionan.

\subsubsection{Calidad Total:}

La calidad total incluye todas las funciones y fases que intervienen en el desarrollo de un producto o servicio, no sólo en cuanto al producto en sí, sino a la gestión de la organización en su totalidad, poniendo en juego todos los recursos necesarios para la prevención de los errores, involucrando a todo el personal, sistematizando en todas sus vertientes las múltiples relaciones proveedor-cliente (interno y externo), mejorando el clima organizacional y las relaciones entre los miembros integrantes y reduciendo las pérdidas de tiempos, movimientos y recursos, provocados por una gestión deficiente. Tiene en cuenta la totalidad de las necesidades y expectativas de los clientes con la finalidad de satisfacerlas.

La calidad total abarca a toda la organización y a todas sus actividades que tiene como meta la satisfacción del cliente y al menor costo.

La calidad total se fundamenta en los siguientes principios:

$\checkmark$ La organización se debe orientar hacia el cliente, identificando y satisfaciendo sus necesidades.

$\checkmark$ La calidad la hacen las personas.

$\checkmark$ La calidad alcanza a toda actividad de la organización.

$\checkmark$ La mejora continua es el pilar básico de la calidad total.

$\checkmark$ La mejora de la calidad implica una actuación sobre la simplificación y agilización de los procesos.

$\checkmark$ El espíritu de colaboración, una de cuyas expresiones es el trabajo en equipo, es el mejor mecanismo para avanzar.

$\checkmark$ La calidad total abarca a toda la organización y todas sus actividades.

$\checkmark$ Es preciso mantener receptividad a expresiones e innovaciones acaecidas en otras organizaciones, públicas o privadas, en la búsqueda de mejores prácticas.

$\checkmark$ Reducción de costos. 


\subsubsection{Orientar la organización hacia el cliente:}

Satisfacer las necesidades del cliente es lo principal. La organización debe girar en torno a los procesos que son importantes para este fin y que aportan valor añadido. Es toda la organización, la que debe participar en alcanzar dicha satisfacción y no considerar que sólo sean responsables los departamentos encargados del producto o del servicio. Cada una de las partes de la organización debe trabajar en forma coordinada para satisfacer las necesidades del cliente.

La calidad es intrínseca al servicio y es el cliente quien la juzga a partir de sus percepciones. Del mismo modo, la organización debe estar atenta a todas las características y atributos del producto o servicio, pues son éstos los que le entregan valor agregado a los clientes, aumenta su satisfacción, determinan sus preferencias y los hacen fieles a la marca, producto o institución. Una organización con foco en el cliente busca satisfacer las necesidades actuales y anticipar las expectativas de los clientes y mercados potenciales. Con una gestión orientada hacia la clientela, la organización está alerta a los cambios que ocurren a su alrededor, principalmente en relación a nuevas demandas y necesidades. El logro de la satisfacción de los clientes y la conquista de su fidelidad son fundamentales para aumentar la competitividad de la organización que se vuelve un tema estratégico.

En toda referencia a "Cliente" debe entenderse de igual forma el concepto de "Usuarios y Usuarias" empleado en los servicios públicos.

\subsubsection{Ampliar el concepto cliente:}

La organización tiene clientes internos y clientes externos. Tradicionalmente, solo se considera al cliente externo o sea, en el caso de las municipalidades, a los vecinos del municipio $u$ otras personas que pudieran requerir información o un servicio, pero es muy importante también considerar a los funcionarios y trabajadores municipales como clientes internos. El cliente interno es aquel miembro de la municipalidad que recibe el resultado de un proceso anterior, llevado a cabo dentro de la misma; si el resultado es satisfactorio, él podrá realizar eficientemente el proceso que le corresponda, pero si el resultado recibido no es satisfactorio, éste incidirá negativamente en la actividad que 
debe realizar, llevando consigo: errores, omisiones o atrasos. Los clientes internos vienen a constituir un sistema de engranajes uniforme, del cual cada uno de sus partes debe dar productos de calidad, ya que de otro modo, se producirían fluctuaciones y fallas en la calidad de los resultados.

\subsubsection{La calidad total la hacen las personas:}

El papel de los recursos humanos de la organización en la calidad total es fundamental, y constituyen el principal activo de la organización, por lo que su satisfacción es un objetivo preeminente. El establecimiento de un clima organizacional que permita que las personas contribuyan efectivamente al rendimiento de la organización es clave, y representa crear las condiciones adecuadas hacia la calidad total.

Valorando su experiencia y capacidad creativa mediante la participación en la gestión de los procesos de la organización y el trabajo en equipo, privilegiando su calidad de vida y clima laboral.

La comprensión de que el desempeño de la organización depende de la capacitación, motivación y bienestar de la fuerza laboral, crea un ambiente de trabajo propicio en participación y desarrollo de las personas. El desarrollo de éstas depende cada vez más de las oportunidades para aprender en un ambiente favorable donde desarrollar sus capacidades y potencialidades.

La participación en todos los aspectos del trabajo es fundamental para desarrollar su potencial, lo que contribuirá a lograr los resultados de la organización.

\subsubsection{La mejora continua:}

Todo es susceptible de ser mejorado.

La mejora continua debe incorporarse al modo habitual de trabajar de la municipalidad, a su propia cultura organizacional, siendo asumida como un valor fundamental. Debe constituir un estilo de gestión, cuya principal característica es que no finaliza nunca. Se puede definir que mejora continua es obtener un grado de rendimiento mejor que el anterior.

El principio de mejora continua se basa en: 


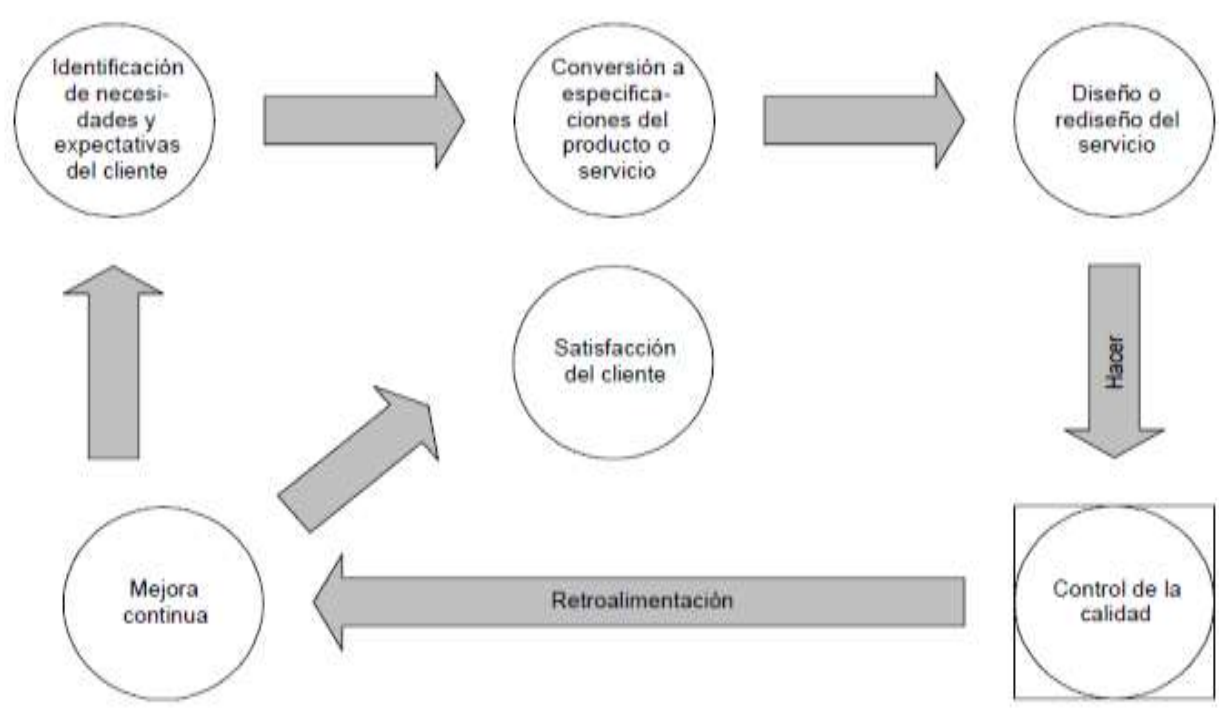

\subsubsection{Simplificación y agilización de procesos:}

Un proceso se define como un conjunto de actividades enlazadas entre sí que partiendo de uno o más insumos (entradas) se transforman generando un producto (servicio o información). Que la Municipalidad posea procesos simples y ágiles es otro de los elementos fundamentales para alcanzar la calidad total, ya que permite brindar una mejor y más rápida atención al cliente, así como optimizar los recursos existentes en la Municipalidad y reducir trámites, costos y tiempos para el usuario.

\subsubsection{Trabajo en equipo:}

Todos los miembros de la Municipalidad deben tener bien definidas y asignadas sus funciones, las cuales deben estar orientadas a alcanzar los objetivos institucionales. Los beneficios que el trabajo en equipo puede ofrecer son incuestionables. Entre los factores que influyen en el buen desempeño de los equipos están:

- Un grupo de personas trabajando estructuradamente, pueden alcanzar sinergia, lo que significa que el resultado global obtenido por el grupo es superior a la suma de los resultados que tendrían los funcionarios y empleados municipales trabajando cada uno por su lado.

- Mediante los equipos se procura la motivación, el sentido de pertenencia y compromiso de cada uno de sus miembros con la Municipalidad. 


\subsubsection{La calidad total abarca a toda la organización y todas sus actividades:}

La calidad total persigue facilitar productos satisfactorios al cliente, para lo cual habrá que orientar a toda la municipalidad y sus actividades para alcanzar:

$\checkmark$ La calidad en los insumos

$\checkmark$ La calidad en los procesos

$\checkmark$ La calidad en los recursos humanos

$\checkmark$ La calidad en los recursos técnicos

$\checkmark$ La calidad en la infraestructura

$\checkmark$ La calidad en la gestión

$\checkmark$ La calidad en los servicios, productos e información

\subsubsection{Receptividad a quejas e innovaciones:}

Los funcionarios y empleados municipales deben estar abiertos a recibir, analizar y evaluar quejas e innovaciones que manifiestan los vecinos y público en general, a fin de tomar las decisiones que les permita mejorar de manera continua.

\subsubsection{Reducción de costos:}

La calidad tiene un costo el cual es provocado por la prevención y la evaluación, sin embargo el costo de la calidad es menor que el costo de la no calidad. Así, por ejemplo se pueden mencionar algunos costos provocados por la no calidad, los cuales son producidos por:

$\checkmark$ Duplicar procesos

$\checkmark$ Procesos largos y engorrosos

$\checkmark$ Falta de definición en los procesos

$\checkmark$ Repetir trabajos

$\checkmark$ Corregir errores

$\checkmark$ Soportar costos por reclamaciones ante trabajos y servicios mal realizados

$\checkmark$ Almacenar excedentes innecesarios 


\subsubsection{Expectativas del cliente respecto de la organización}

Dentro de los factores básicos que determinan que el cliente está satisfecho por la información o servicio obtenido, se encuentran:
$\checkmark$ Confiabilidad
$\checkmark$ Simplicidad, sencillez y agilidad en los trámites de la gestión
$\checkmark$ Claridad en la comunicación oral y escrita
$\checkmark$ Capacidad de respuesta y agilidad
$\checkmark$ Seguridad
$\checkmark$ Idoneidad
$\checkmark$ Atención individualizada
$\checkmark$ Ambiente adecuado
$\checkmark$ Transparencia
$\checkmark$ Facilidad para formular sugerencias, quejas y reclamaciones
$\checkmark$ Flexibilidad en los horarios de atención al público
$\checkmark$ Existencia de oficinas próximas al domicilio o lugar de trabajo.

\subsubsection{Confiabilidad:}

Tener la confianza que la municipalidad puede realizar el servicio prometido de manera precisa, continua y sin errores. O sea, prestar el servicio bien.

\subsubsection{Simplicidad, sencillez y agilidad en los trámites de la gestión:}

Que los trámites que le corresponde realizar sean pocos, simples y rápidos, eliminando requisitos o pasos innecesarios y reduciendo los tiempos de atención y gestión. Involucra también que los requisitos y pasos del procedimiento estén claramente establecidos.

\subsubsection{Claridad en la comunicación oral y escrita:}

Facilitar la comunicación con la población y los procedimientos que ésta tiene que llevar a cabo. Esto equivaldría a simplificar formularios y documentos, hacer más accesible el lenguaje administrativo y unificar procedimientos afines, entre otras acciones a tomar.

Dentro de este aspecto también es muy importante considerar que tanto los trabajadores como los funcionarios municipales asuman su rol como servidores públicos. 


\subsubsection{Capacidad de respuesta y agilidad:}

Disposición de los funcionarios y trabajadores municipales a prestar el servicio a la población de forma rápida, atenta y personalizada.

\subsubsection{Seguridad:}

Capacidad de trasmitir credibilidad y confianza, mediante el conocimiento y atención mostrados por los funcionarios y empleados municipales. En este aspecto, es importante también que exista transparencia en el manejo de los recursos municipales, a fin que los vecinos se sientan seguros que sus impuestos y contribuciones están siendo bien invertidos.

\subsubsection{Idoneidad:}

Preparación, competencia, amabilidad y buen trato personal de los funcionarios y empleados municipales, principalmente aquellos que atienden a los vecinos y público en general.

\subsubsection{Atención individualizada:}

Que el vecino o usuario sienta que el servicio que se le proporciona se personaliza y que es tratado como un ser humano, no como un número más o alguien más en la cola. Incluye la capacidad para entender al cliente y de comunicarse con él en forma clara y concisa.

\subsubsection{Ambiente adecuado:}

Los elementos físicos que están presentes en la prestación del servicio: instalaciones, equipos, áreas cómodas de espera, señalización, iluminación, ventilación, temperatura, servicios sanitarios, formularios, lapiceros y otros servicios que hagan más agradable la permanencia del vecino o usuario dentro de la municipalidad. De igual forma, el ambiente adecuado contribuye para que el trabajador se desempeñe de manera más eficiente, así como que el vecino o usuario se sienta mejor atendido.

\subsubsection{Transparencia:}

Facilitar información clara, precisa y continua, identificación del personal que presta el servicio y facilidad de acceso a archivos y registros públicos. 


\subsubsection{Facilidad para formular sugerencias, quejas y reclamaciones:}

Tener un encargado o buzón de sugerencias, quejas o reclamos a disposición del cliente. Implica estar dispuesto a escuchar al cliente sobre los trámites que realiza y tomar las medidas correctivas que sean necesarias para mejorar la calidad del servicio.

\subsubsection{Flexibilidad en los horarios de atención al público:}

Mientras más amplios sean los horarios, los vecinos y usuarios tendrán que hacer menor esfuerzo para realizar sus trámites. Es recomendable, que las autoridades municipales analicen la posibilidad de atender al público por lo menos la mañana del día sábado o extender por lo menos un día a la quincena el horario de la jornada laboral hasta las 18:00 horas, lo que facilitaría que los vecinos que trabajan puedan hacer sus gestiones municipales ese día, evitando pedir permisos innecesarios en sus respectivos trabajos.

\subsubsection{Existencia de oficinas próximas al domicilio o lugar de trabajo:}

Mientras más cerca se esté la oficina al vecino o usuario, éste tendrá que hacer menor esfuerzo para realizar sus trámites. Dependiendo cantidad de usuarios, las distancias, acceso, área geográfica y otras características propias del municipio, los funcionarios municipales podrán analizar la posibilidad de abrir otra oficina municipal en otro lugar fuera de la cabecera municipal o crear una oficina móvil que se desplace periódicamente hacia los lugares que presenten problemas a los vecinos para llegar hasta la cabecera municipal.

\subsection{Definición de términos básicos:}

\section{Usuario}

El usuario es para quién se crean los productos o servicios, son el objeto del diseño, y la conformación de las características físicas y tangibles, dándole, las especificaciones de manufactura y la definición de sus componentes.

\section{Cliente}

El cliente es todo aquel que ya ha tenido experiencia con el producto o servicio que se ofrece, y que ha obtenido buenos resultados, haciendo que regrese a 
requerir el producto o servicio, de una forma sistemática o casual, es decir el cliente es el que regresa, el que vuelve por lo que ya conoce, de forma voluntaria y ante otras alternativas.

\section{Metodología de la Investigación}

\subsection{Universo y Muestra}

\subsubsection{Universo}

Para el servicio que se estudió -la Dirección Operativa de Licencias de Conducir de la Municipalidad de La Plata-, el universo está constituido por los habitantes de la Municipalidad de La Plata (654.324 habitantes).

\subsubsection{Muestra}

La población bajo estudio para esta investigación está constituida por todos los habitantes del Partido de La Plata en condiciones de utilizar el servicio de Licencias de Conducir (con "N" desconocido). De la misma se considera extraer una muestra aleatoria estratificada cuyo tamaño " $n$ " se calcula mediante la expresión:

$$
n=\frac{Z_{\alpha}^{2} \cdot p \cdot q}{e^{2}}
$$

La misma corresponde al cálculo del tamaño muestral cuando se desea estimar la proporción de éxitos $p$, con universo desconocido.

Donde:

p = prevalencia esperada del parámetro a evaluar, que en caso de desconocerse, se aplica la opción más desfavorable $(p=0,5)$, que hace mayor el tamaño muestral

$q$ = complemento de la prevalencia esperada del parámetro a evaluar, es decir $1-p=0,5$ 
$Z=1,95996$ para $\alpha=5 \%$, o sea un nivel de confianza del $95 \%$

e $=6,21 \%$ error de muestreo

$n=250$ personas a encuestar (tamaño de la muestra)

Dado que se trata de cinco áreas a estudiar, se ha distribuido el total por "afijación simple" o equitativamente entre las mismas, lo cual implica un $20 \%$ del total para cada una de las siguientes áreas:

\begin{tabular}{lr}
\multicolumn{1}{c}{ Area } & Encuestas \\
\hline Licencias de conducir & 50 \\
\hline Dirección de Obras Particulares & 50 \\
\hline Defensa del consumidor & 50 \\
\hline Juzgado de faltas & 50 \\
\hline Agencia Platense de Recaudación & 50 \\
\hline \multicolumn{2}{c}{ Total }
\end{tabular}

\subsection{Tipo de Investigación}

Se trató de una investigación de tipo exploratoria y de naturaleza cuantitativa

\subsection{Técnicas de Recolección de Datos}

\subsubsection{Encuestas}

En la cultura organizacional actual, se busca por parte de las empresas generar un servicio que proporcione una ventaja competitiva, pero dicha ventaja sólo se consigue teniendo la capacidad suficiente para satisfacer las necesidades del cliente.

Frente a todo se encuentra un obstáculo al menos aparente, como es la dificultad de la intangibilidad de los servicios, y más aún de los servicios públicos; dificultad que empezó a resolverse gracias a la aportación de Parasuraman, Zeithmal y Berry $(1985,1988)$.

Estos autores crearon una metodología que definieron como "un instrumento resumido de escala múltiple, con un alto nivel de fiabilidad y validez que las 
empresas pueden utilizar para comprender mejor las expectativas y percepciones que tienen los clientes respecto a un servicio", identificando el término "Escala" con una clasificación de preguntas. Por lo tanto consistía en un cuestionario con preguntas estandarizadas desarrollado en los Estados Unidos con el apoyo del Marketing Science Institute llamado escala SERVQUAL.

A nivel mundial, las organizaciones buscan satisfacer a sus clientes para que éstos sigan consumiendo el servicio que la institución u organización provee. En el caso de instituciones públicas, en una perspectiva comercial buscan dar un buen servicio para que las autoridades que las provean generen una buena imagen en la retina de los clientes (ciudadanos), y de esta manera ser tomados en cuenta para próximos comicios.

Cabe recalcar, que este modelo SERVQUAL se puede utilizar para medir la satisfacción del usuario de cualquier tipo de servicio, ya sea de una organización pública o privada.

El modelo SERVQUAL define la calidad del servicio como la diferencia entre las percepciones reales por parte de los clientes del servicio y las expectativas que sobre éste se habían formado previamente. De ésta forma, un cliente valorará negativamente (positivamente) la calidad de un servicio en el que las percepciones que ha obtenido sean inferiores (superiores) a las expectativas que tenía. Por ello, las compañías de servicios en las que uno de sus objetivos es la diferenciación mediante un servicio de calidad, deben prestar especial interés al hecho de superar las expectativas de sus clientes.

Las encuestas permitieron obtener información por parte de los ciudadanos con relación al servicio que se le brinda al cliente en la Dirección Operativa de Licencias de Conducir de la Municipalidad de La Plata. Se utilizó la encuesta como herramienta para recolección y procesamiento de datos realizada a través de preguntas del tipo "cerradas", con el fin de facilitar su respuesta. 
En cada una de ellas se le pidió a los encuestados que puntúen tanto su percepción del servicio, como las expectativas con las que llegaban a la Dirección Operativa de Licencias de Conducir.

Se interrogó a las personas que voluntariamente quisieron participar sobre cinco dimensiones asignando calificaciones entre 1 y 5 , correspondiendo el 1 a la mejor calificación y 5 a la peor opción.

Las dimensiones fueron definidas de la siguiente manera:

1) Elementos tángibles: apariencia de las instalaciones físicas, equipos, personal y materiales de comunicación.

2) Confiabilidad: habilidad para ejecutar el servicio prometido de forma confiable y cuidadosa.

3) Capacidad de respuesta: disposición y voluntad de los empleados para ayudar al cliente y proporcionar el servicio

4) Seguridad: conocimiento y atención mostrados por los empleados y sus habilidades para inspirar credibilidad y confianza

5) Empatía: atención individualizada que ofrece la organización a los clientes.

Para llevar a cabo las encuestas, se contó con la ayuda de dos encuestadores externos presentes en las oficinas municipales para encuestar a los clientes que acudieron al municipio.

\subsubsection{Observación Directa}

Sirvió de gran ayuda, ya que permitió verificar la información obtenida al momento de realizar las encuestas, debido a que se observó la reacción de los ciudadanos al momento de recolectar la información.

\subsection{Técnicas de Análisis}

El análisis de la información se llevó a cabo luego de la confección de una base de datos. Los datos obtenidos en las encuestas fueron cargados a una matriz, donde cada campo representará cada pregunta de la encuesta. Las respuestas fueron codificadas numéricamente, para facilitar la carga. A su vez, se llevó a cabo un análisis univariado. 
Luego se calculó el "Saldo de respuesta"1 de cada pregunta realizada, en función de la fórmula siguiente:

$$
\text { Saldode Re spuesta }=\frac{\sum_{i=1}^{n} F_{i} \cdot i}{\sum_{i=1}^{n} F_{i}}
$$

Donde:

$\mathrm{Fi}=$ Es la cantidad de respuestas (frecuencias) de cada ítem para cada valor de las opciones de respuesta

$\mathrm{i}=$ Es el valor de cada uno de las opciones de respuesta

El cálculo consiste en multiplicar los componentes de las cantidades de respuestas (frecuencias) por el tipo de respuesta dado y luego sumar esos productos. Posteriormente a ese número se lo divide por la sumatoria de la cantidad de respuestas.

Luego se calculó la frecuencia de la brecha de satisfacción sobre la calidad del servicio, como la diferencia entre las percepciones y las expectativas que tienen los clientes de la Dirección Operativa de Licencias de Conducir.

La brecha de satisfacción del cliente es la resultante de la resta entre la calificación otorgada a la expectativa que un cliente tiene sobre un aspecto del servicio y la percepción respecto del servicio obtenido. Dado que las calificaciones, para ambos aspectos, eran números enteros del uno al cinco, se definieron las categorías según la tabla que sigue:

\footnotetext{
1 El cálculo de ese promedio sigue idéntica metodología que la del Global Competitiveness Index del World Economic Forum para el procesamiento de la Executive Opinion Survey en que se pregunta sobre una serie de cuestiones y se solicita que se califique en un rango que va de 1 a 7 en que 1 es lo peor y 7 lo mejor y que luego se sintetiza a través de un promedio. Xavier Sala-i-Martin (Cabrera de Mar, Barcelona, España, 1963), es un economista de origen español y de nacionalidad estadounidense, articulista, catedrático de economía en la Universidad de Columbia y Asesor Jefe ("Chief Advisor") del World Economic Forum donde, además, es coautor del Global Competitiveness Report y el padre intelectual del Global Competitiveness Index que ordena a más de 140 países del mundo según su competitividad.
} 


\begin{tabular}{|c|c|c|c|}
\hline Expectativa & Percepción & Brecha & Situación \\
\hline 5 & 1 & 4 & Insatisfacción total \\
\hline 5 & 2 & 3 & Muy insatisfecho \\
\hline 4 & 1 & 3 & Muy insatisfecho \\
\hline 5 & 3 & 2 & Bastante Insatisfecho \\
\hline 4 & 2 & 2 & Bastante Insatisfecho \\
\hline 3 & 1 & 2 & Bastante Insatisfecho \\
\hline 5 & 4 & 1 & Algo Insatisfecho \\
\hline 4 & 3 & 1 & Algo Insatisfecho \\
\hline 3 & 2 & 1 & Algo Insatisfecho \\
\hline 2 & 1 & 1 & Algo Insatisfecho \\
\hline 5 & 5 & 0 & Satisfecho \\
\hline 4 & 4 & 0 & Satisfecho \\
\hline 3 & 3 & 0 & Satisfecho \\
\hline 2 & 2 & 0 & Satisfecho \\
\hline 1 & 1 & 0 & Satisfecho \\
\hline 4 & 5 & -1 & Algo más que Satisfecho \\
\hline 3 & 4 & -1 & Algo más que Satisfecho \\
\hline 2 & 3 & -1 & Algo más que Satisfecho \\
\hline 1 & 2 & -1 & Algo más que Satisfecho \\
\hline 3 & 5 & -2 & Bastante más que Satisfecho \\
\hline 2 & 4 & -2 & Bastante más que Satisfecho \\
\hline 1 & 3 & -2 & Bastante más que Satisfecho \\
\hline 2 & 5 & -3 & Mucho más que Satisfecho \\
\hline 1 & 4 & -3 & Mucho más que Satisfecho \\
\hline 1 & 5 & -4 & Satisfacción absoluta \\
\hline
\end{tabular}

Fuente: Elaboración propia.

Finalmente, para determinar el orden de importancia de las dimensiones según los usuarios encuestados, se utilizó la fórmula de la importancia promedio ponderada (similar a la de "saldo de respuesta") definida como la suma de la productoria entre la frecuencia de la importancia asignada y la importancia, todo ello dividido por la sumatoria de la frecuencia.

\section{Resultados de la Investigación}

\subsection{Análisis descriptivo de la muestra}

- Se realizaron 50 encuestas

- El $64 \%$ fueron hombres y el $36 \%$ mujeres 


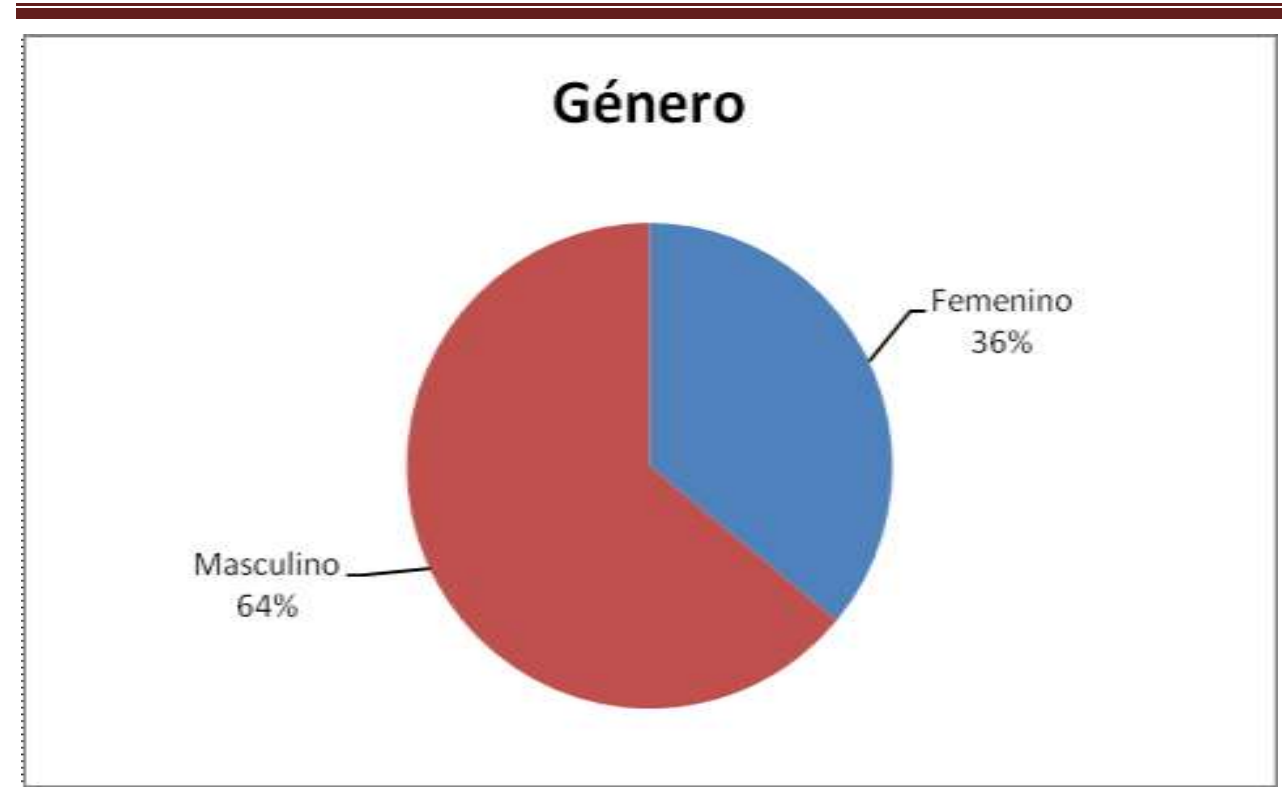

- El rango de edad de los encuestados fue el siguiente:

\begin{tabular}{lrr} 
Edades & Frecuencia & Porcentaje \\
\hline Hasta 20 años & 4 & $8,00 \%$ \\
\hline E/ 20 Y 30 años & 11 & $22,00 \%$ \\
\hline E/ 30 y 40 años & 12 & $24,00 \%$ \\
\hline E/ 40 y 50 años & 14 & $28,00 \%$ \\
\hline E/ 50 y 60 años & 5 & $10,00 \%$ \\
\hline Más de 60 años & 4 & $8,00 \%$ \\
\hline Totales & 50 & $100,00 \%$
\end{tabular}

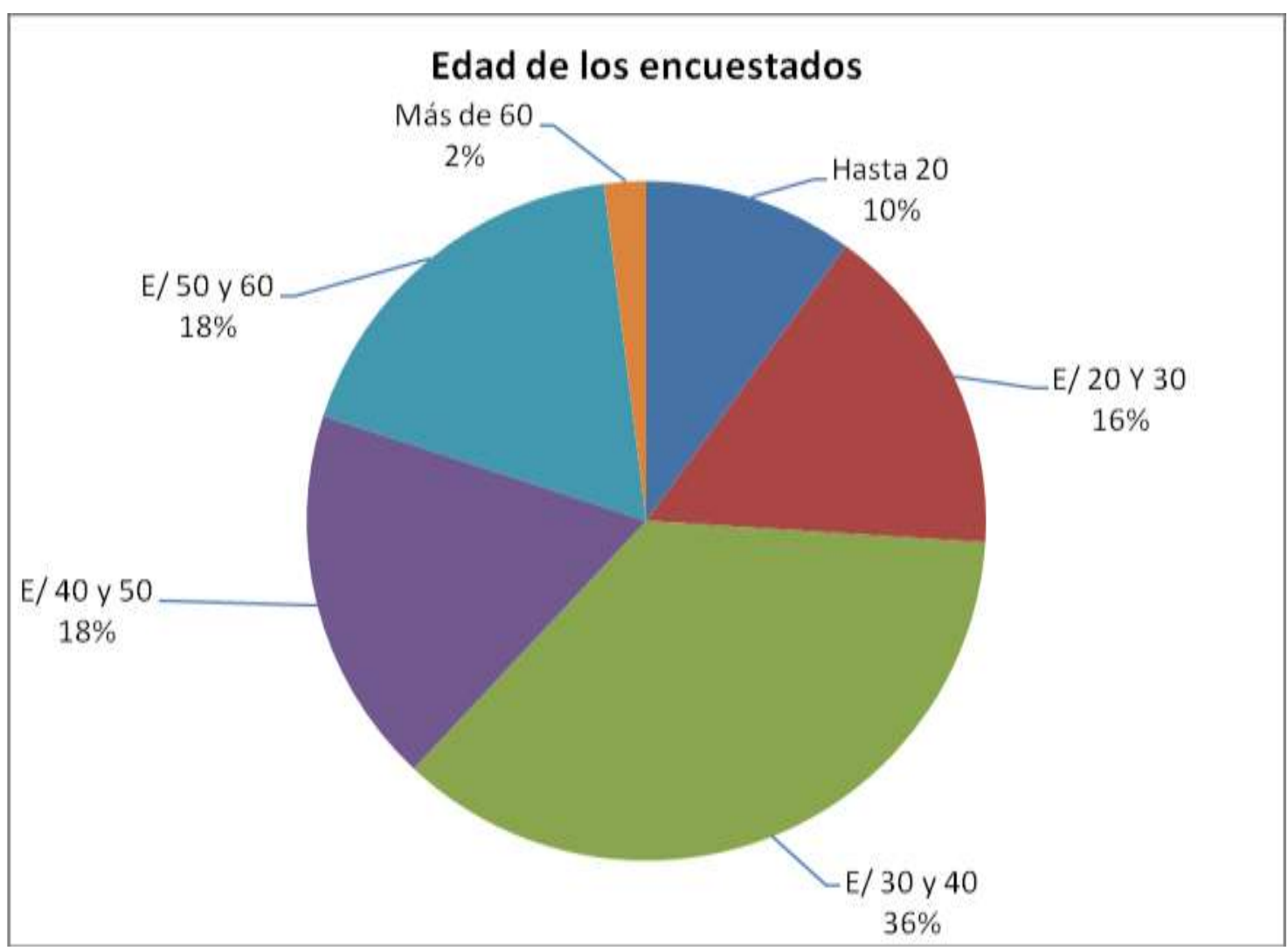




\section{$\underline{7.2}$ Frecuencia de utilización del servicio de Licencias de Conducir}

Se encontró que más del $68 \%$ de los usuarios de esa dependencia municipal, se presenta en las oficinas municipales cada varios años, mientras que el $32 \%$ restante de los encuestados lo hacen una vez al año.

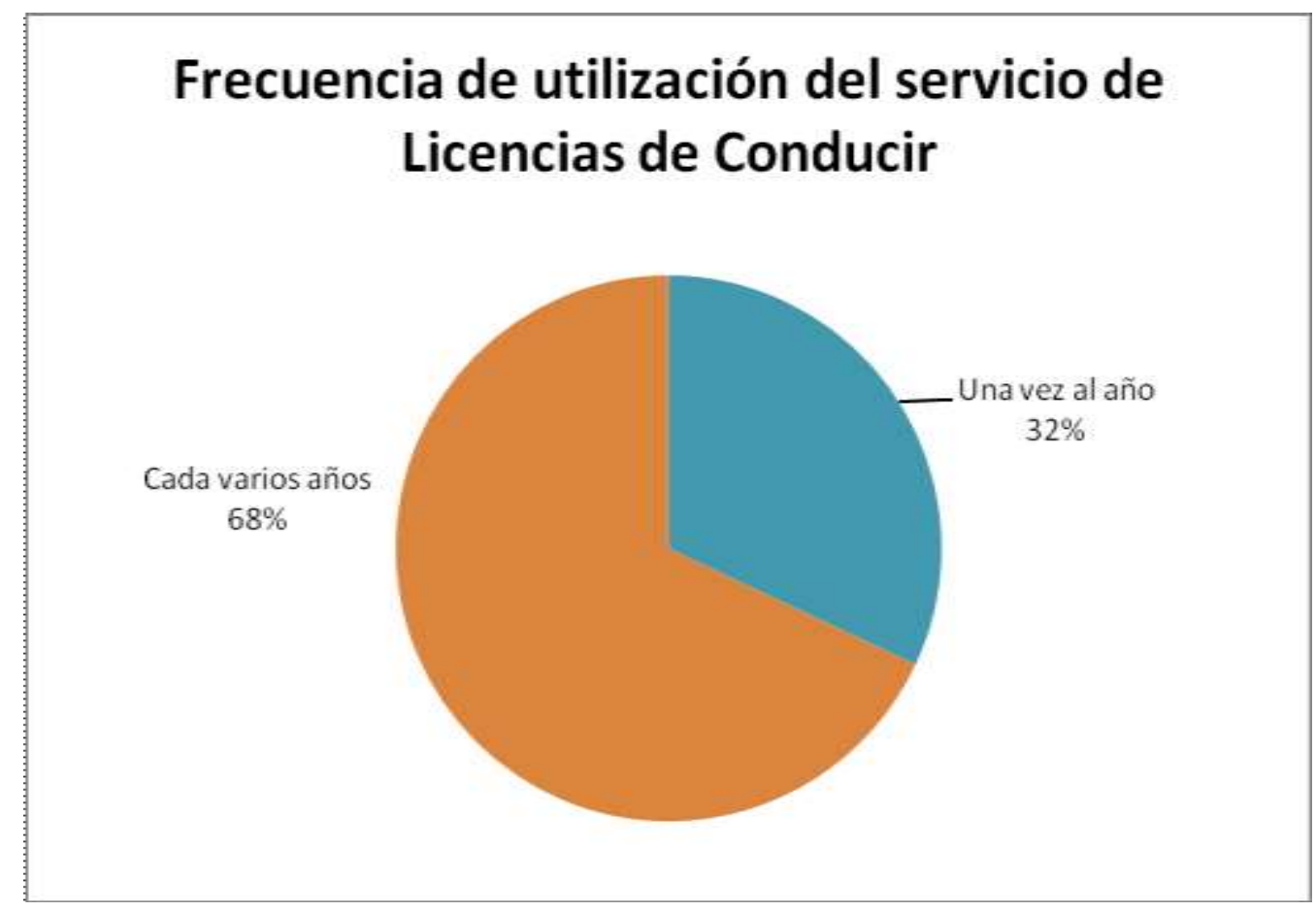

También se consultó acerca de cómo calificaría la organización integral del servicio, en una escala de cinco opciones que iban entre "excelente" a "pésimo". Ésta última calificación fue la elegida por el $6 \%$ de los encuestados; el $14 \%$ lo consideró malo; el $28 \%$ como regular, la mayor parte, el $46 \%$ lo definió como bueno, y, sólo un 6 \% respondió excelente:

\begin{tabular}{lrr}
$\begin{array}{l}\text { Calificación de la organización del } \\
\text { servicio }\end{array}$ & Frecuencia & \multicolumn{2}{l}{ Calificación } \\
\hline Excelente & 3 & $6,00 \%$ \\
\hline Bueno & 23 & $46,00 \%$ \\
\hline Regular & 14 & $28,00 \%$ \\
\hline Malo & 7 & $14,00 \%$ \\
\hline Pésimo & 3 & $6,00 \%$ \\
\hline Totales & 50 & $100,00 \%$
\end{tabular}




\section{Organización del servicio de Licencias de Conducir}

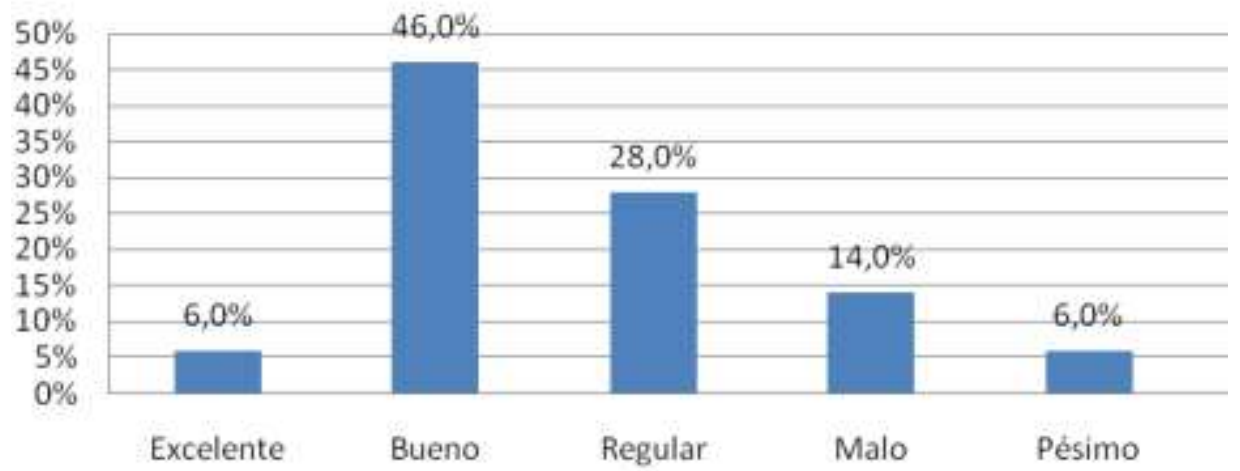

Calificaciones

7.3 Dimensión l: Elementos Tangibles: Apariencia de la instalaciones físicas, equipos, personal y materiales de comunicación

A continuación se exponen los resultados obtenidos en la Dirección Operativa de Licencias de Conducir en los elementos equipos, instalaciones físicas, apariencia física de los empleados, y, apariencia visual de los elementos de comunicación.

\subsubsection{Equipos}

\subsubsection{Expectativa}

En principio se consultó a los encuestados acerca de las expectativas que traían sobre los equipos que se utilizan en el servicio de Licencias de Conducir, entre opciones que iban desde modernos a obsoletos, obteniendo los siguientes resultados: 


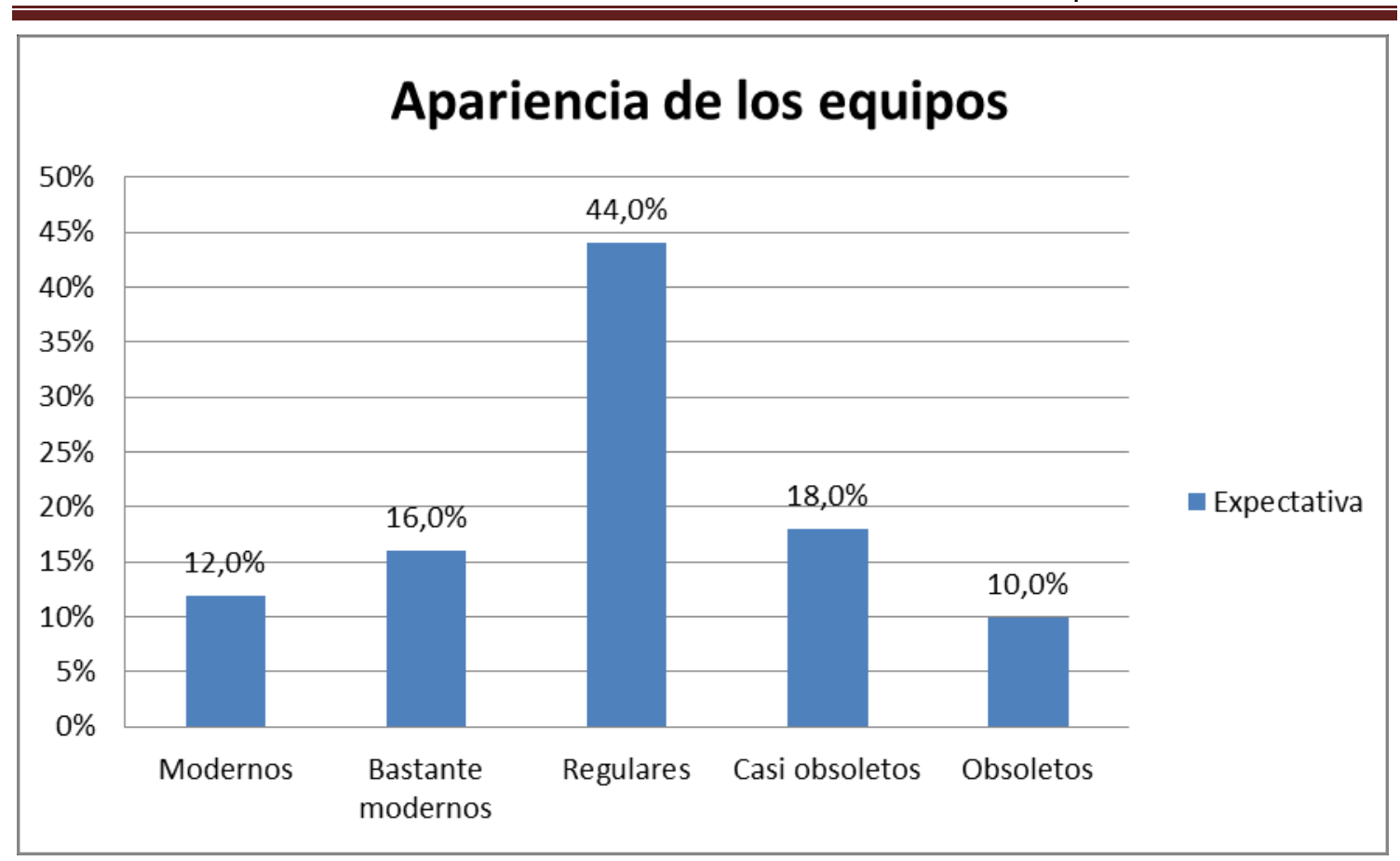

Saldo de respuesta: 2,98 "regulares".

\subsubsection{Percepción}

La percepción de los encuestados sobre los equipos con los que cuenta el servicio de Licencias de Conducir fue la siguiente:

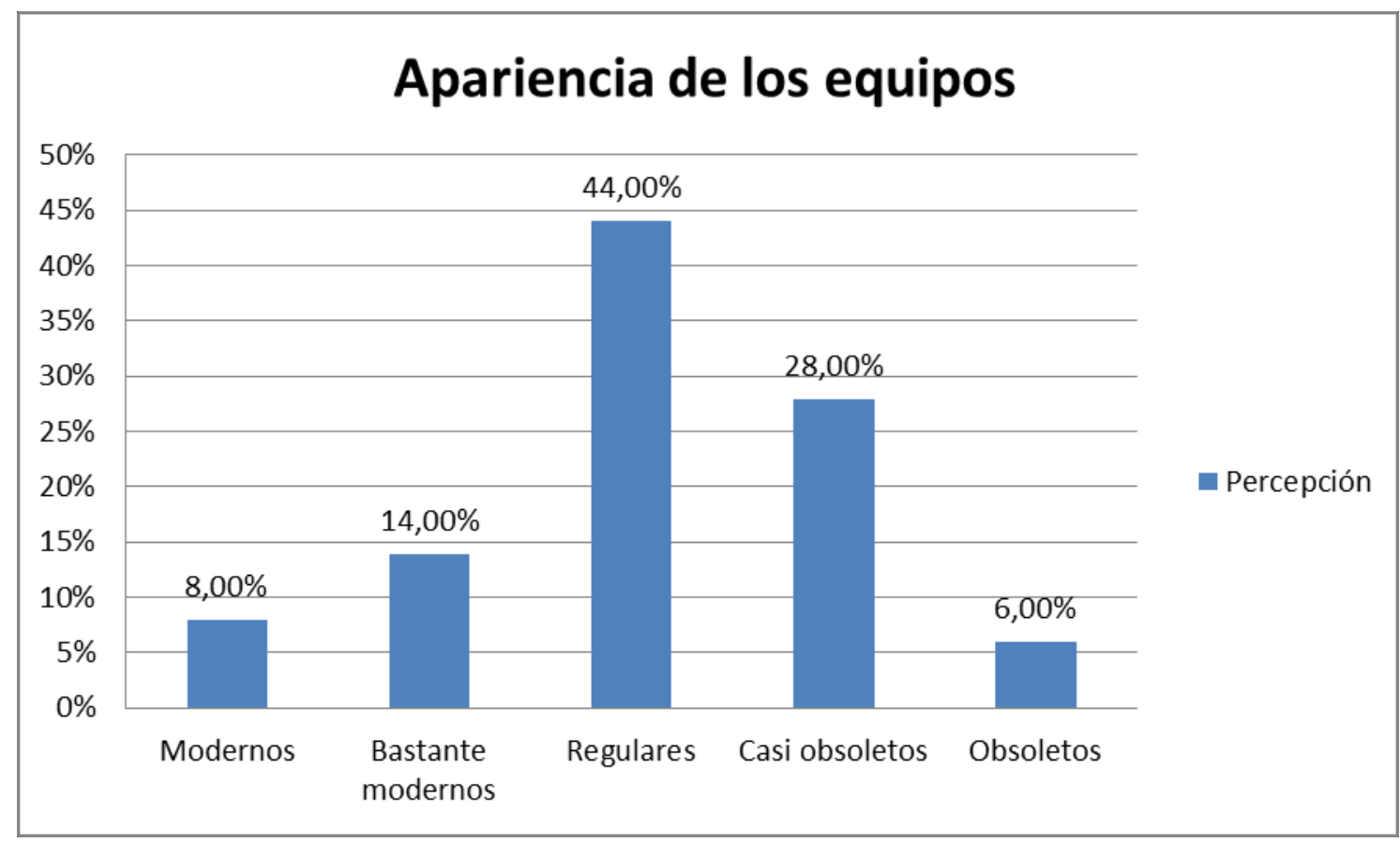

Los usuarios del sistema de Licencias de Conducir calificaron a los equipos de "regulares" a "casi obsoletos", con un Saldo de Respuesta de 3,10.

\subsubsection{Brecha}


En el siguiente gráfico se puede observar la apreciación por parte de los clientes, de los equipos del servicio junto con las expectativas que traían los encuestados:

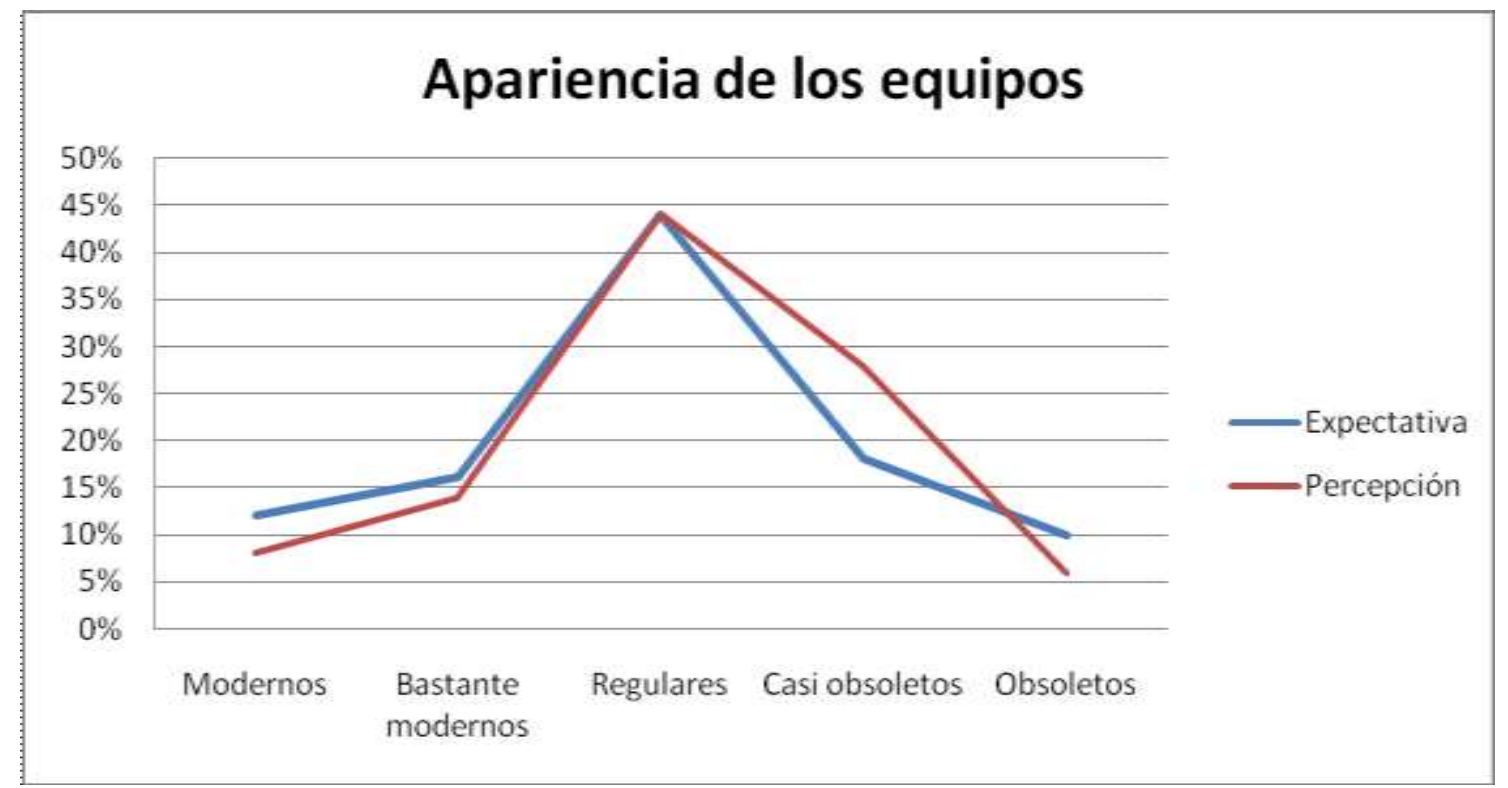

Como se observa en el gráfico precedente, es evidente que los clientes esperaban en su mayoría encontrar un nivel de equipos de regulares a modernos.

En el esquema siguiente se muestra la brecha de satisfacción entre lo que esperan y las percepciones de los equipos del servicio una vez que hacen uso de la Dependencia:

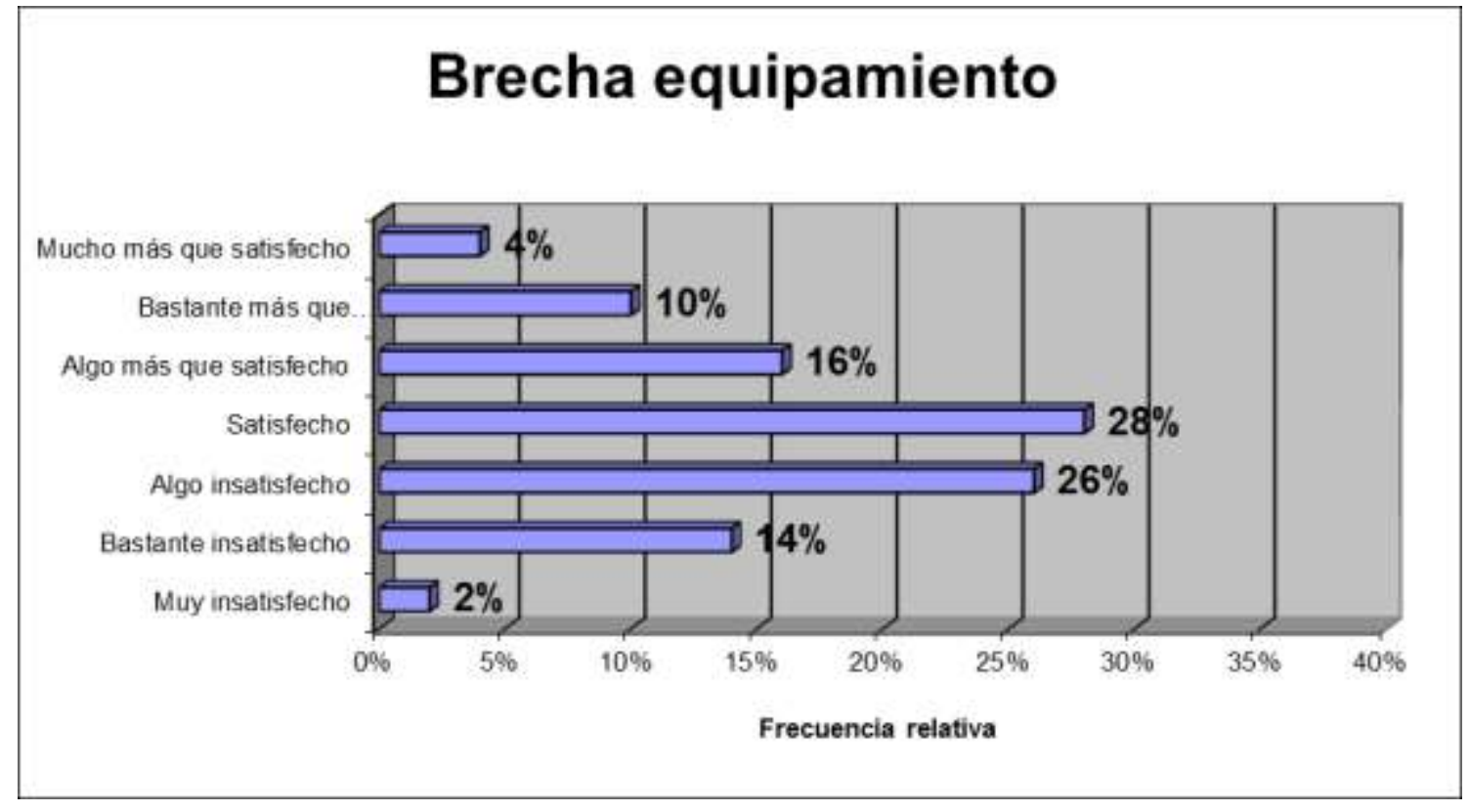

Saldo de respuesta: -0,12 "algo insatisfecho" con tendencia a "satisfecho" 


\subsubsection{Instalaciones físicas}

\subsubsection{Expectativa}

En cuanto a las expectativas sobre las instalaciones físicas de la dependencia se observaron los siguientes resultados:

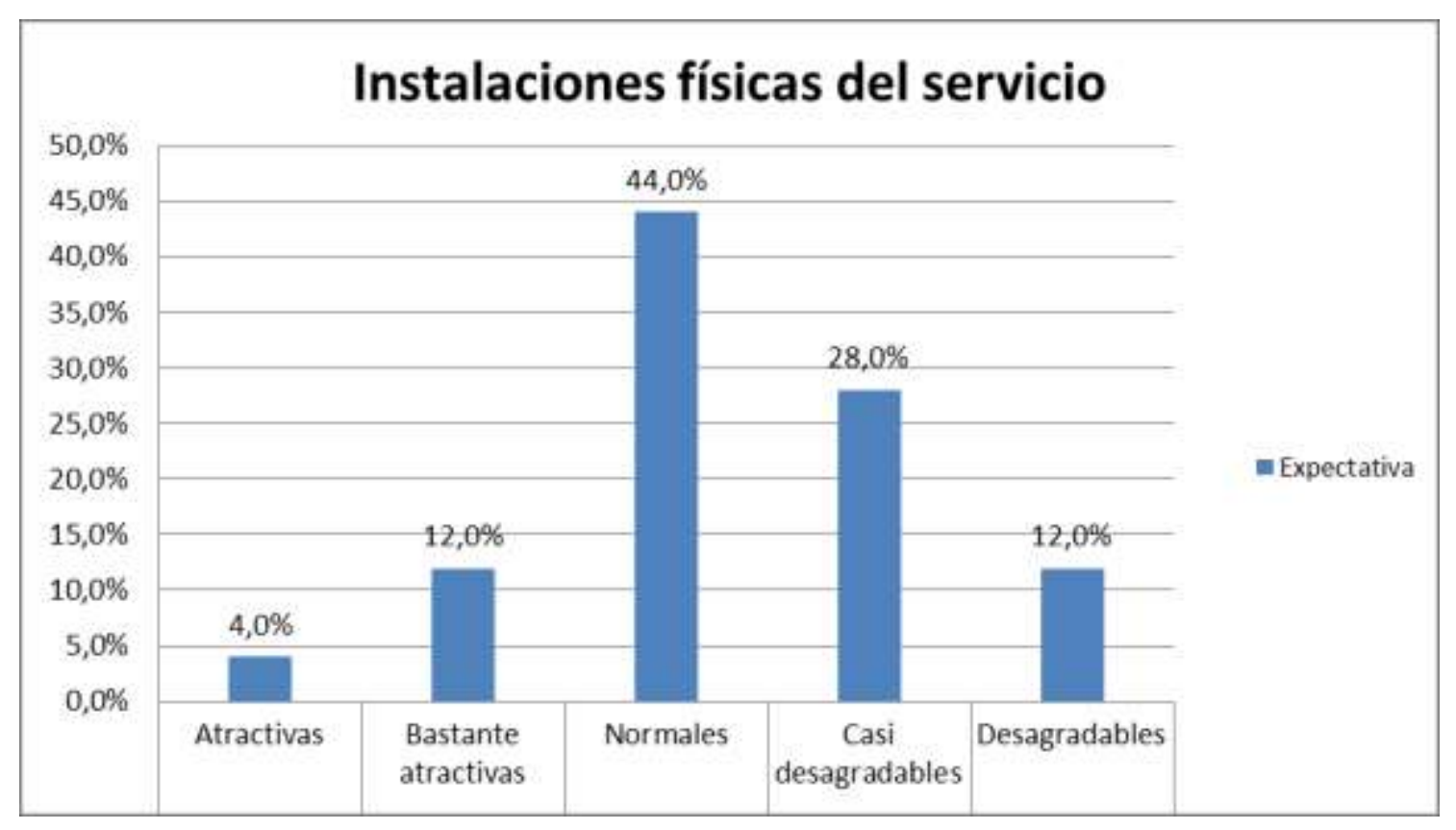

Saldo de respuesta: 3,32 "normales" a "casi desagradables".

\subsubsection{Percepción}

Se muestran a continuación los resultados de las percepciones sobre las instalaciones físicas:

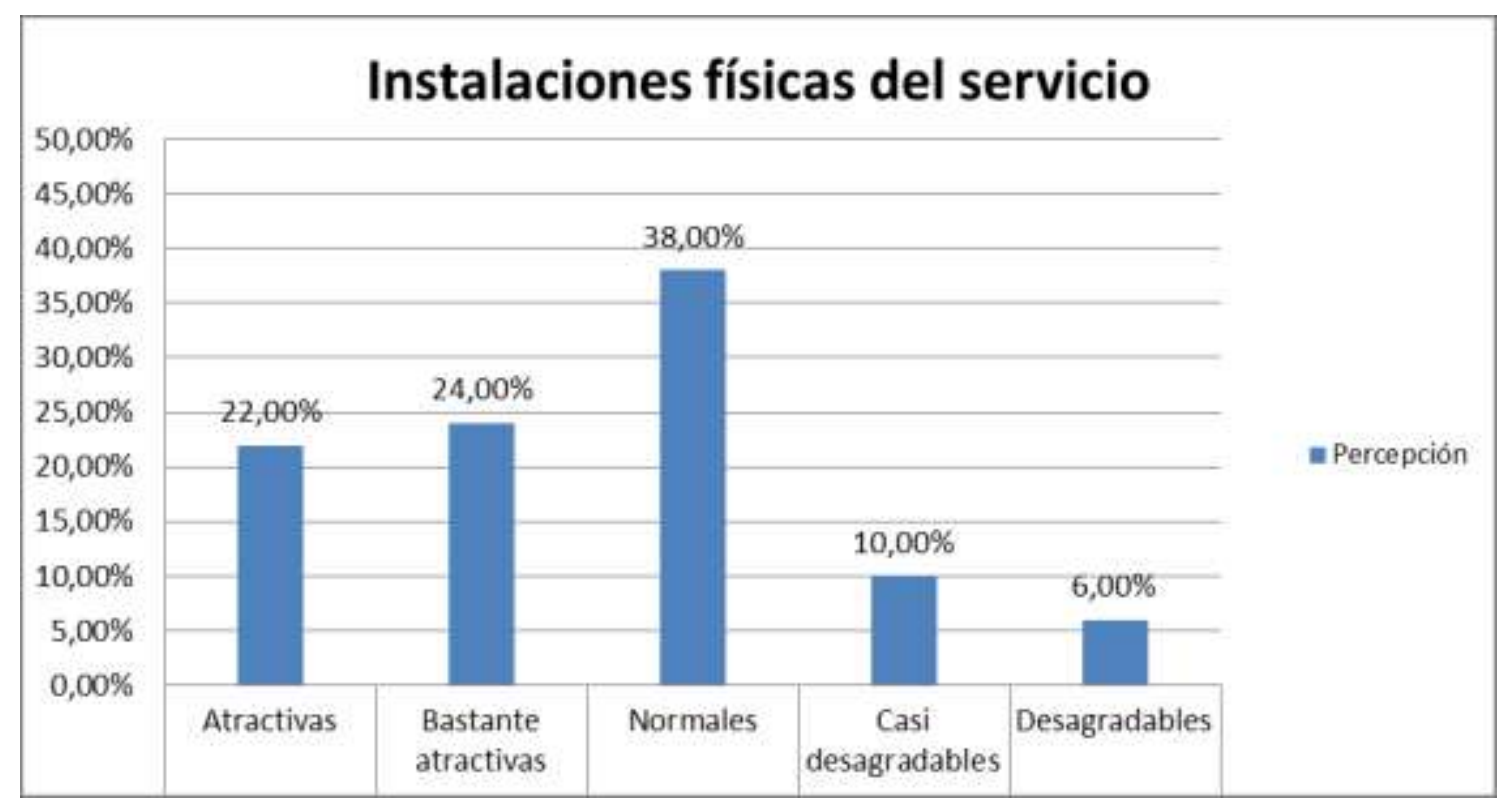


El Saldo de Respuesta de las percepciones sobre las instalaciones físicas fue de 2,54 en el rango que va de "normales" a "bastante atractivas".

\subsubsection{Brecha}

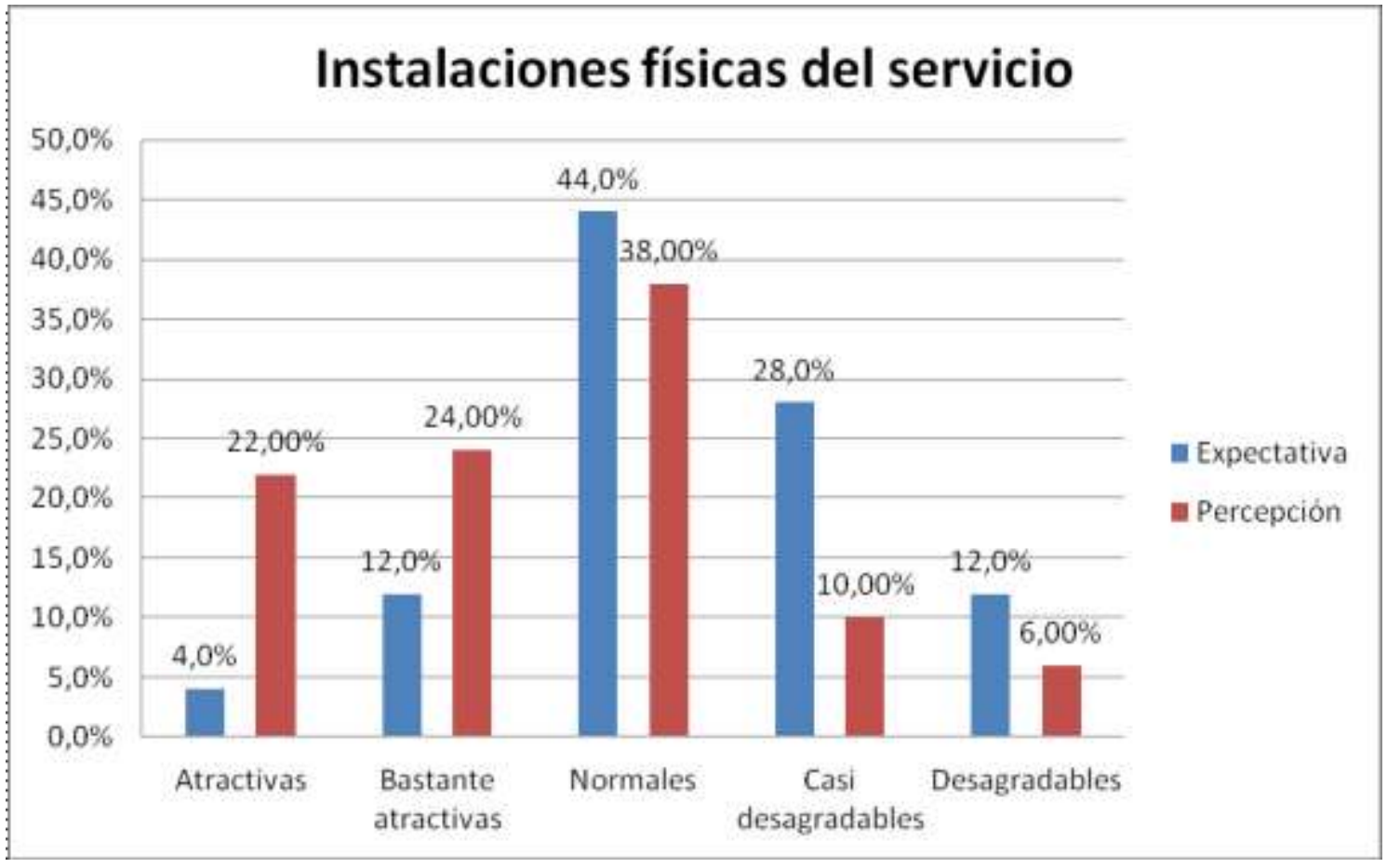

La brecha de satisfacción de las instalaciones físicas se asemeja bastante a la obtenida en el caso de los equipos, como se muestra a continuación:

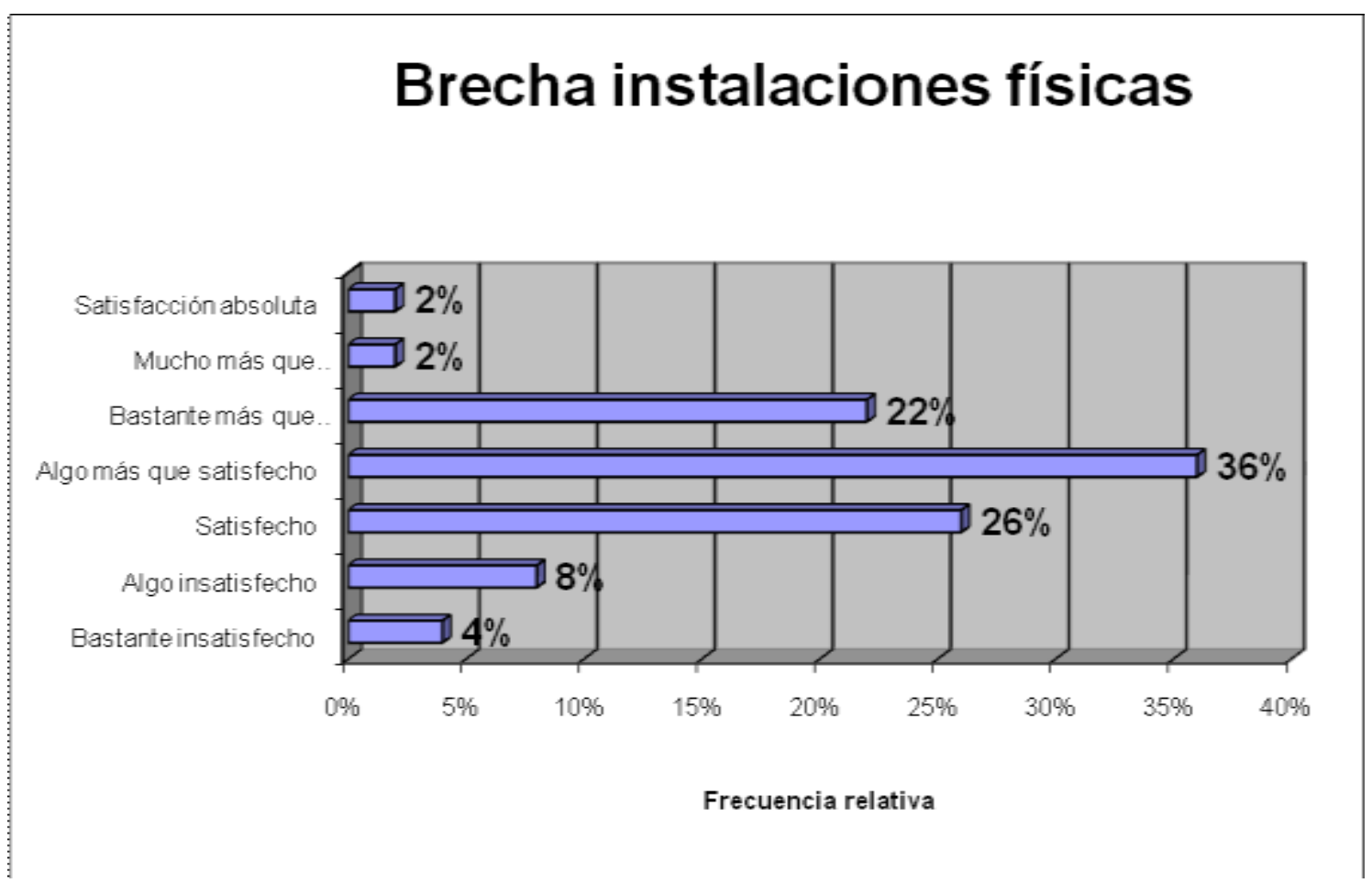

Saldo de respuesta: 0,78 "satisfecho" con tendencia a "algo mas que satisfecho" 


\subsubsection{Apariencia física de los empleados}

\subsubsection{Expectativa.}

Con un Saldo de Respuesta de 3,10 los usuarios confiaban en que el aspecto físico de los empleados del servicio sería normal, como se muestra a continuación .

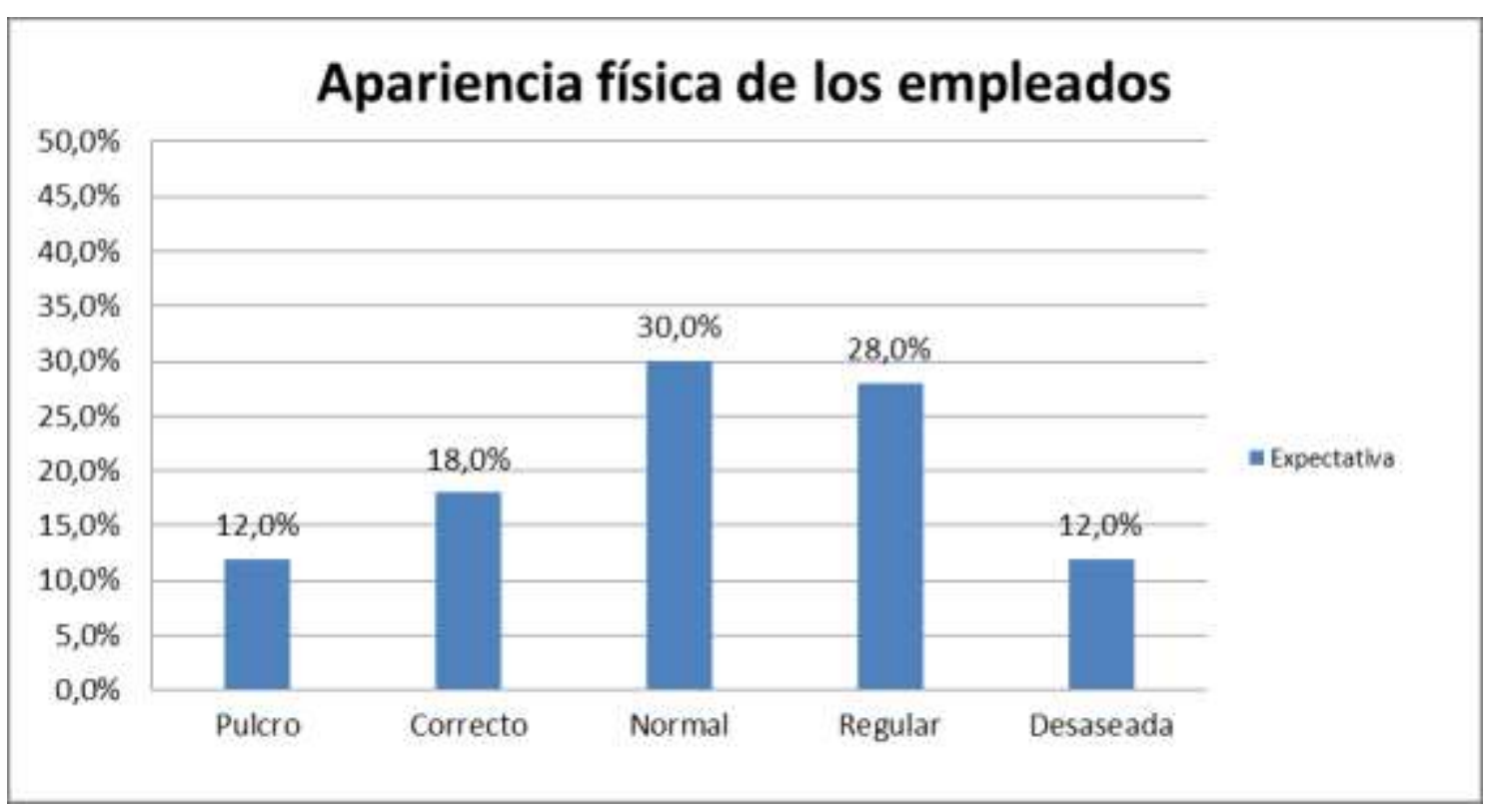

Saldo de respuesta: 3,10 "normal" con tendencia a "regular"

\subsubsection{Percepción}

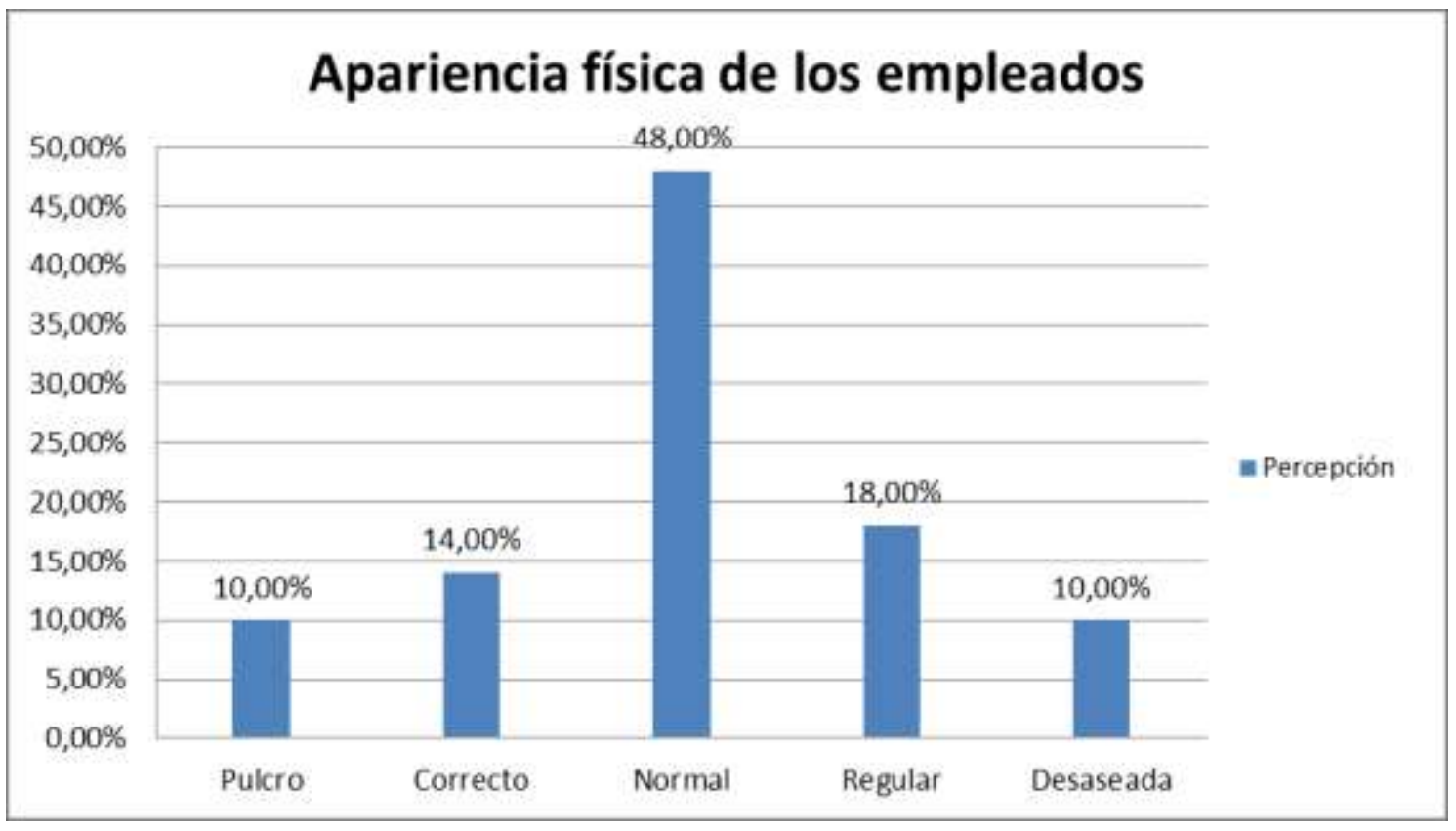

Con un Saldo de Respuesta de 3,04 se evalúa la apariencia física de los empleados es "normal". 


\subsubsection{Brecha}

Comparando en un mismo gráfico la percepción y las expectativas que traían los usuarios respecto de la apariencia física de los empleados se obtuvo:
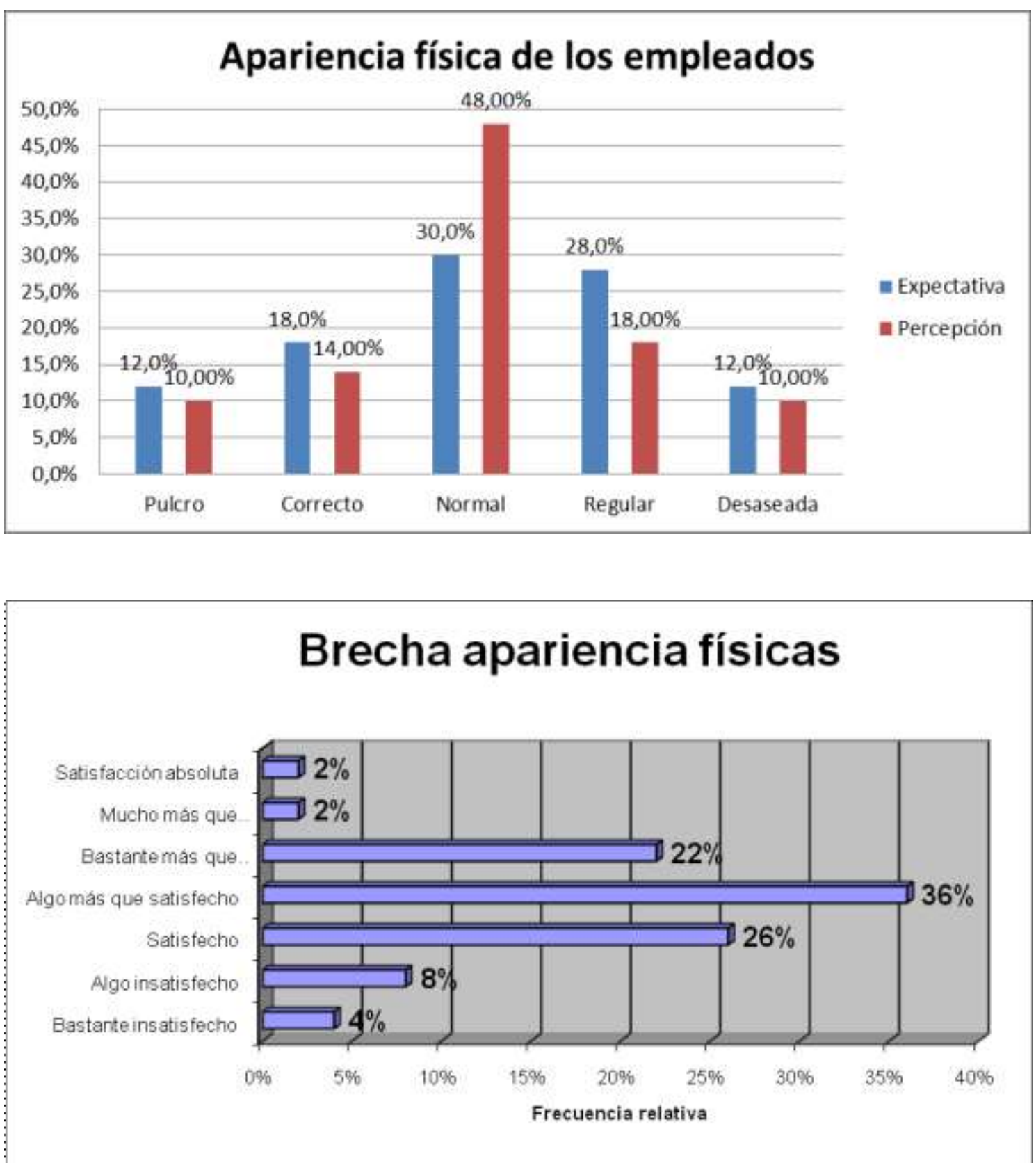

Saldo de respuesta: 0,78 "algo mas que satisfecho" con tendencia a "satisfecho". 


\subsubsection{Apariencia visual de los elementos materiales de comunicación}

\subsubsection{Expectativa}

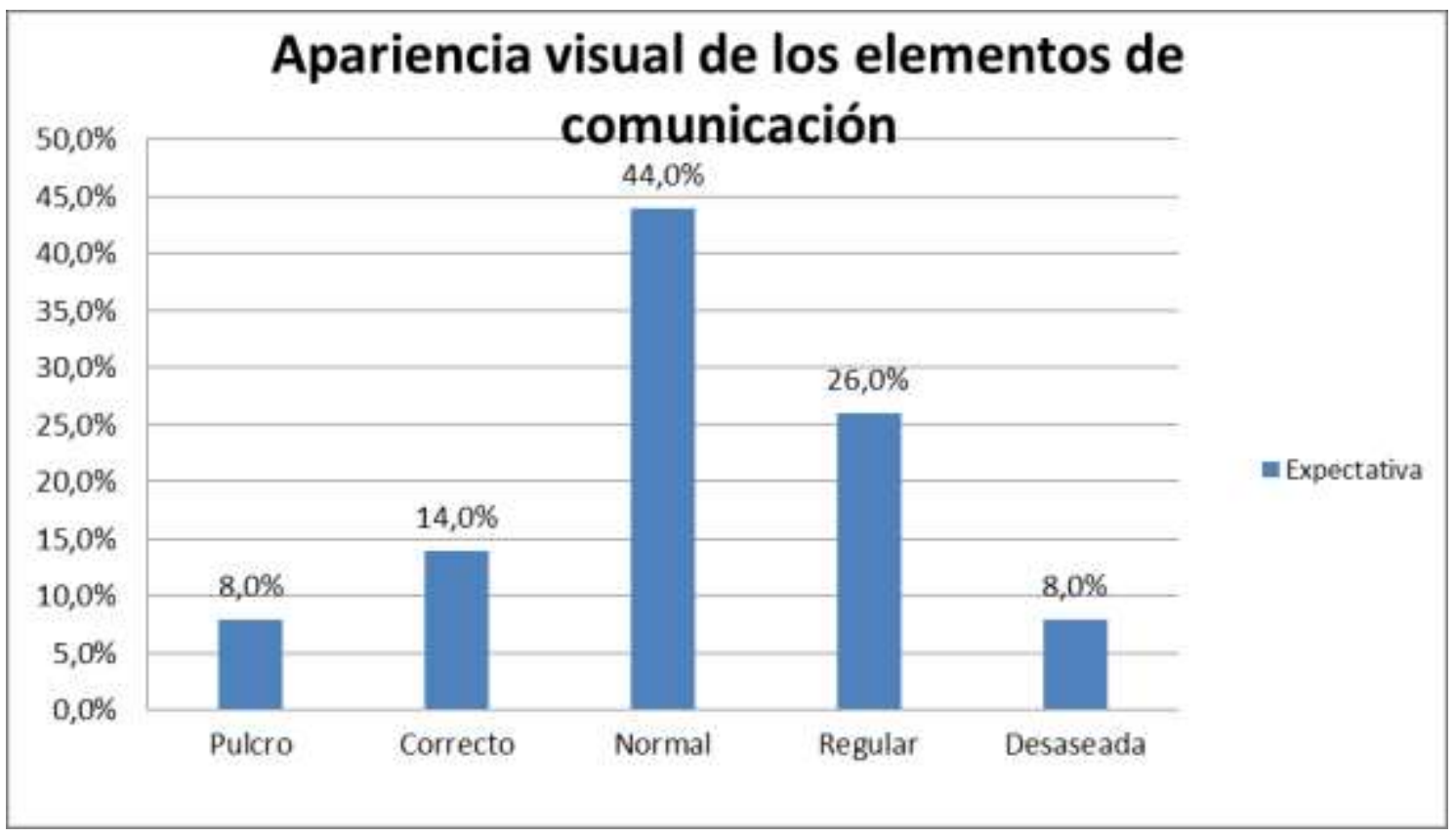

Saldo de respuesta: 3,12 "normal"

\subsubsection{Percepción}

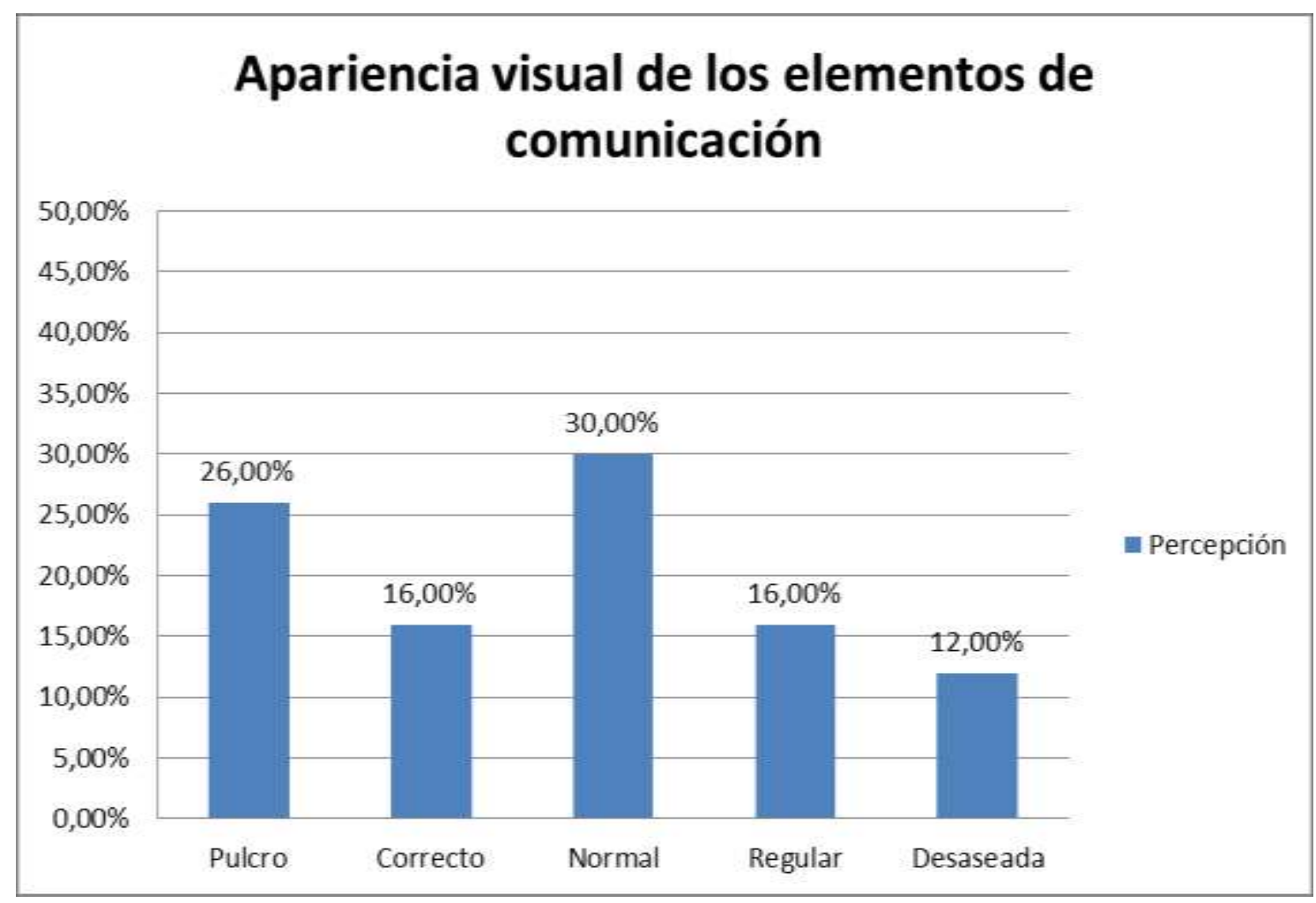

El Saldo de Respuesta de la apariencia de los elementos de comunicación es de 2,72 ubicándose en el rango de "normal" con leve tendencia a "correcto". 


\subsubsection{Brecha}

Al evaluar el diferencial entre las expectativas y las percepciones recogidas, se obtuvieron los siguientes niveles de satisfacción:
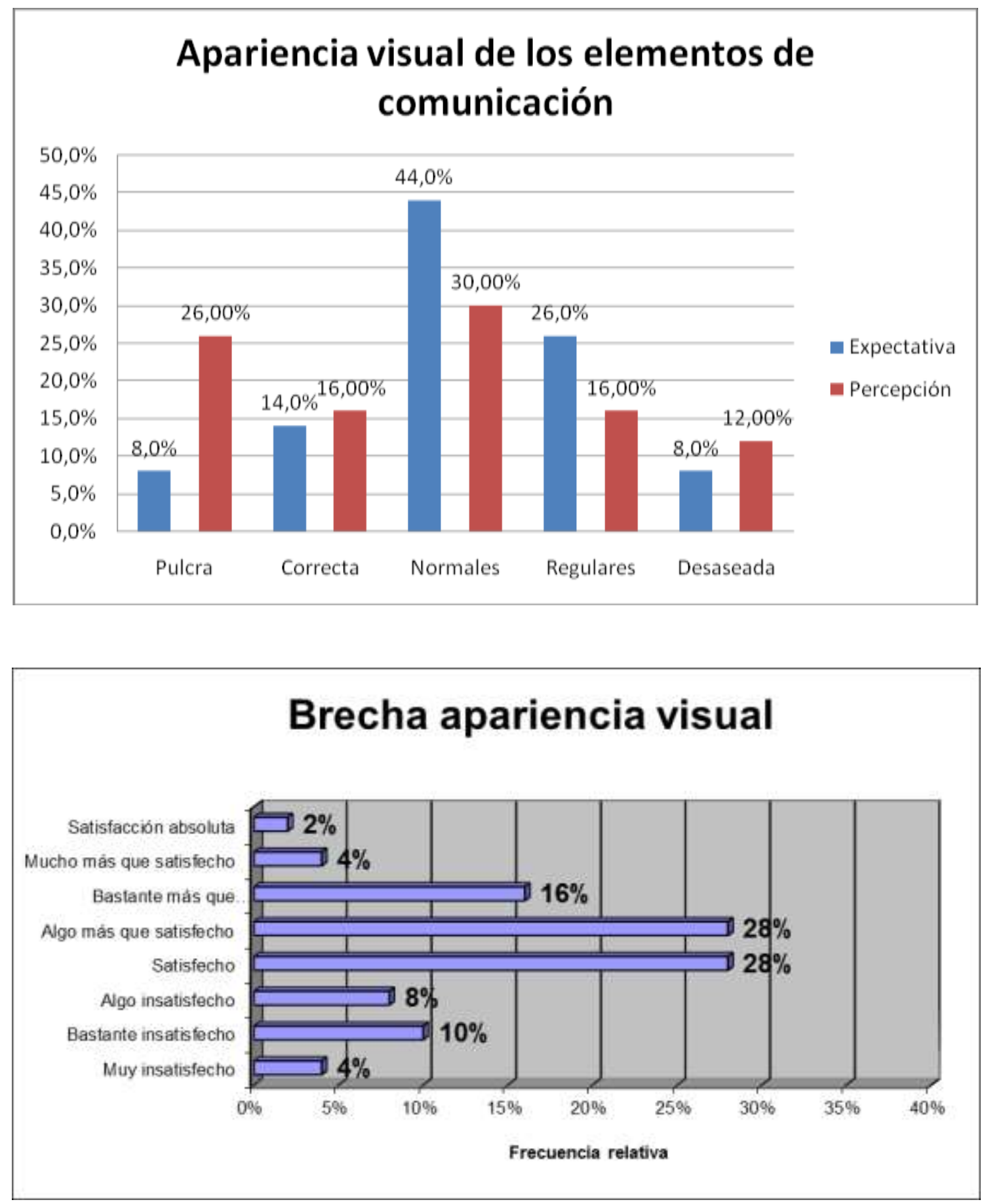

Saldo de respuesta: 0,40 "satisfecho". 
7.4 Dimensión II: Confiabilidad. Habilidad para ejecutar el servicio prometido de forma confiable y cuidadosa

En esta dimensión se obtuvieron resultados respecto del cumplimiento, el interés, la eficacia, el tiempo de cumplimiento y la eficiencia de los prestadores del servicio de Licencias de Conducir.

7.4.1 Los empleados del servicio municipal cumplen lo que prometen

\subsubsection{Expectativa}

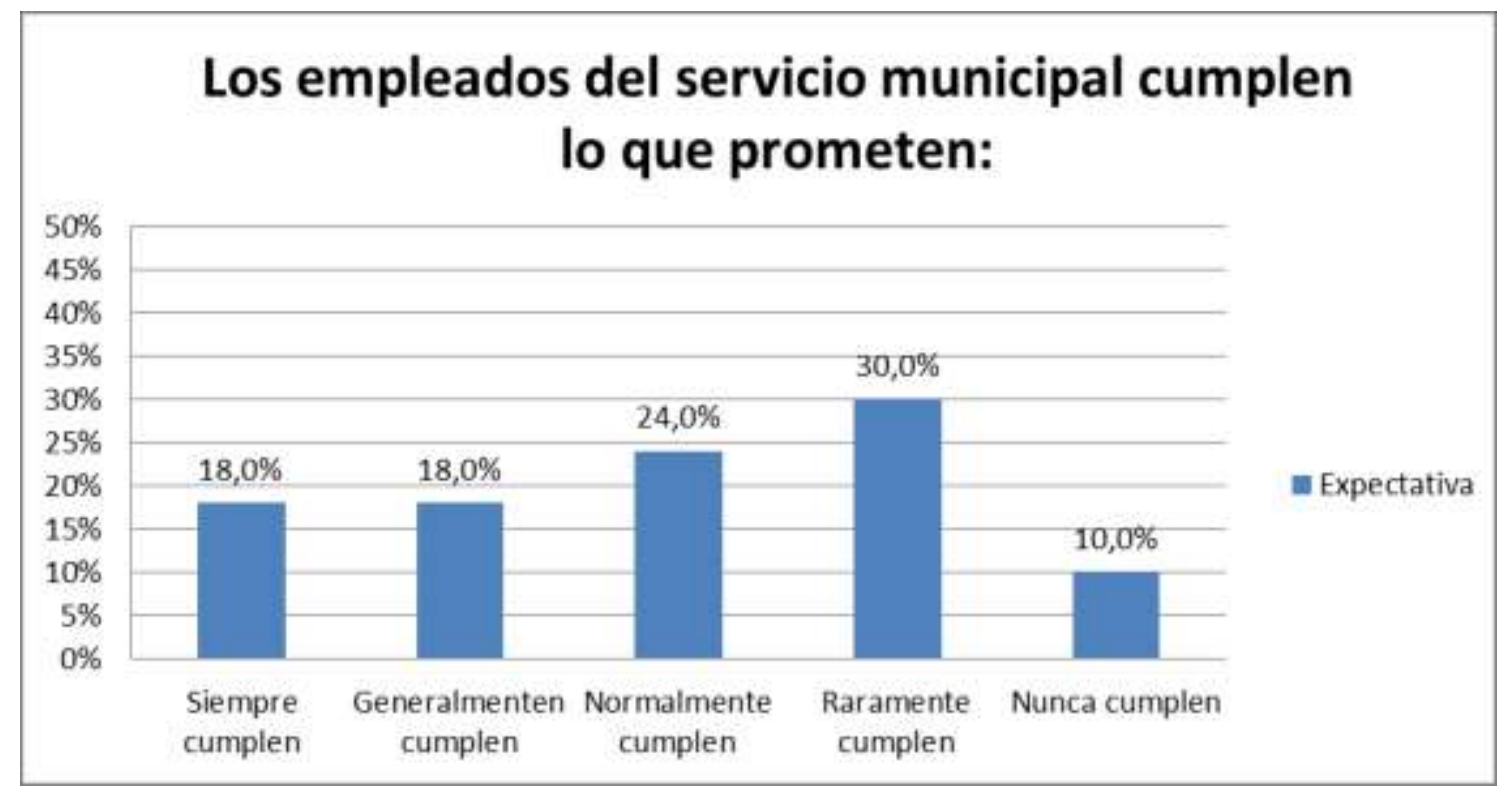

Saldo de respuesta: 2,96 "normalmente cumplen".

\subsubsection{Percepción}

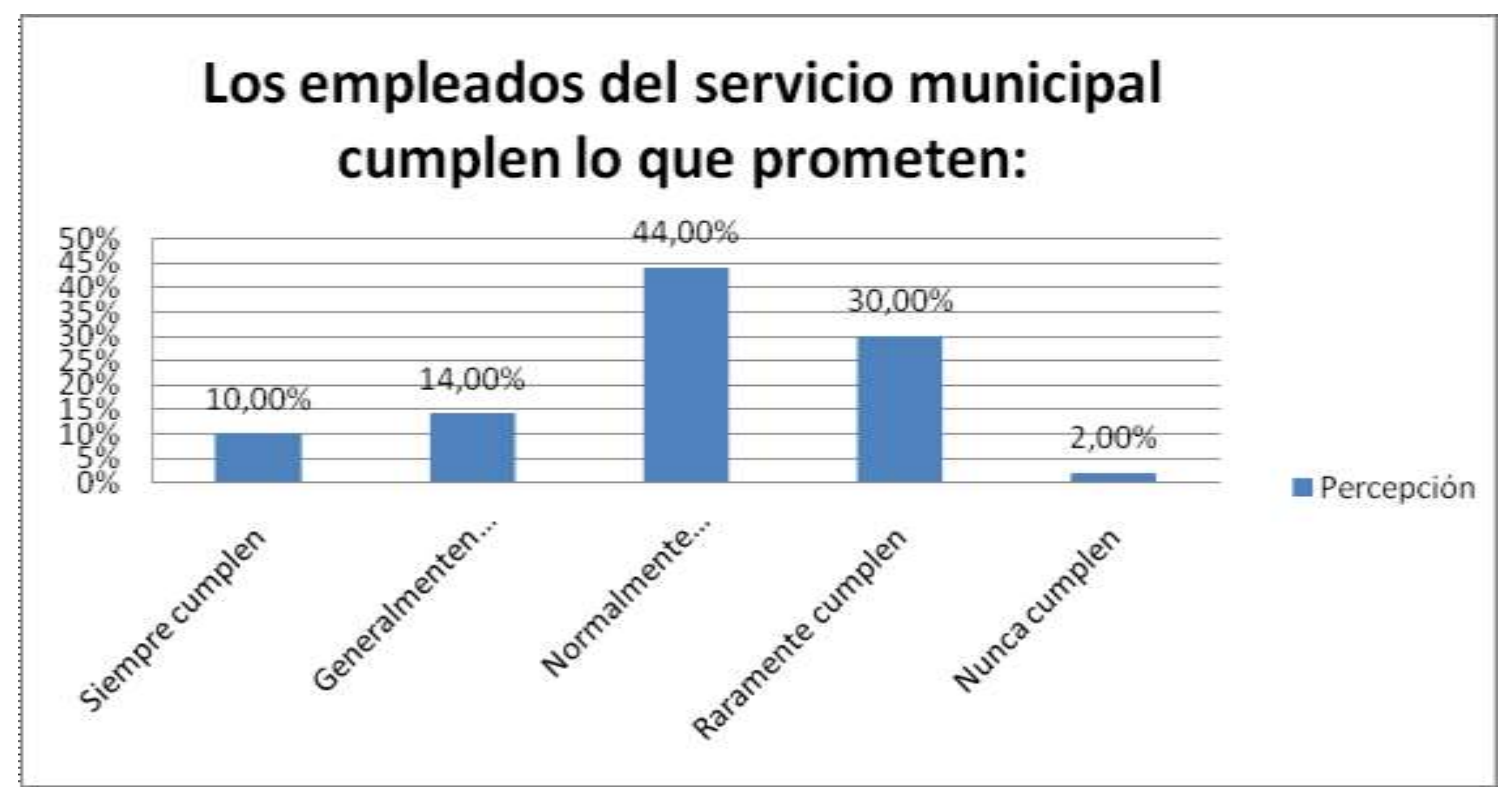


El Saldo de Respuesta en las opiniones de los usuarios es de 3, "normalmente" los empleados municipales cumplen lo que prometen.

\subsubsection{Brecha}
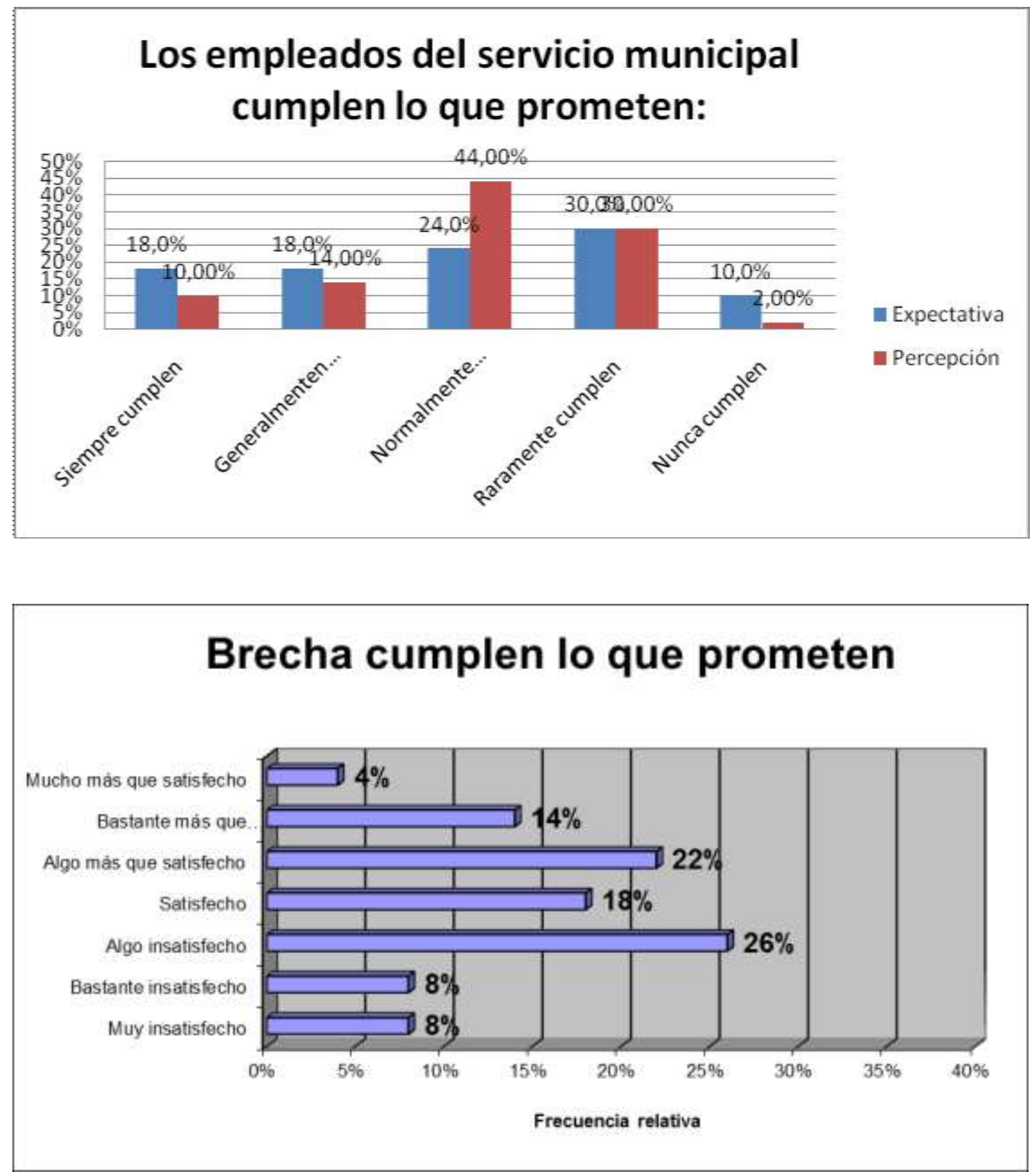

Saldo de respuesta: -0,04 "algo insatisfecho". 
7.4.2 Interés que tienen los empleados del servicio municipal por solucionar los problemas

\subsubsection{Expectativa}

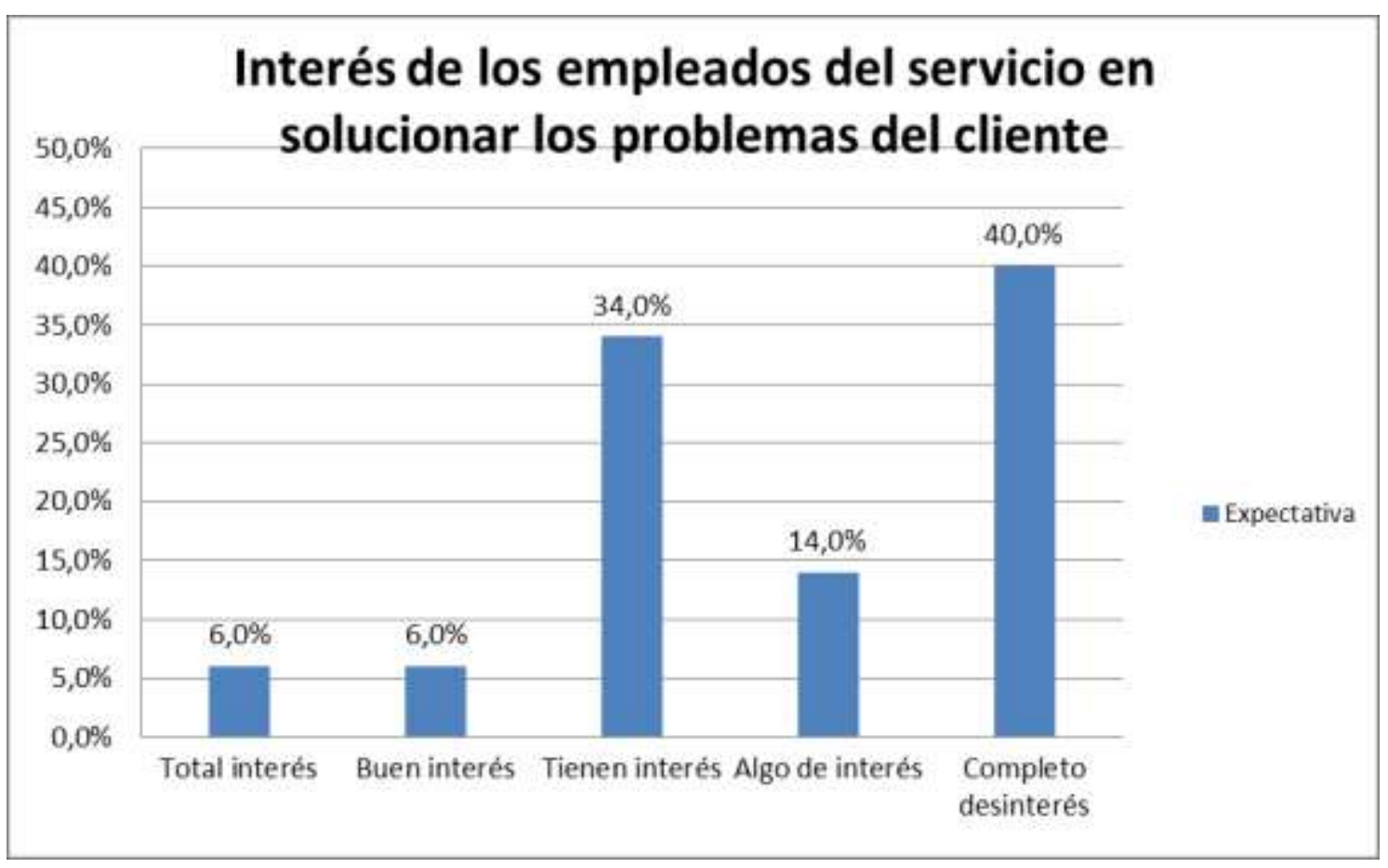

Saldo de respuesta: 3,76 "algo de interes".

\subsubsection{Percepción}

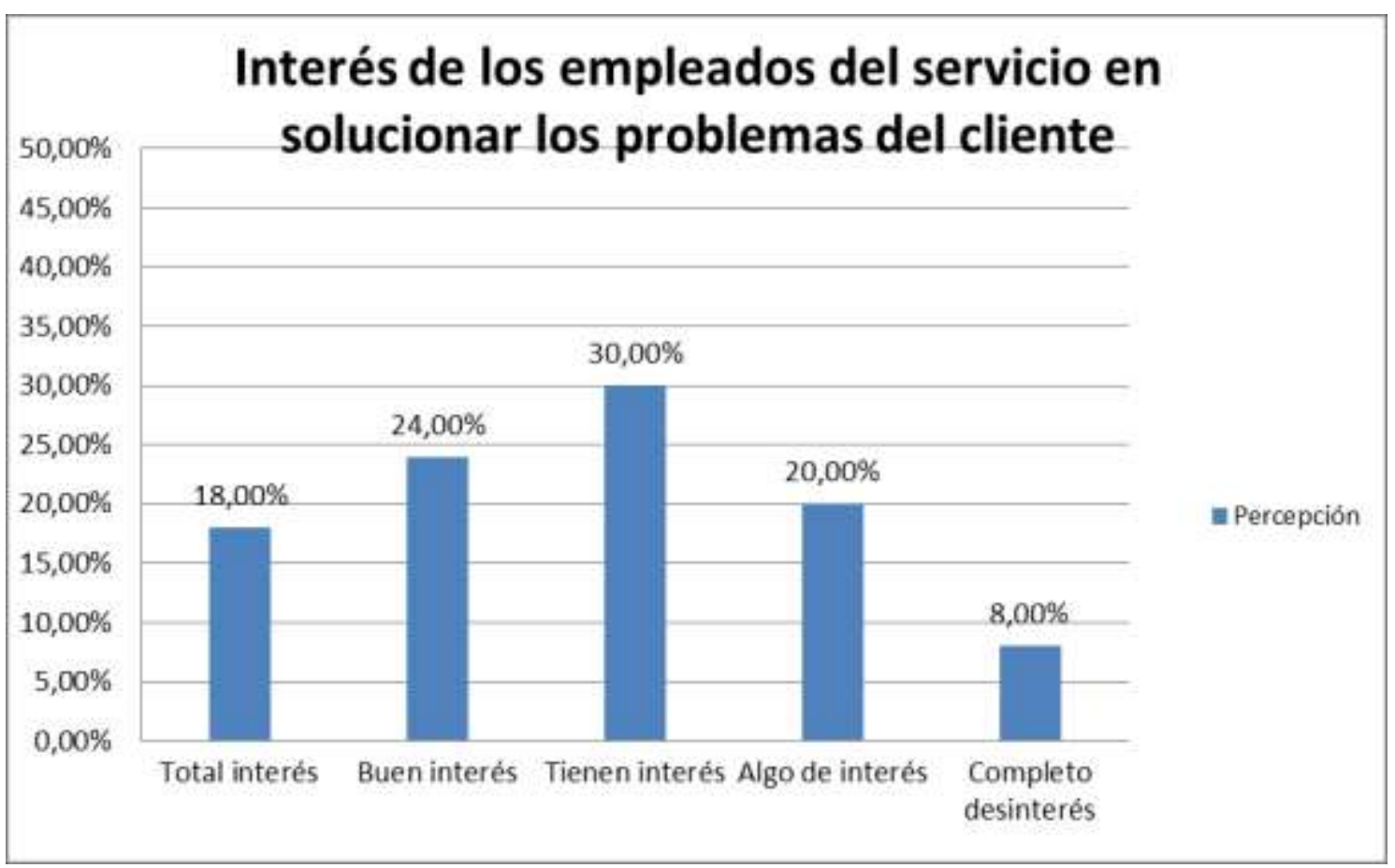

Con un Saldo de Respuesta de 2,76 los usuarios perciben que los empleados tienen interés en solucionar sus problemas, con tendencia "buen interés". 


\subsubsection{Brecha}
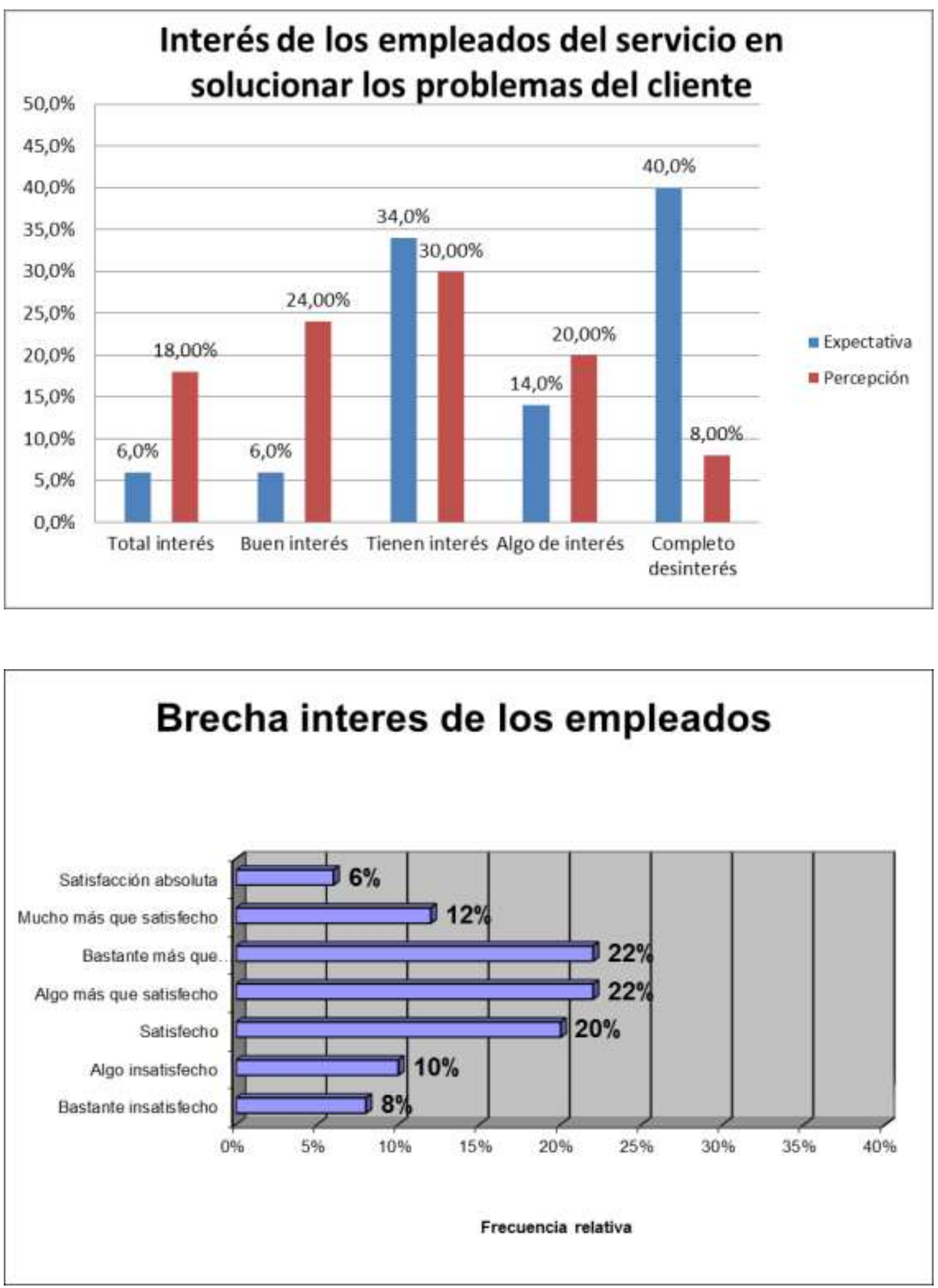

Saldo de respuesta: 1 "bastante satisfecho". 


\subsubsection{Eficacia del servicio de licencias de conducir}

\subsubsection{Expectativa}

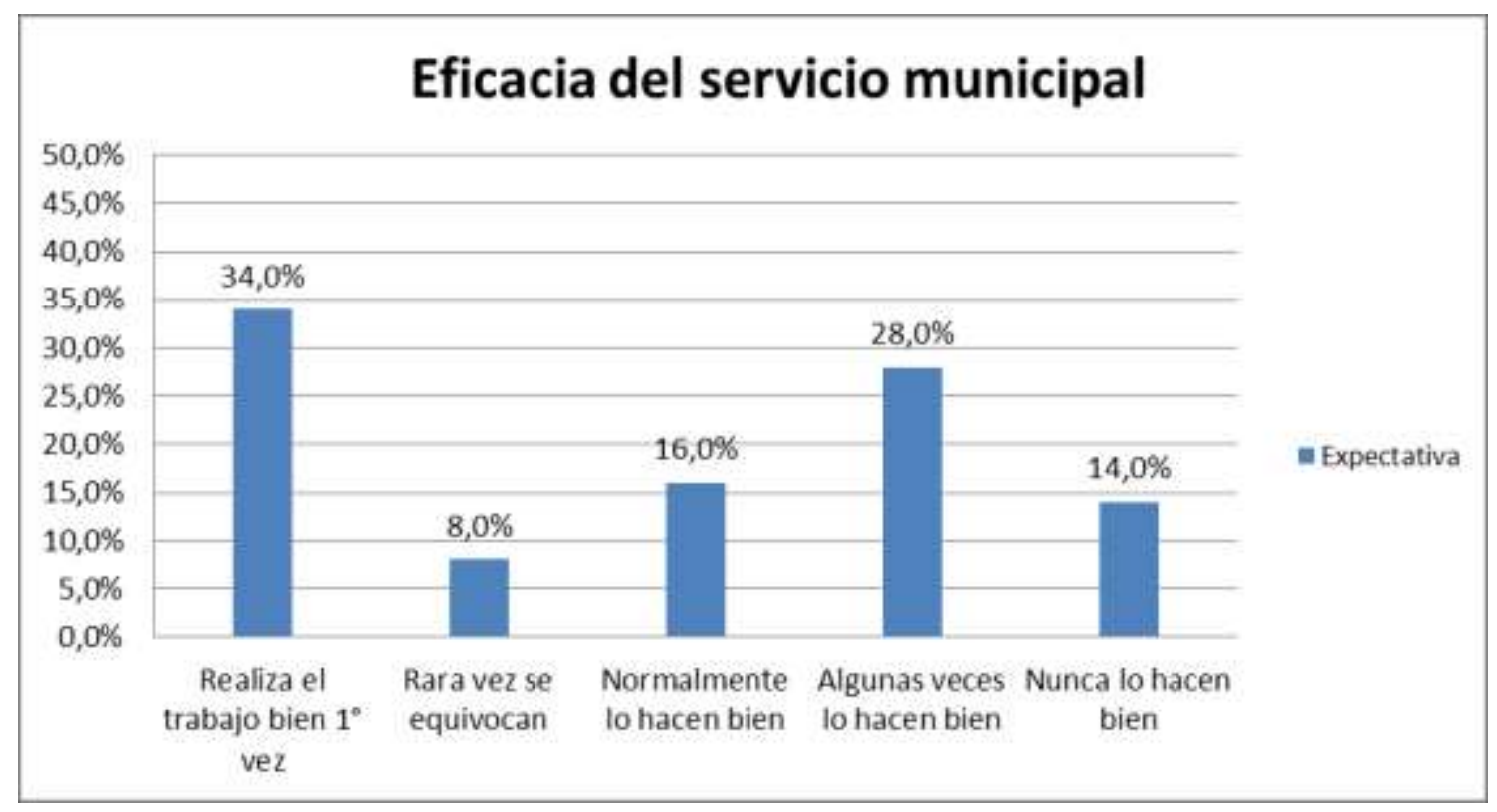

Saldo de respuesta: 2,80 "normalmente lo hacen bien"

\subsubsection{Percepción}

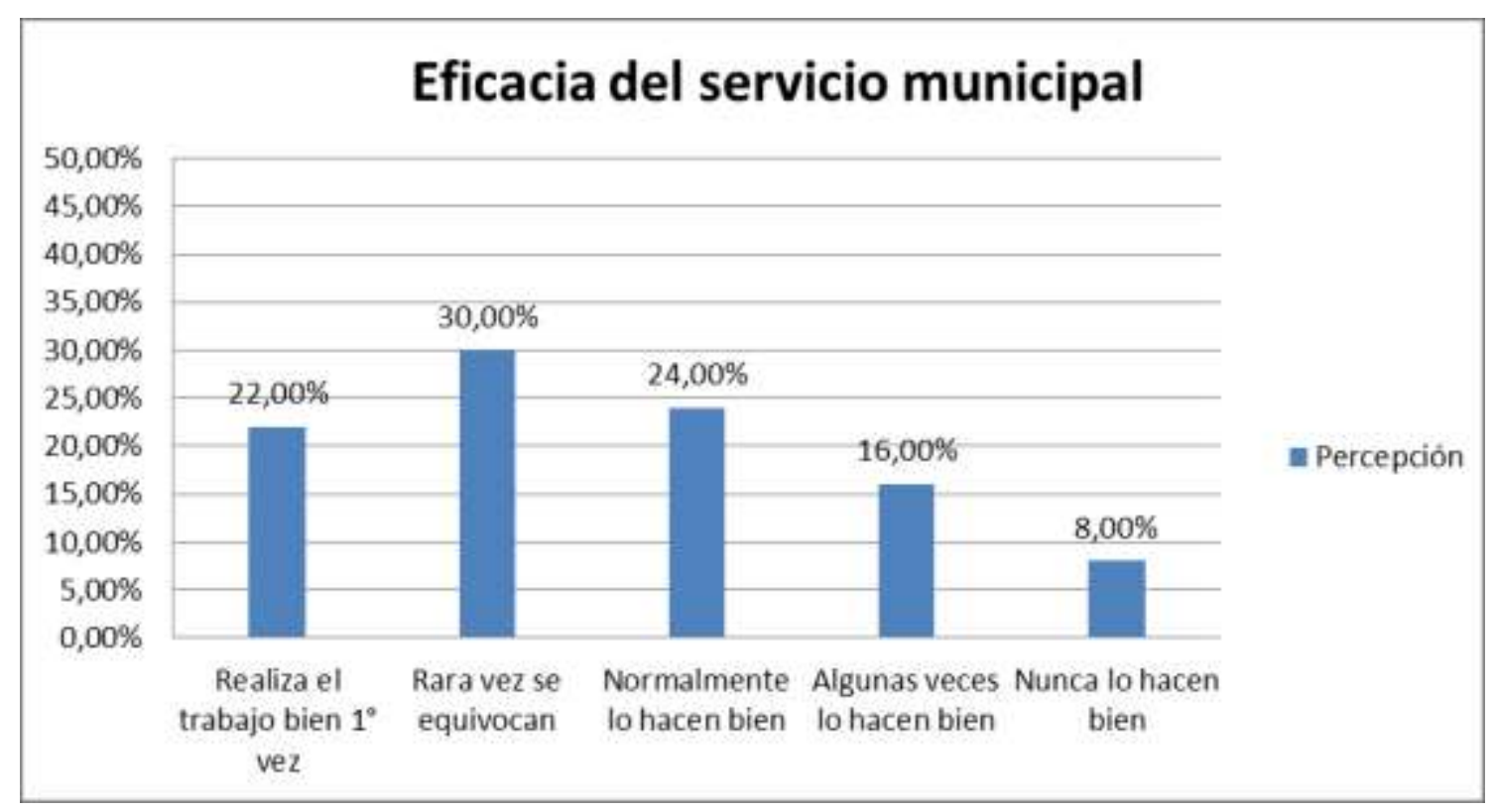

Con un Saldo de Respuesta de 2,58 la eficacia percibida en el servicio es "Normalmente lo hacen bien" con tendencia a "Rara vez se equivocan". 


\subsubsection{Brecha}
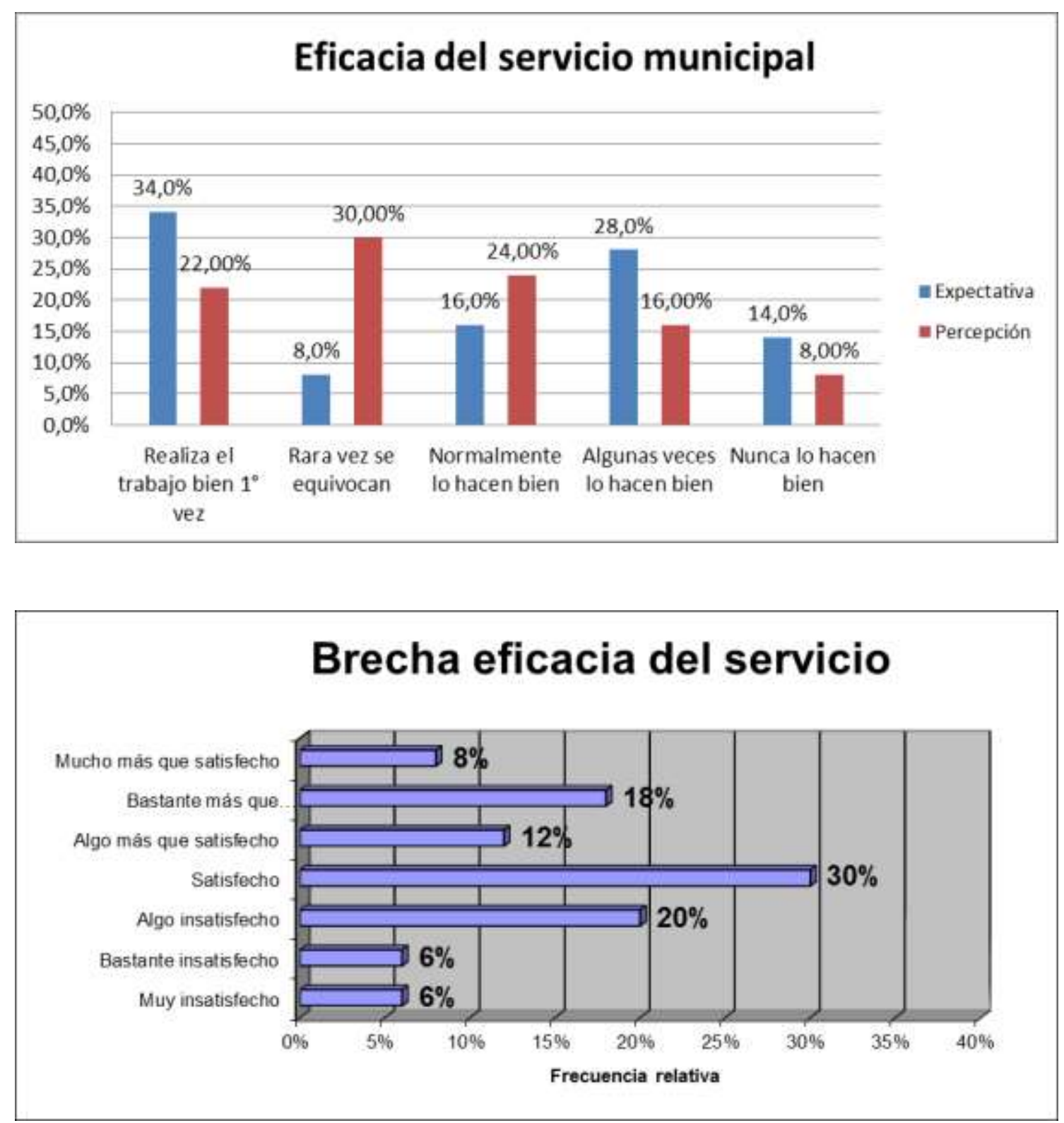

Saldo de respuesta: 0,22 "Satisfecho" 


\subsubsection{Tiempo de cumplimiento del trabajo}

\subsubsection{Expectativa}

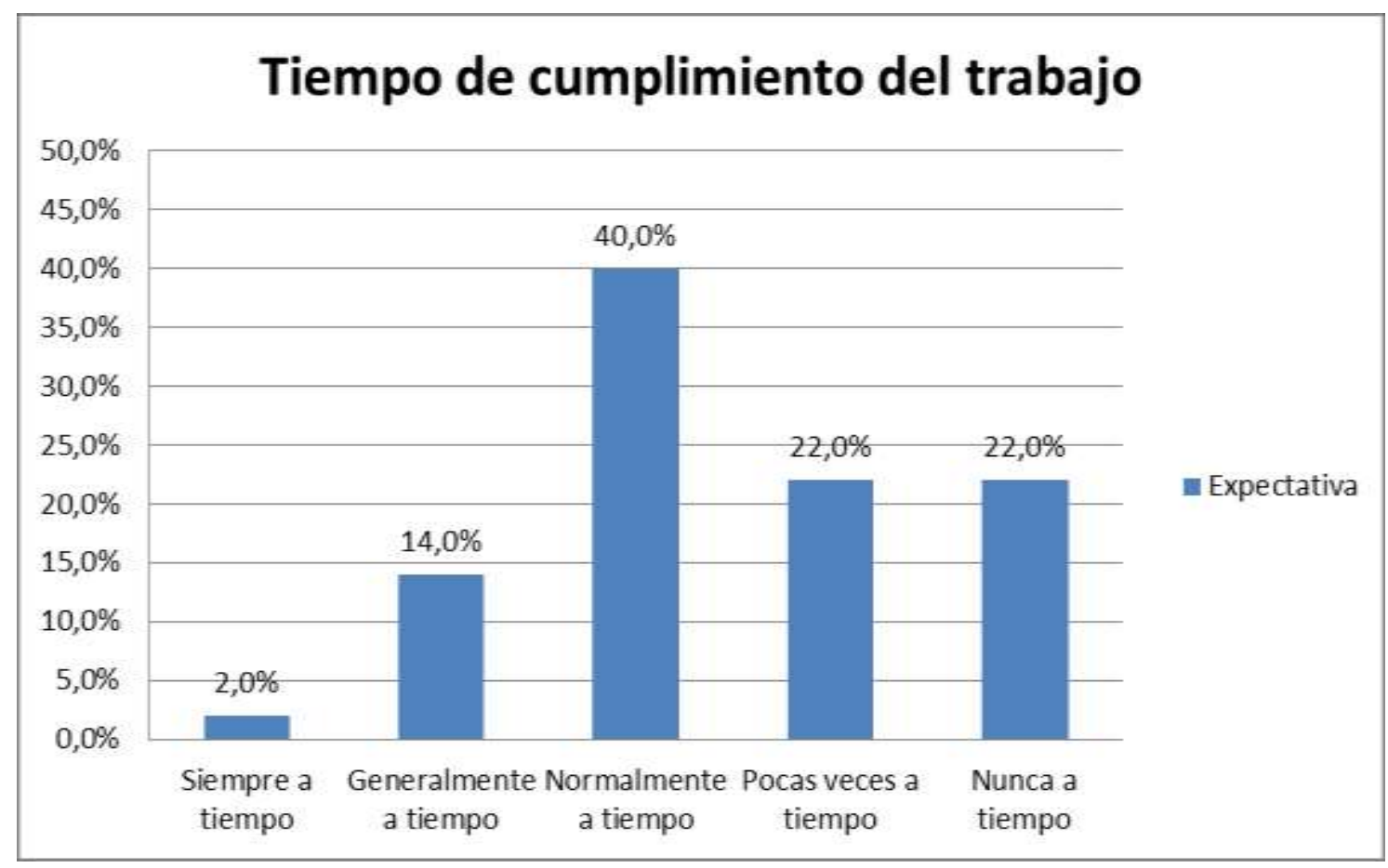

Saldo de respuesta: 3,48 "normalmente a tiempo" con tendencia a "pocas veces a tiempo".

\subsubsection{Percepción}

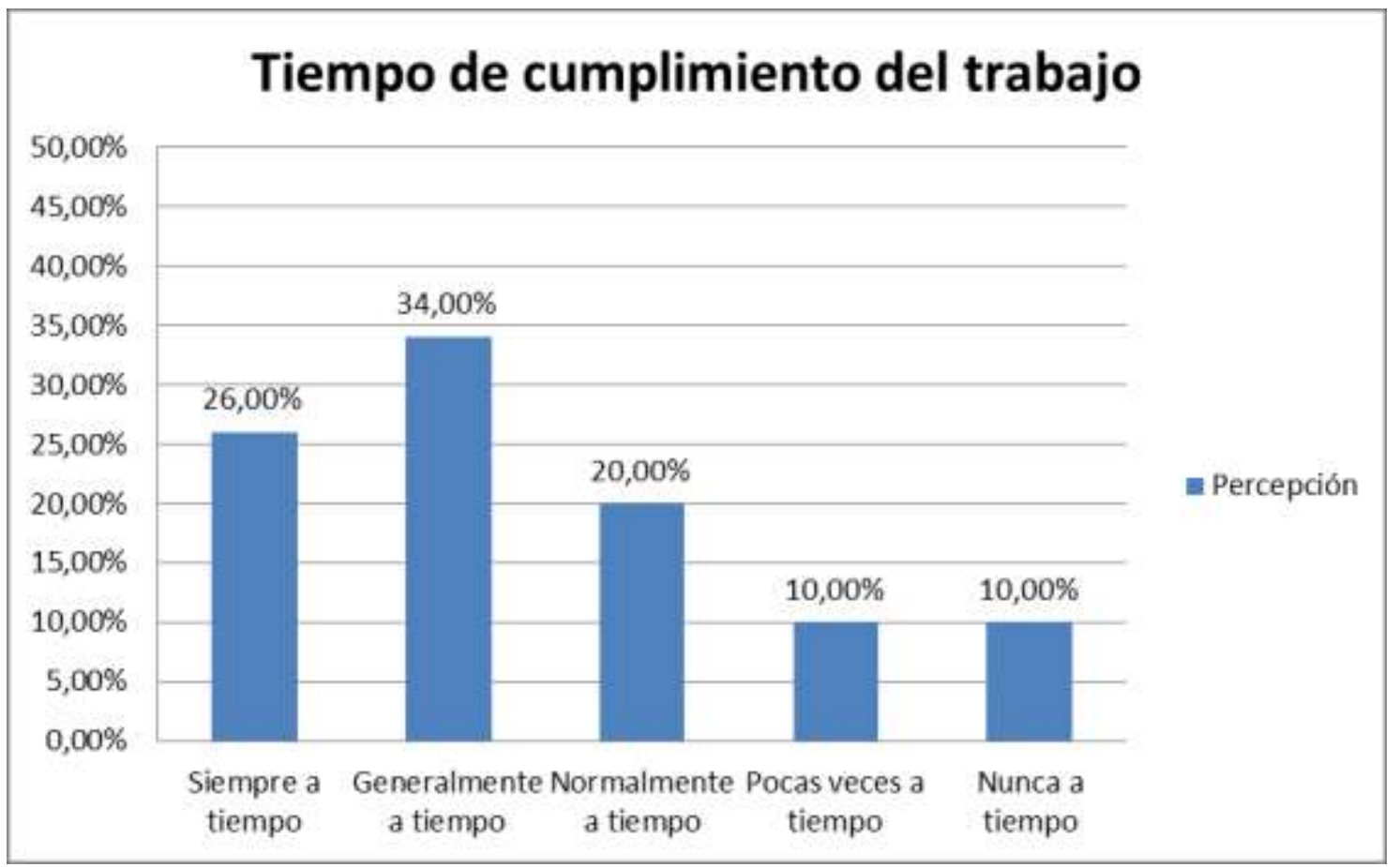

Con un Saldo de Respuesta de 2,44 el tiempo de cumplimiento de trabajo se valora como de "normalmente" a "generalmente" a tiempo. 


\subsubsection{Brecha}
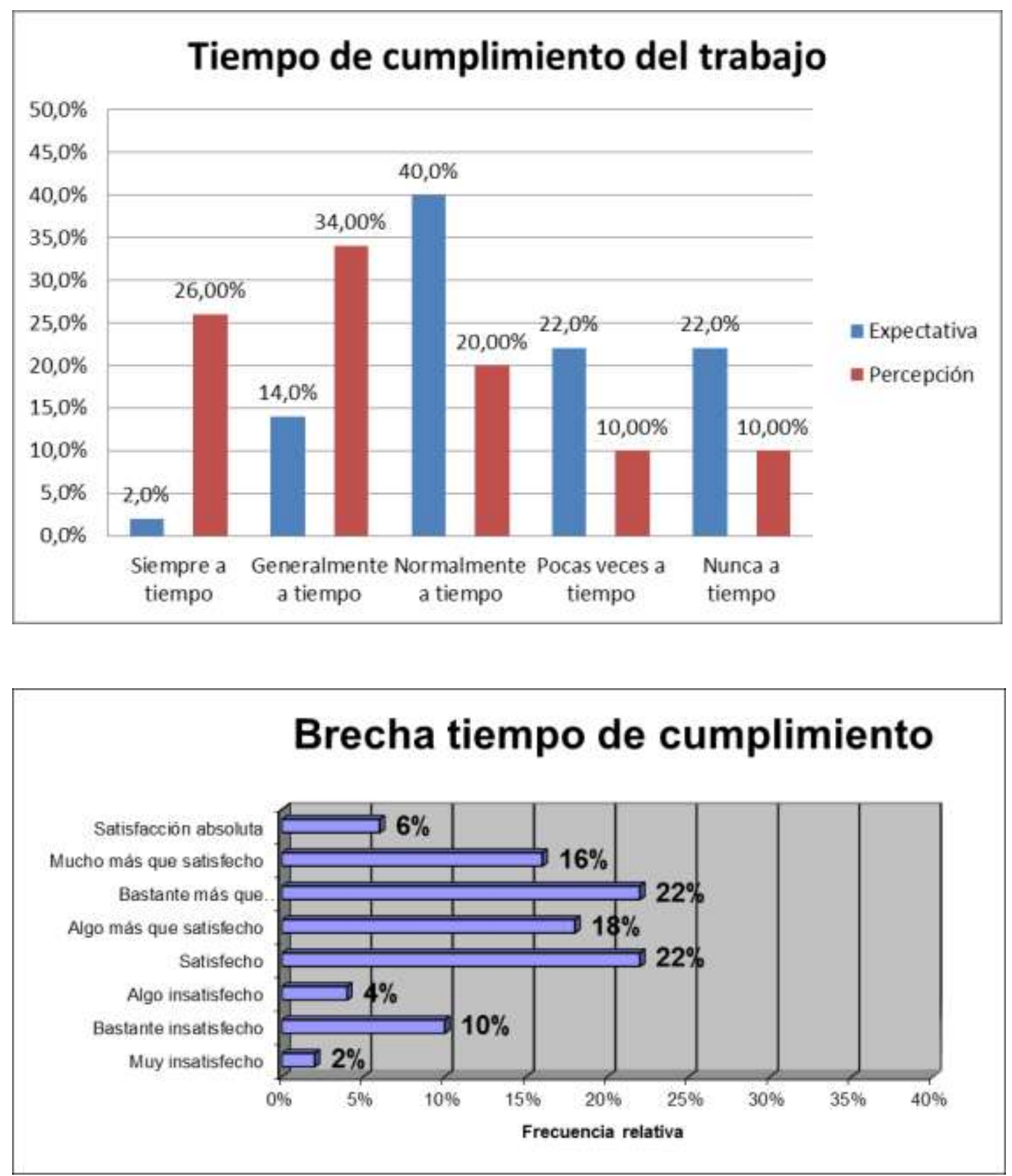

Saldo de respuesta: 1,04 "algo mas que satisfecho". 


\subsubsection{Eficiencia del trabajo del servicio de Licencias de Conducir}

\subsubsection{Expectativa}

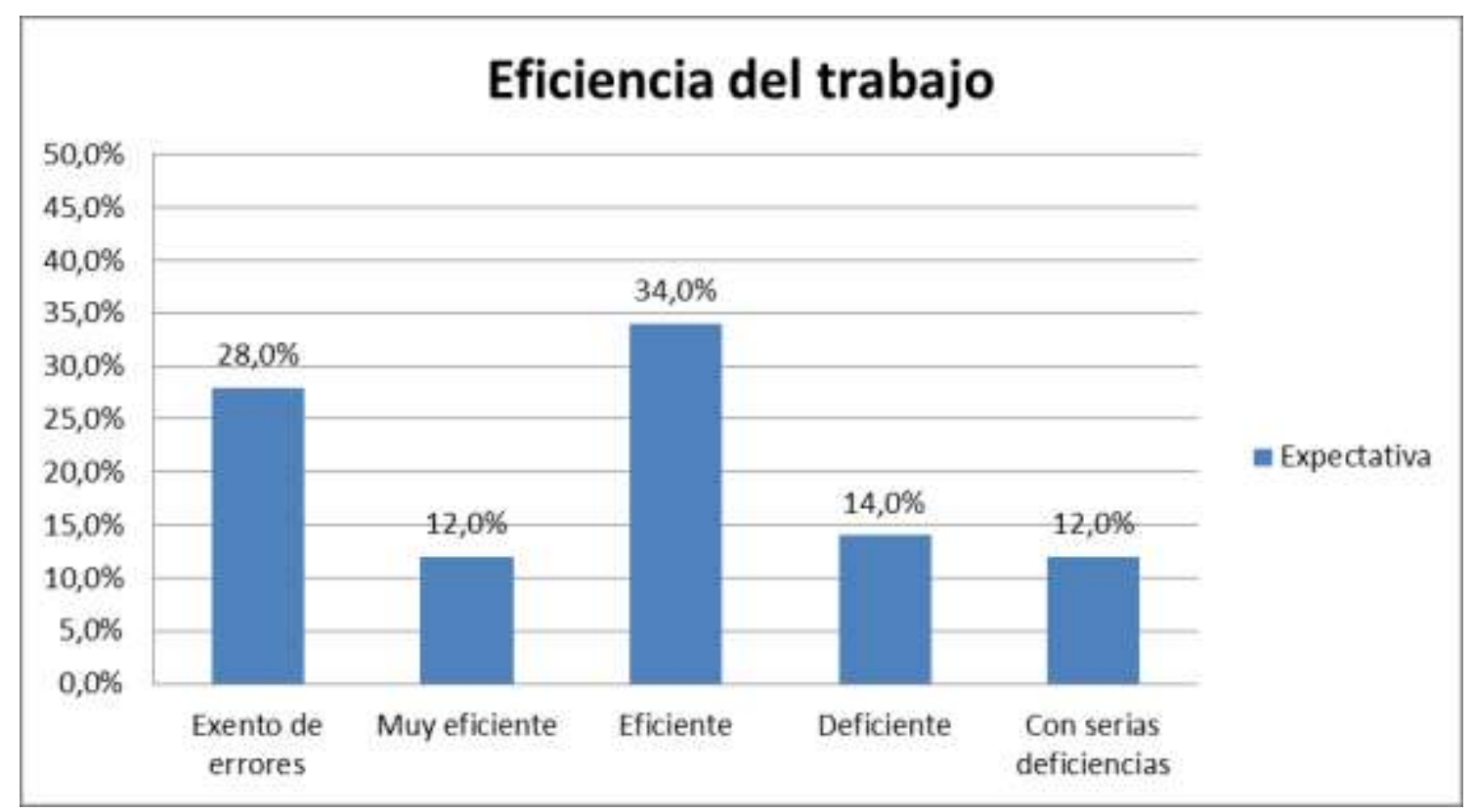

Saldo de respuesta: 2,70 "eficiente"

\subsubsection{Percepción}

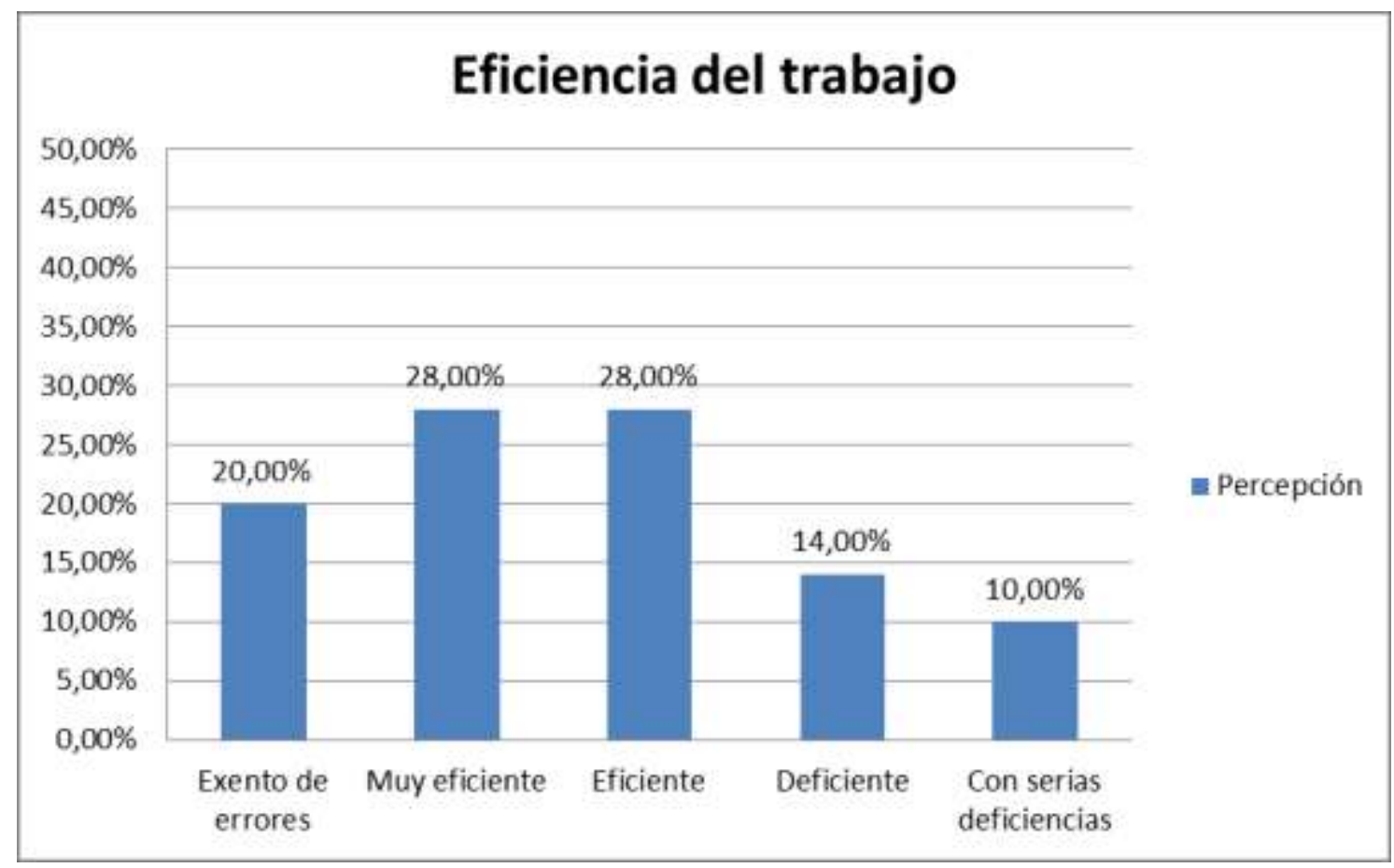

La puntuación acorde con el Saldo de Respuesta fue de 2,66, considerándolo "eficiente" con una tendencia a "muy eficiente". 


\subsubsection{Brecha}

A continuación se exponen los resultados de indicadores de eficiencia, comparando las expectativas y las percepciones una vez utilizado el servicio:
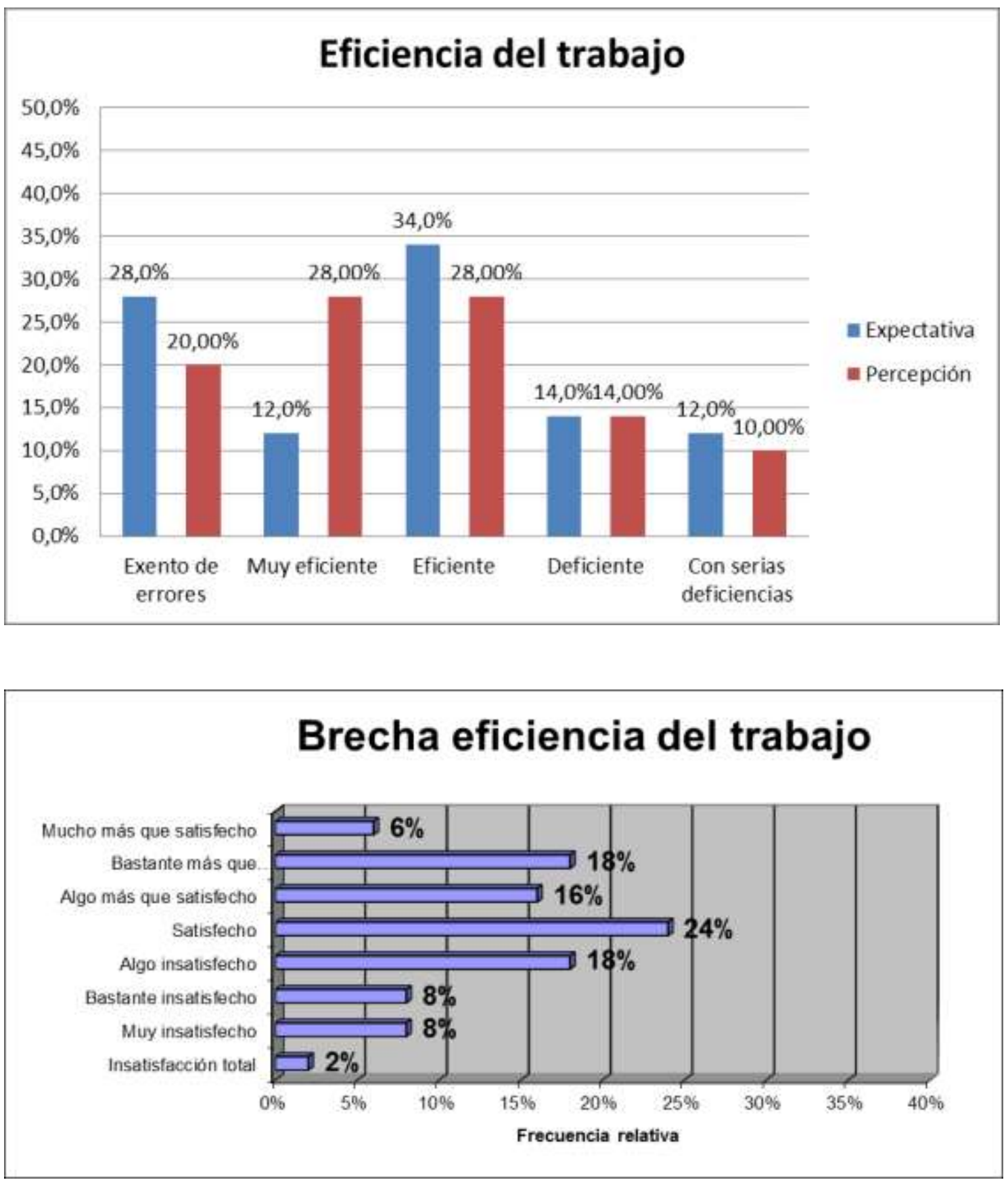

Saldo de respuesta: 0,04 "Satisfecho" 
7.5 Dimensión III: Capacidad de Respuesta - Disposición de los empleados para ayudar al cliente y proporcionar el servicio

A continuación se incorporan los resultados del nivel de comunicación, la velocidad de servicio, la disponibilidad de atención, y, por último, el grado de disponibilidad frente a otras actividades.

\subsubsection{Nivel de comunicación con los empleados}

\subsubsection{Expectativa}

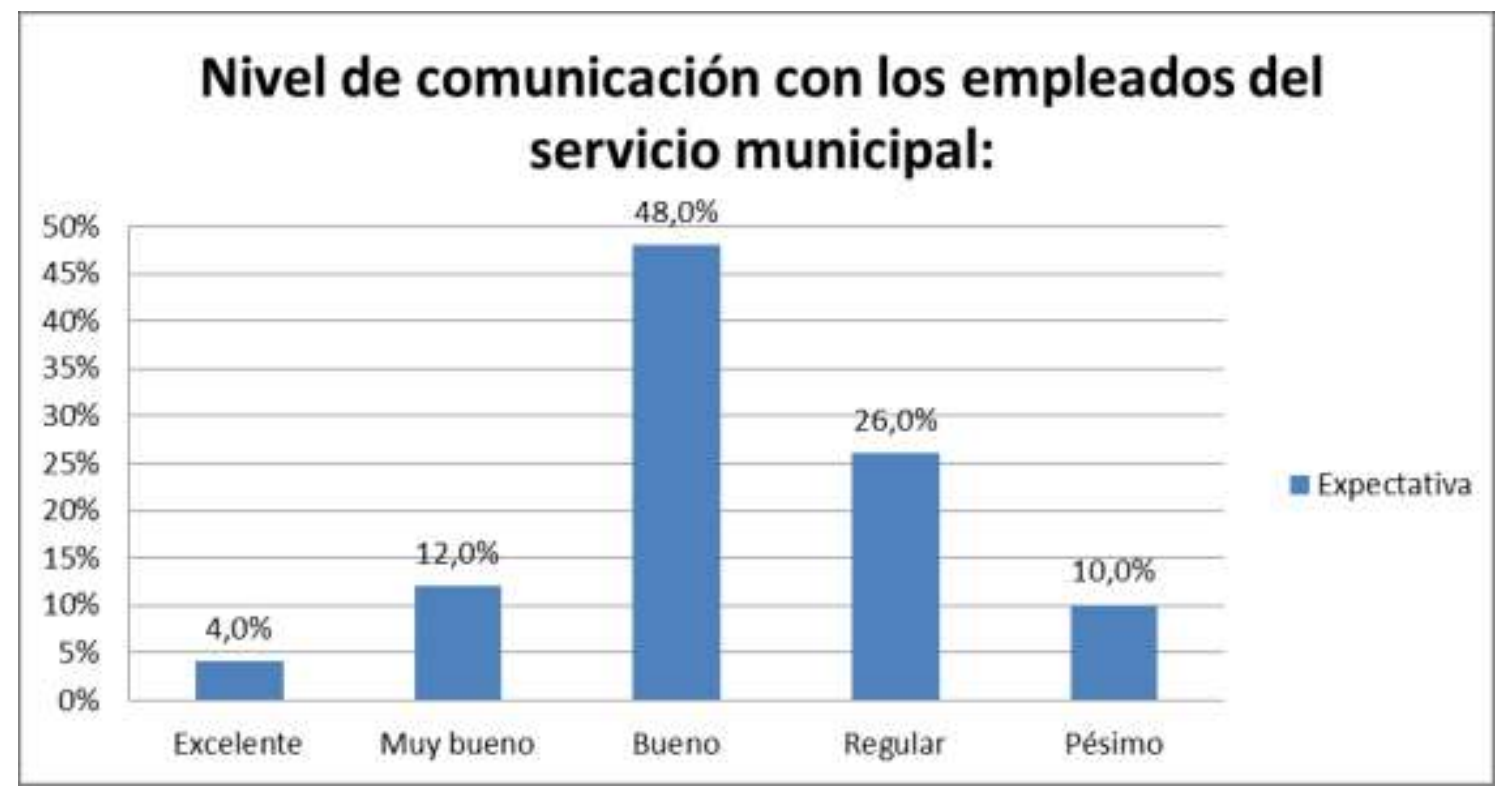

Saldo de respuesta: 3,26 bueno con tendencia a regular

\subsubsection{Percepción}

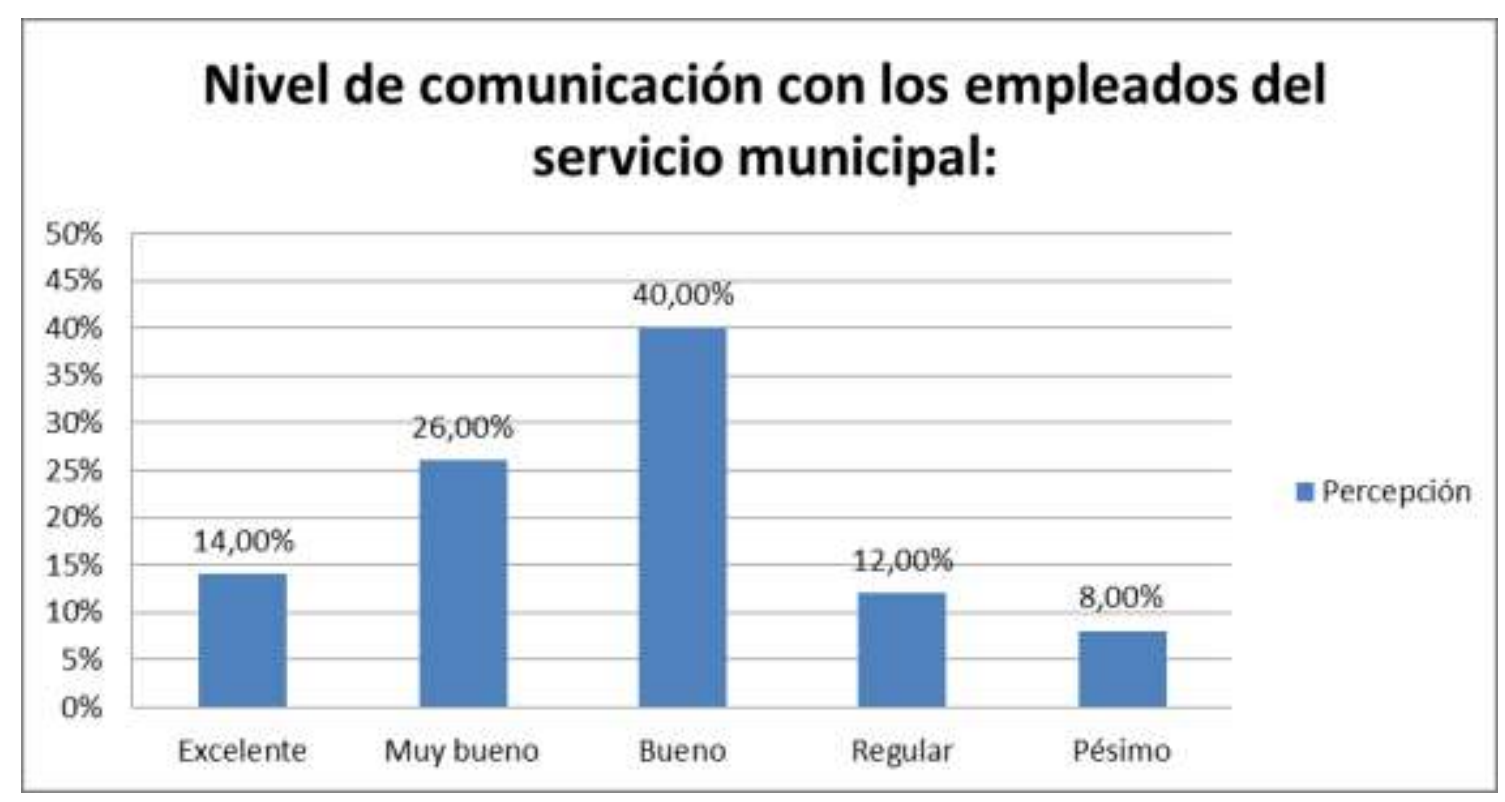

Con un Saldo de Respuesta de 2,74 los usuarios calificaron a la comunicación con los empleados como "Buena" con tendencia a "Muy Buena". 


\subsubsection{Brecha}

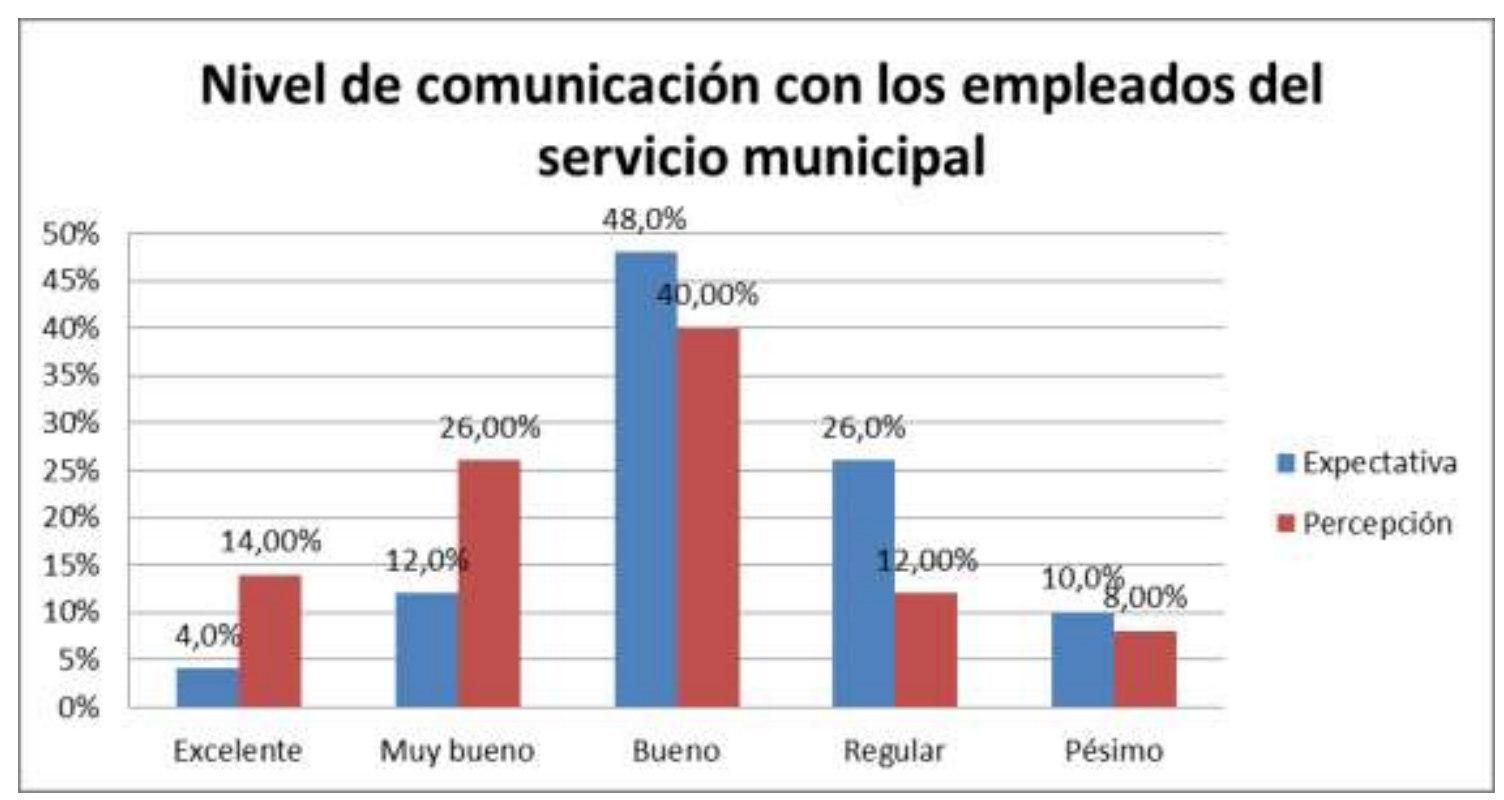

\section{Brecha nivel de comunicación}

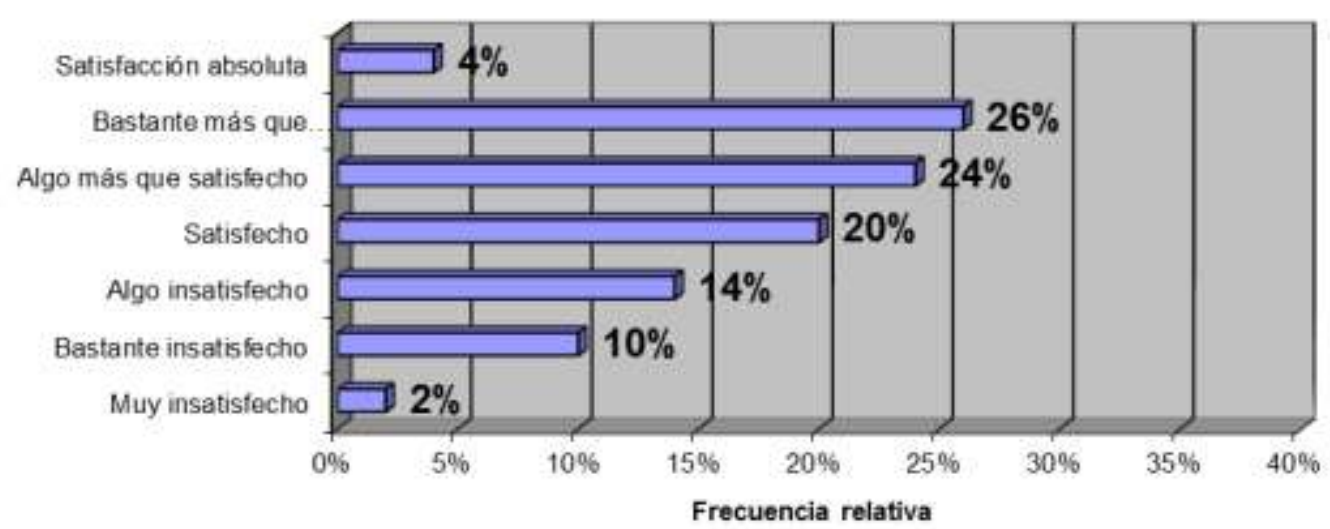

Saldo de respuesta: 0,52 "Satisfecho". 


\subsubsection{Velocidad del servicio}

\subsubsection{Expectativa}

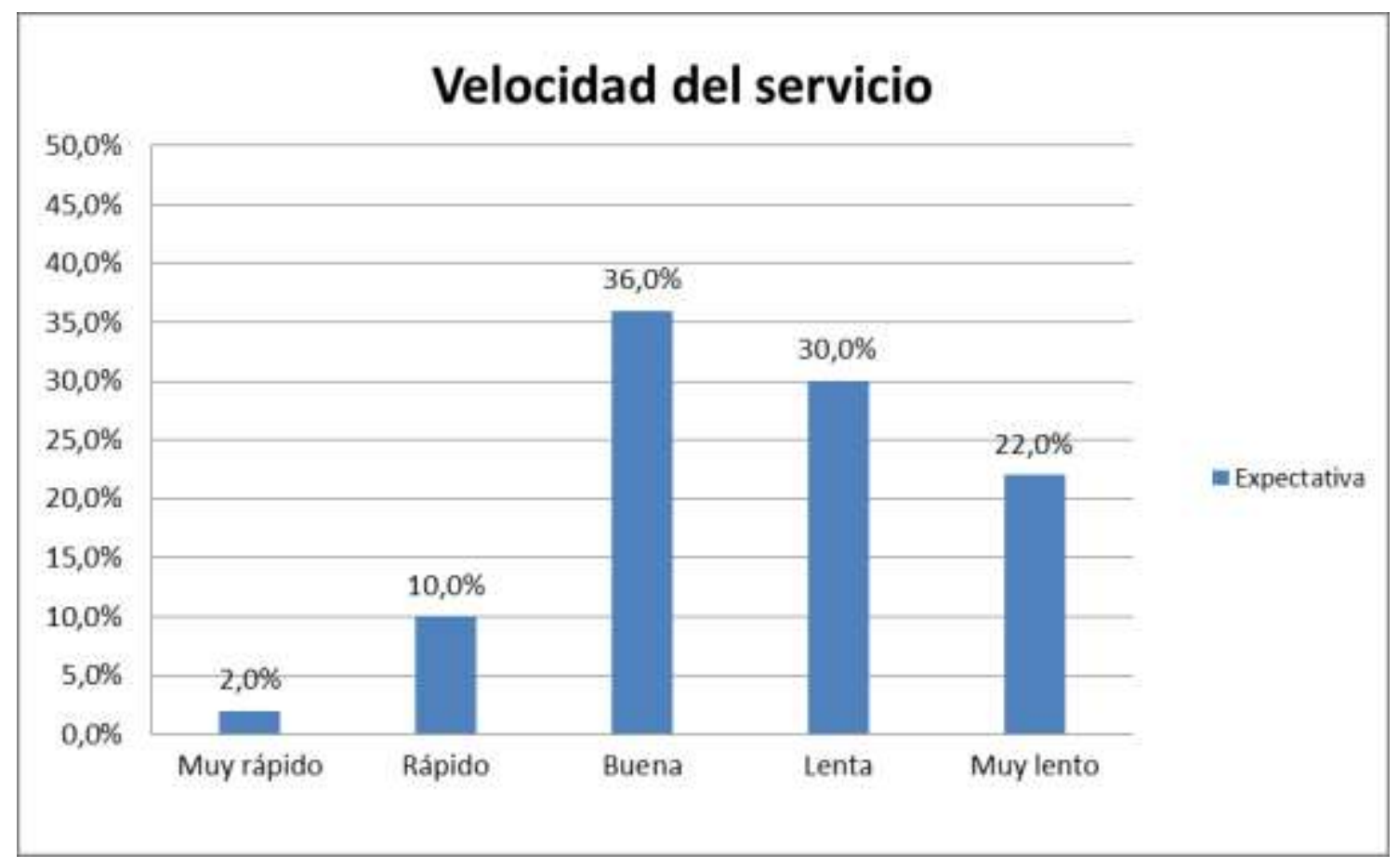

Saldo de respuesta: 3,60 "lenta" con tendencia a "buena"

\subsubsection{Percepción}

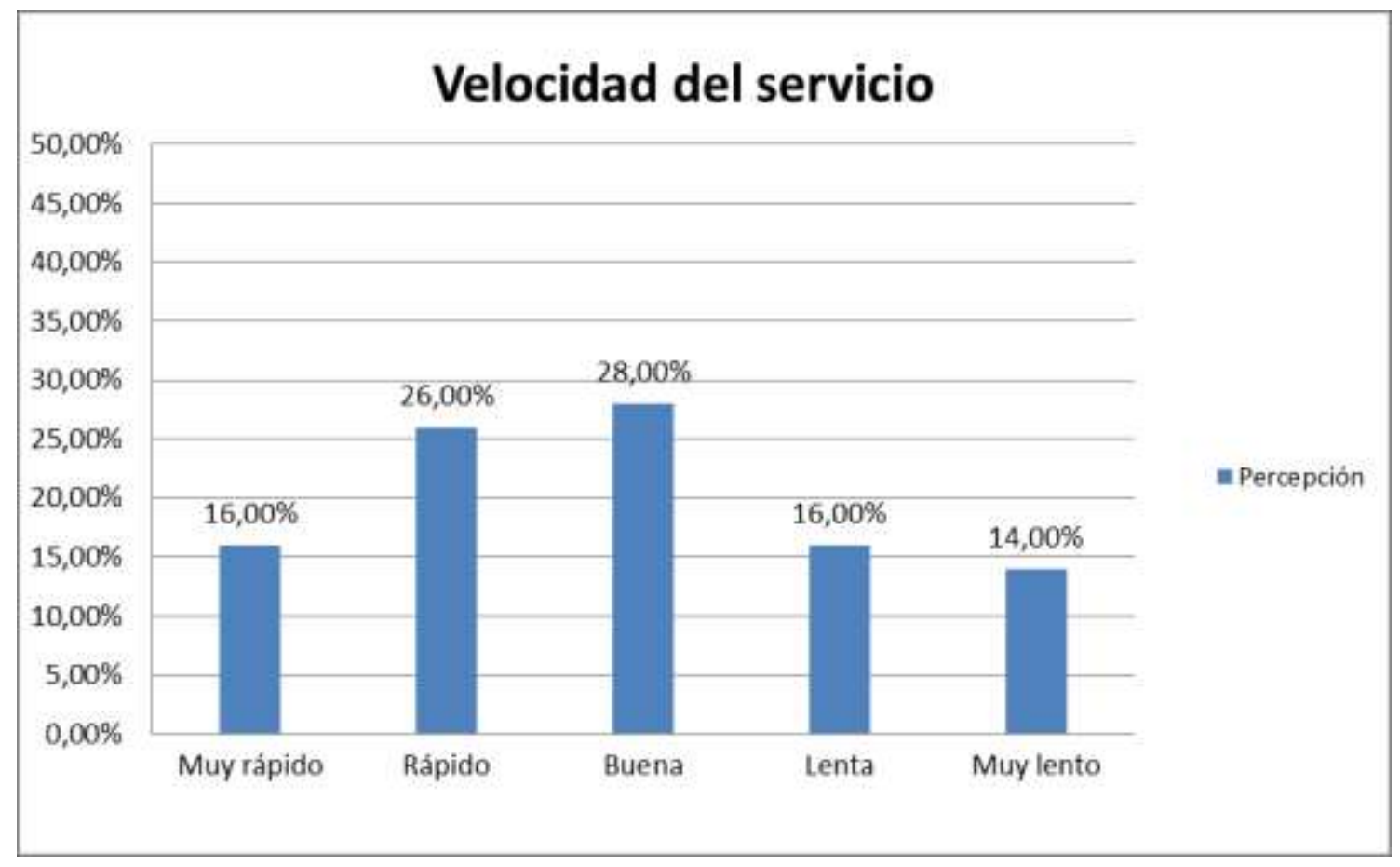

Con un Saldo de Respuesta de 2,86 el nivel de velocidad del servicio fue calificada por los usuarios como Buena con tendencia a rápida. 


\subsubsection{Brecha}

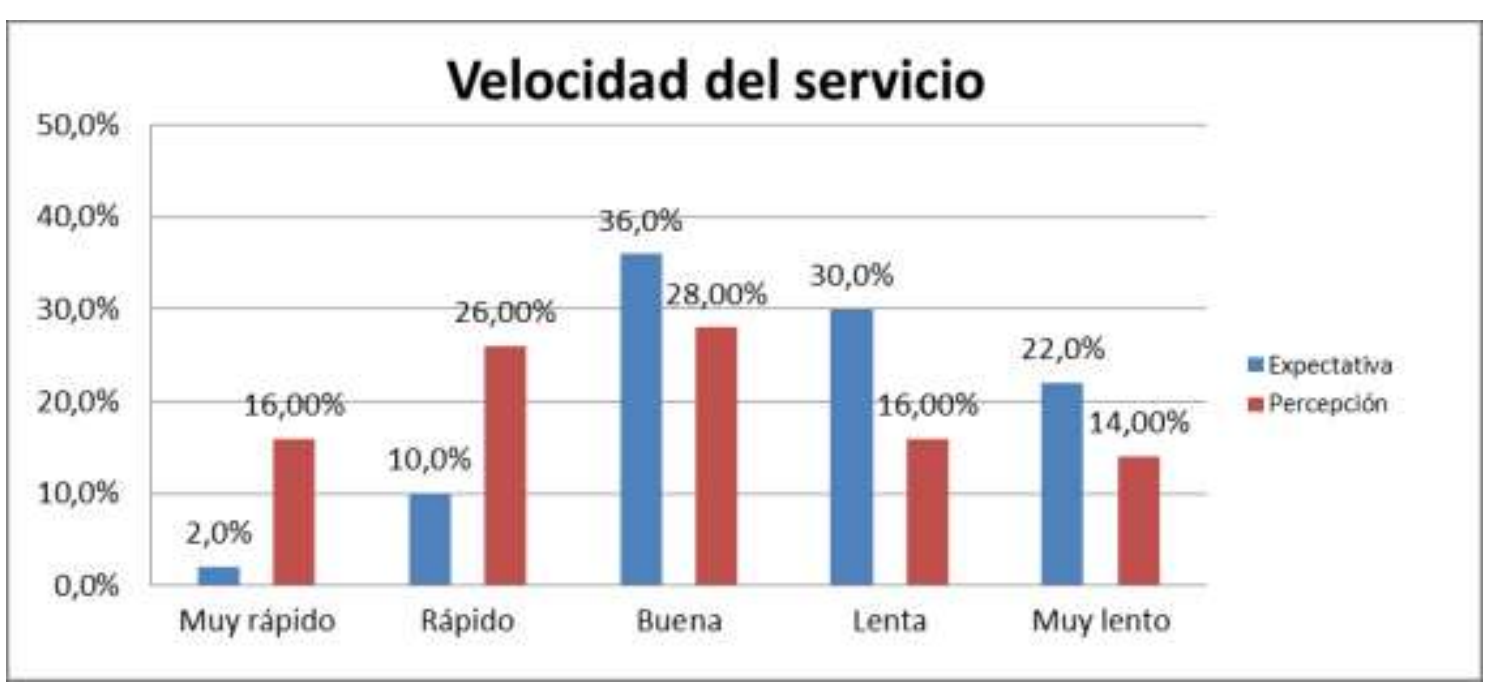

A efectos de poder observar la satisfacción de las percepciones respecto las expectativas que traían los clientes se presenta el gráfico siguiente:

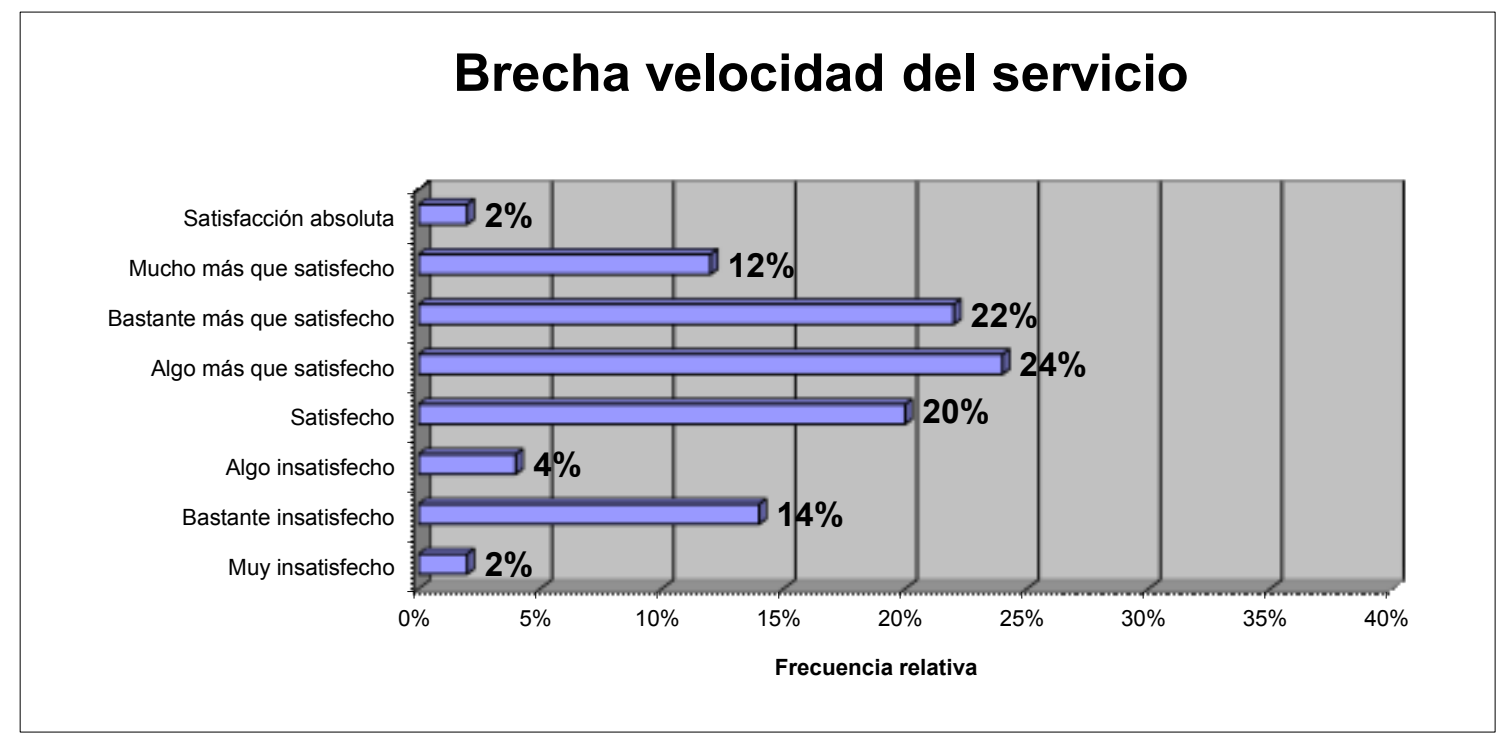

Saldo de respuesta: 0,74 "algo mas que satisfecho".

\subsubsection{Nivel de disponibilidad de atención}

A continuación se analiza la disponibilidad de atención, entre puntuaciones que van desde 1 para siempre disponible, a 5 para nunca disponible. 


\subsubsection{Expectativa}

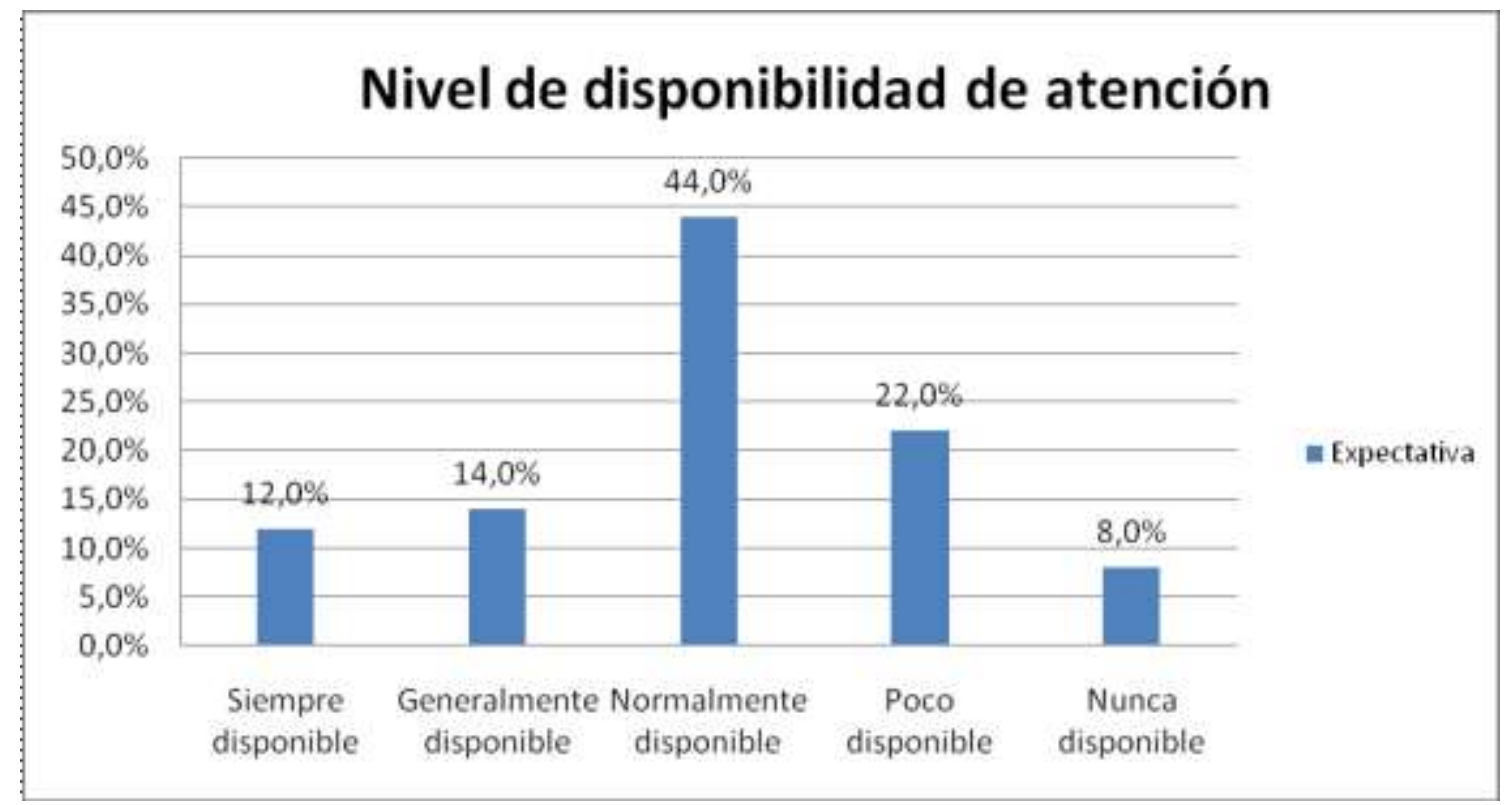

Saldo de respuesta: 3 "normalmente disponible"

\subsubsection{Percepción}

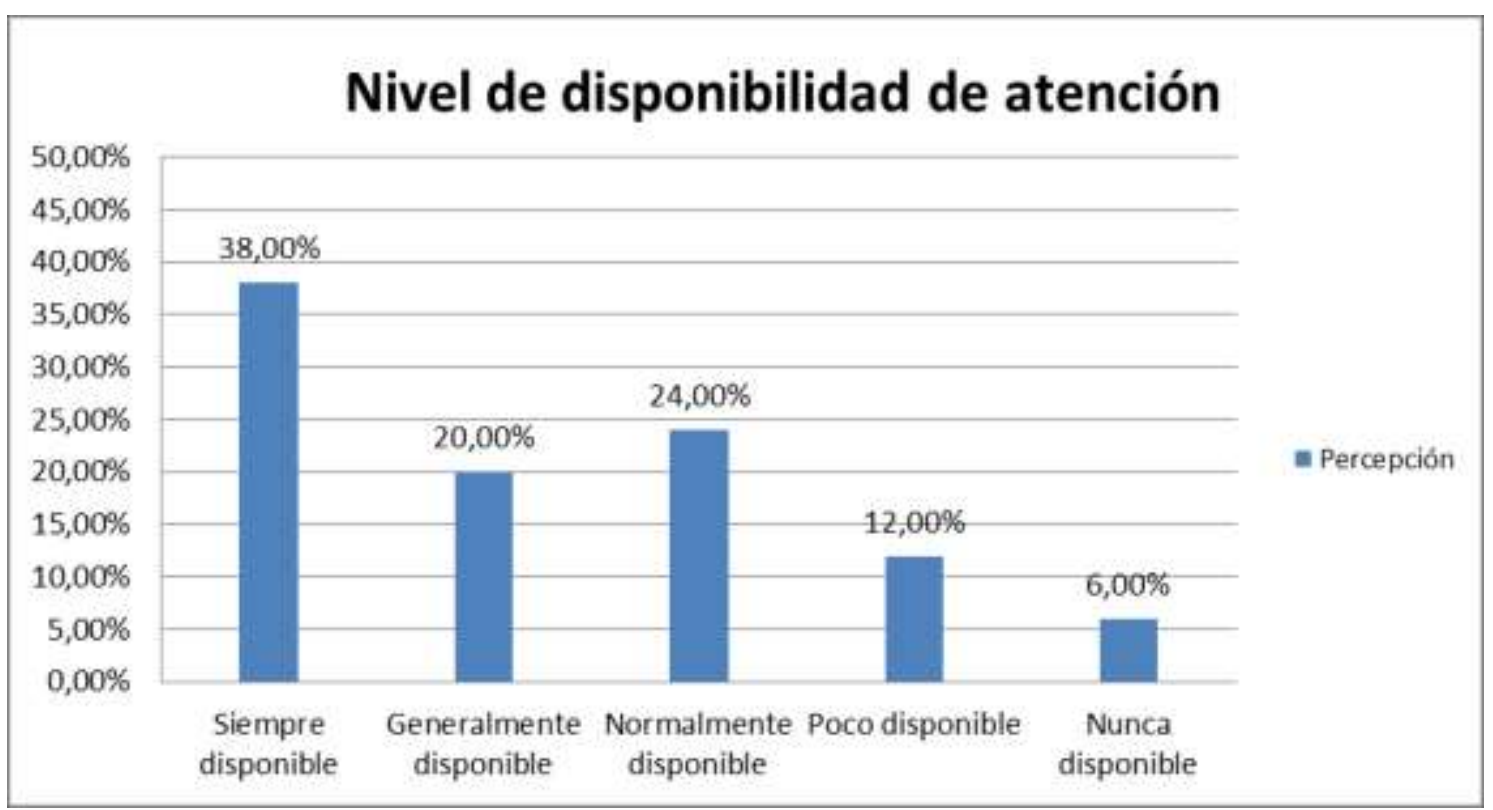

Con un Saldo de Respuesta de 2,28 el nivel de disponibilidad percibido es "Generalmente disponible" con una leve tendencia a "Normalmente disponible". 


\subsubsection{Brecha}
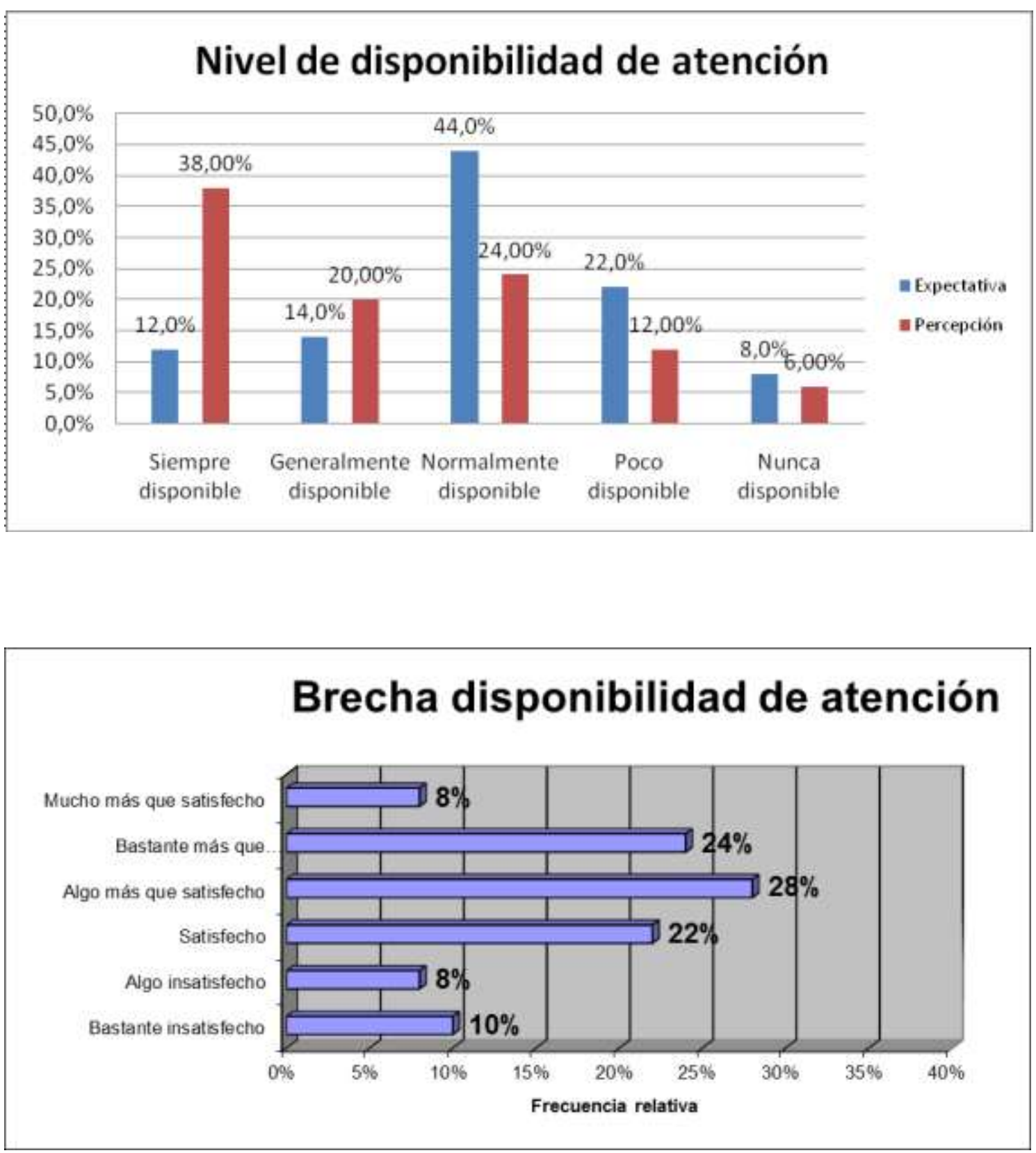

Saldo de respuesta: 0,72 "algo mas que satisfecho". 


\subsubsection{Grado de disponibilidad inmediata frente a otras actividades}

\subsubsection{Expectativa}

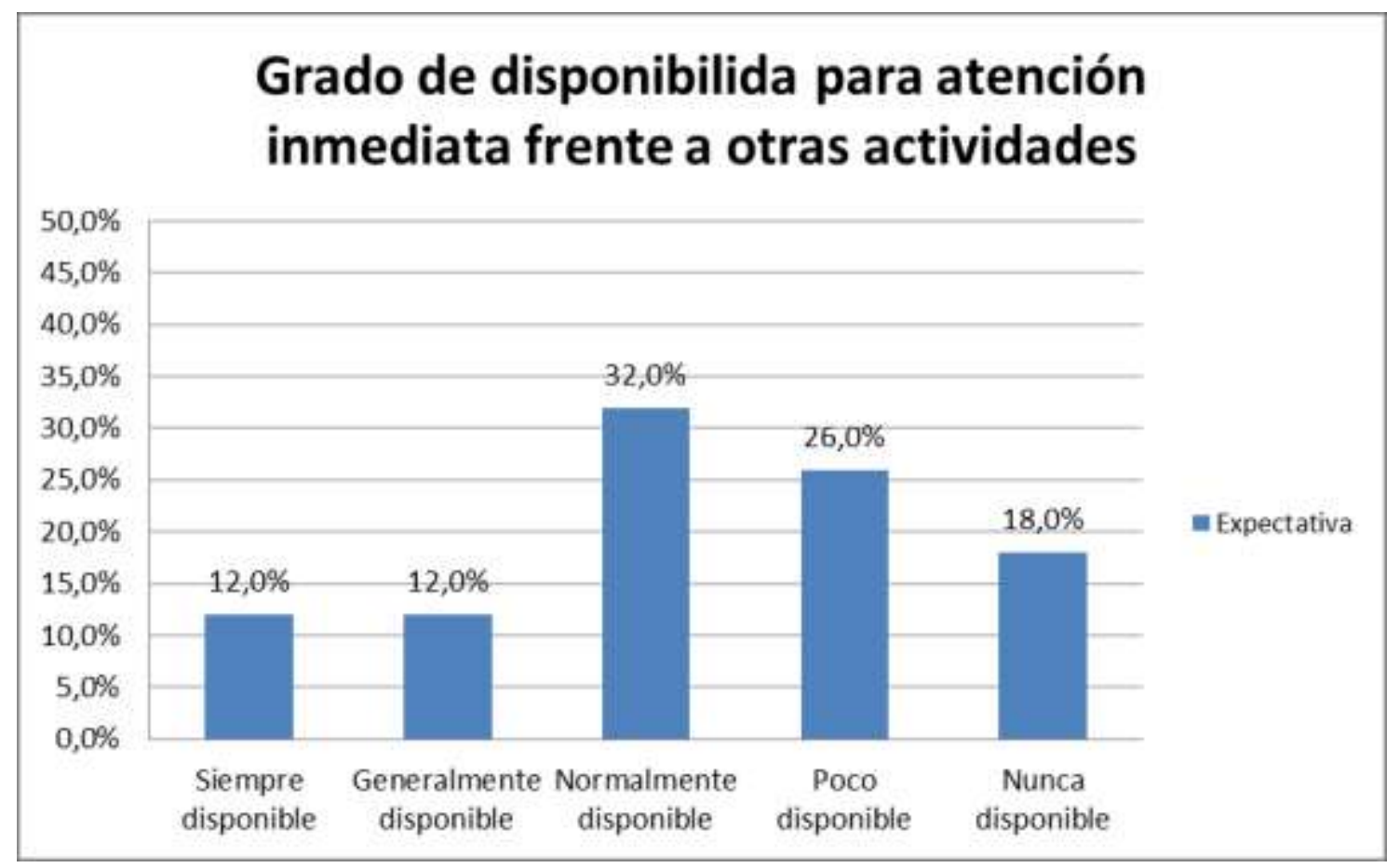

Saldo de respuesta: 3,26 "normalmente disponible" con tendencia a "poco disponible".

\subsubsection{Percepción}

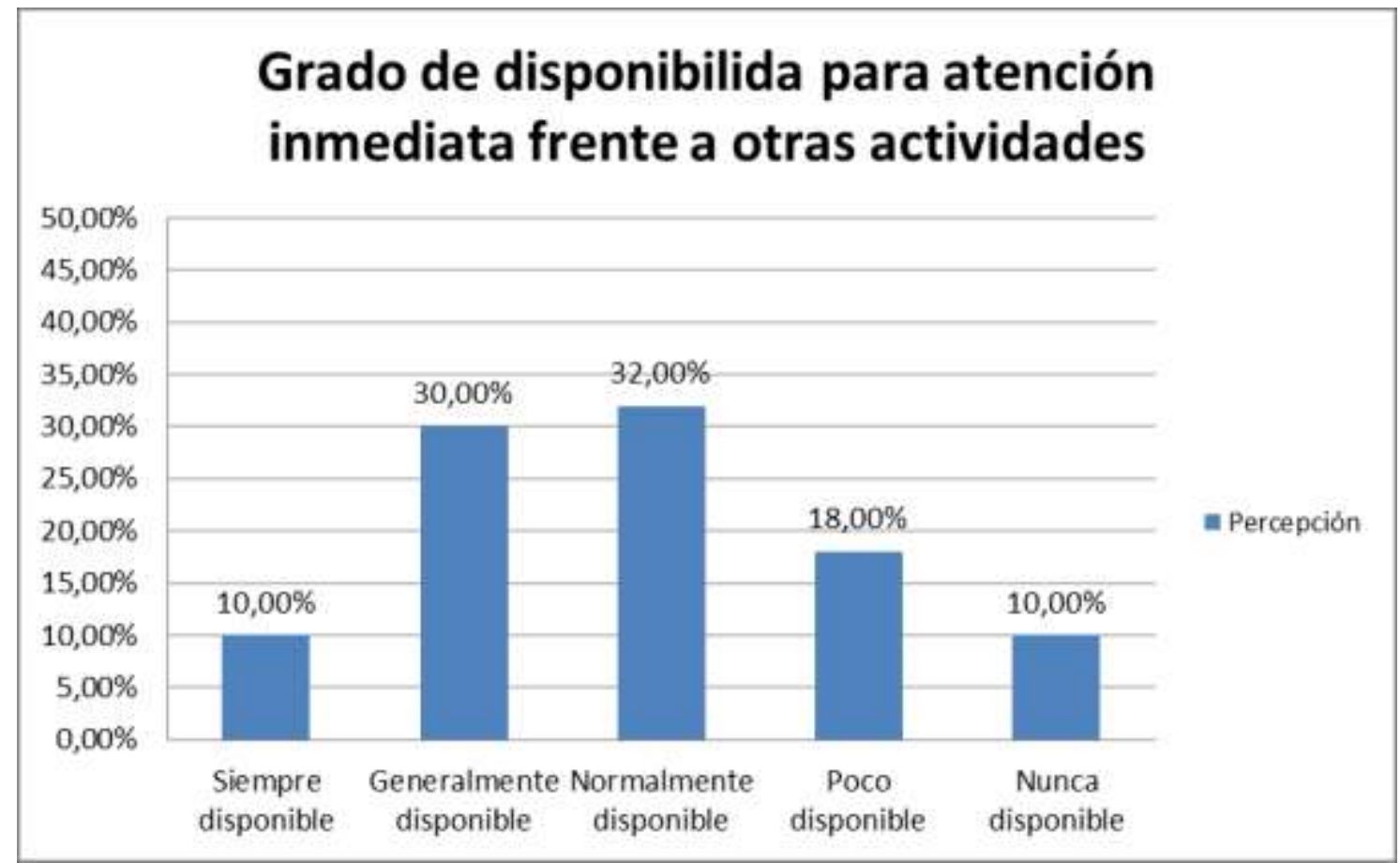

Con un Saldo de Respuesta es de 2,88 el nivel de disponibilidad fue calificado como "Normalmente disponible" con tendencia a "Generalmente disponible". 


\subsubsection{Brecha}
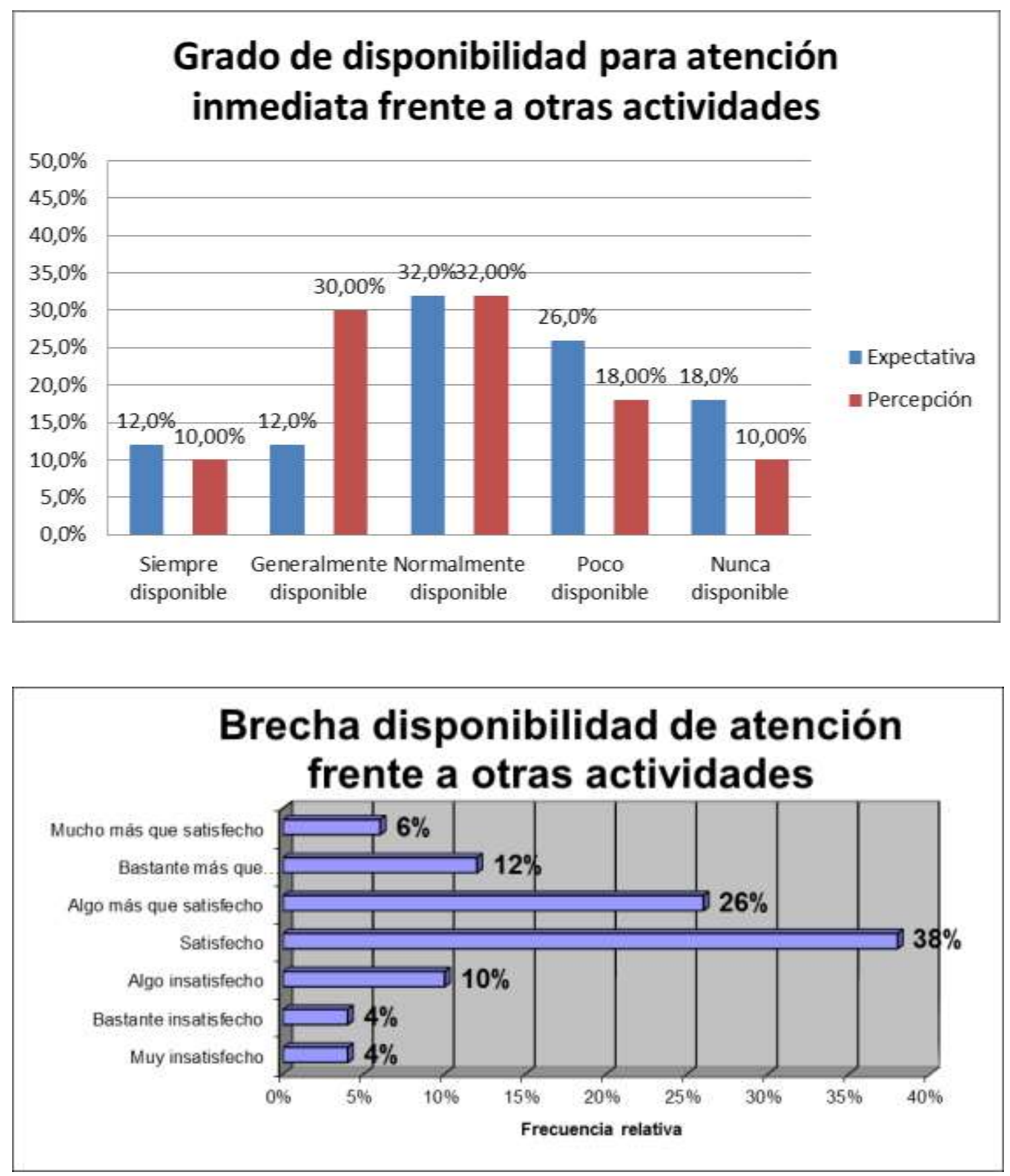

Saldo de respuesta: 0,38 "Satisfecho".

7.6 Dimensión IV: Seguridad - Conocimiento y atención mostrados por los empleados y sus habilidades para inspirar credibilidad y confianza.

En esta dimensión se muestran los resultados obtenidos en cuatro factores: comunicación, seguridad, amabilidad y conocimiento para resolver las inquietudes de los clientes. 


\subsubsection{Confianza que brinda el comportamiento de los empleados}

\subsubsection{Expectativa.}

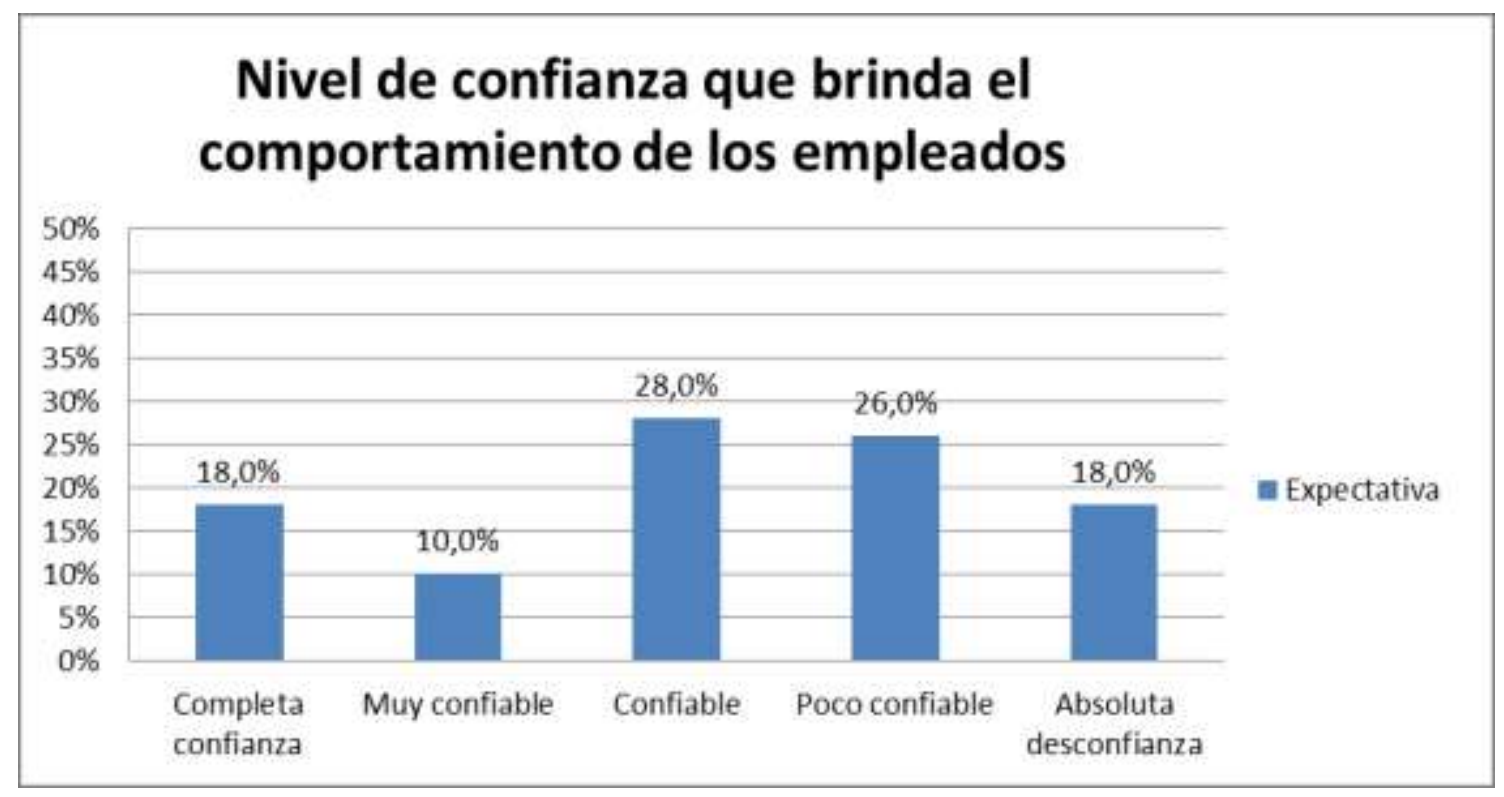

Saldo de respuesta: 3,16 "confiable" con tendencia a "poco confiable"

\subsubsection{Percepción}

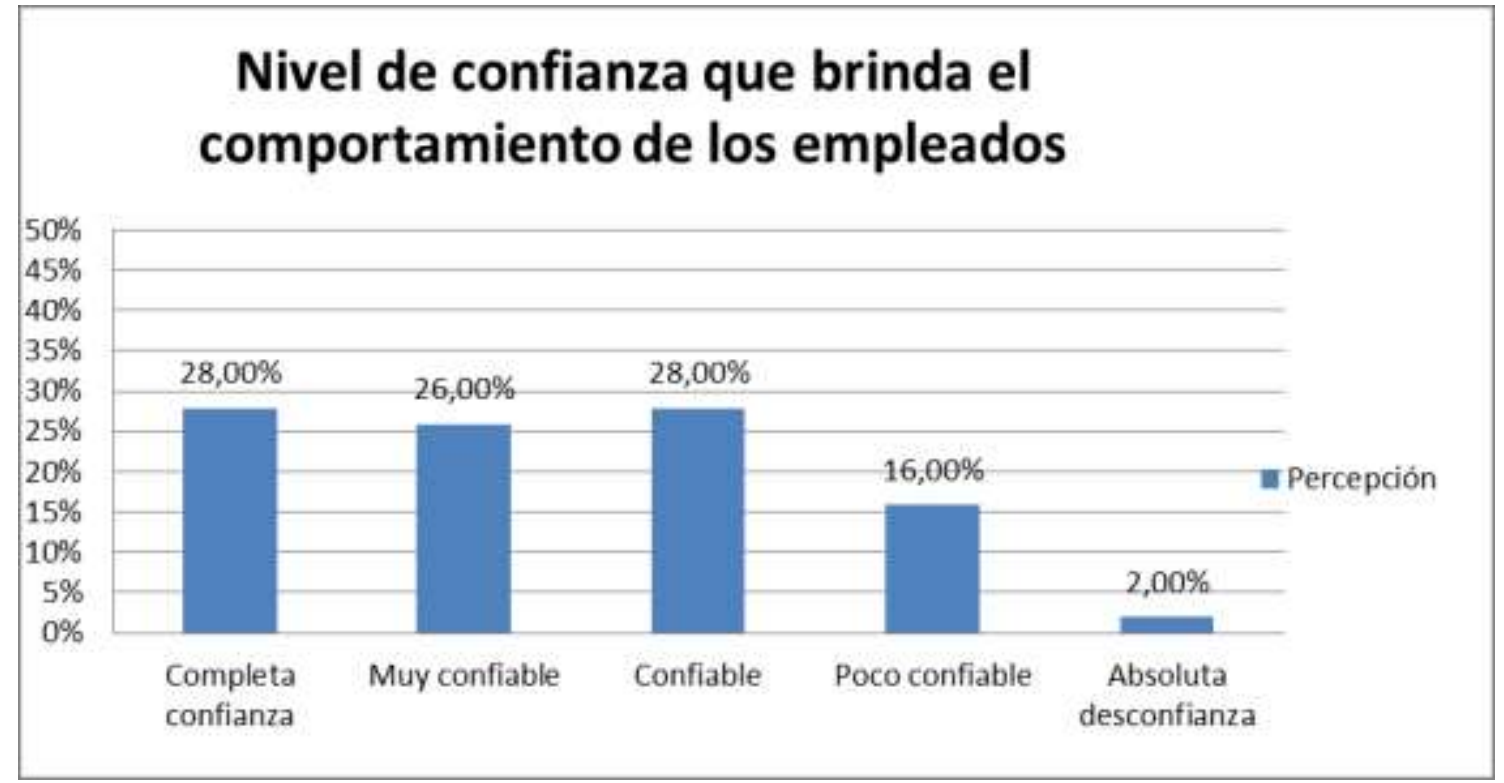

Saldo de respuesta: 2,38 "muy confiable" con tendencia a "confiable". 


\subsubsection{Brecha}
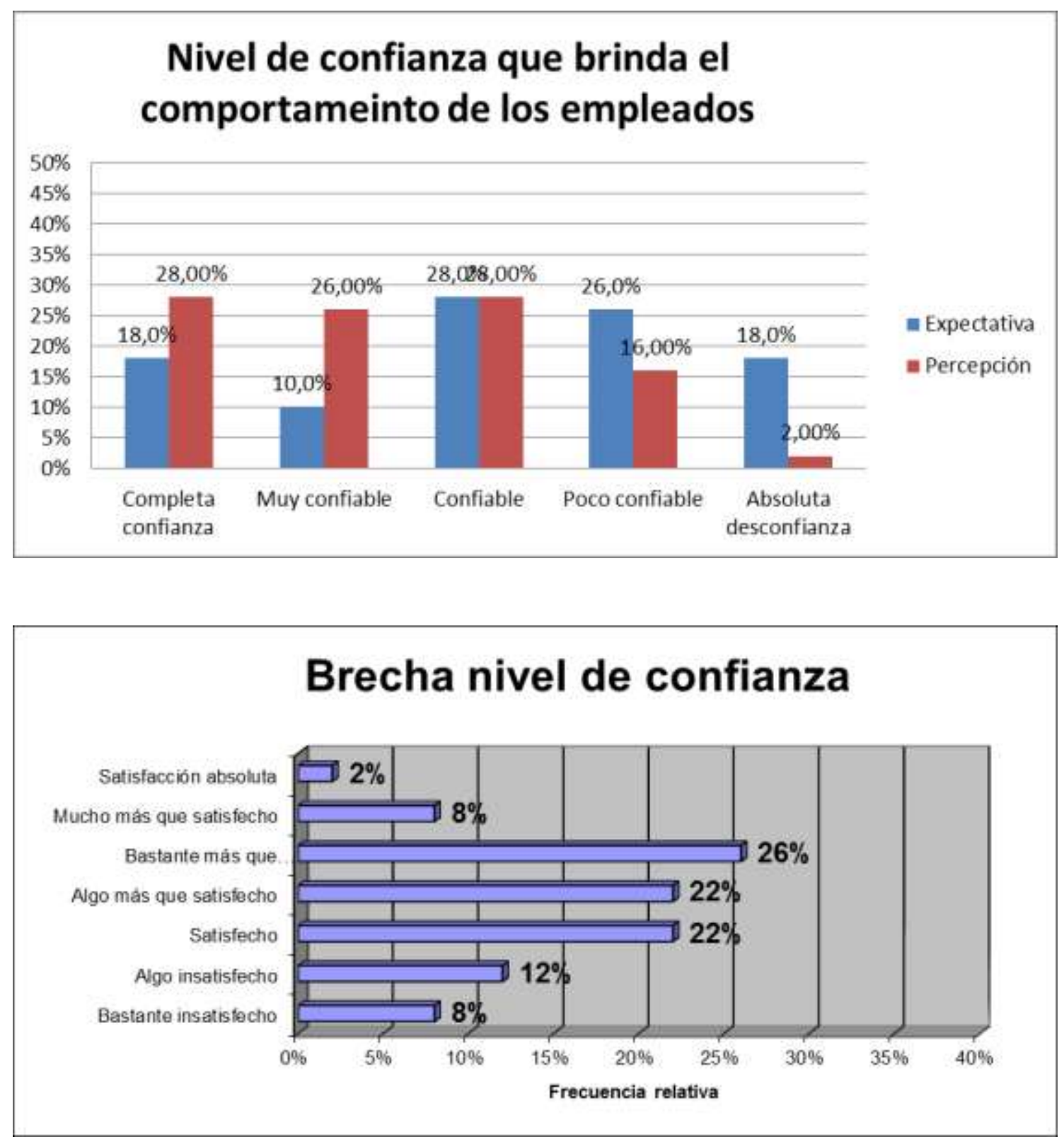

Saldo de respuesta: 0,78 "algo mas que satisfecho" con tendencia a "satisfecho". 
7.6.2 Nivel de seguridad que se siente en las transacciones con el servicio de Licencias de Conducir

\subsubsection{Expectativa}

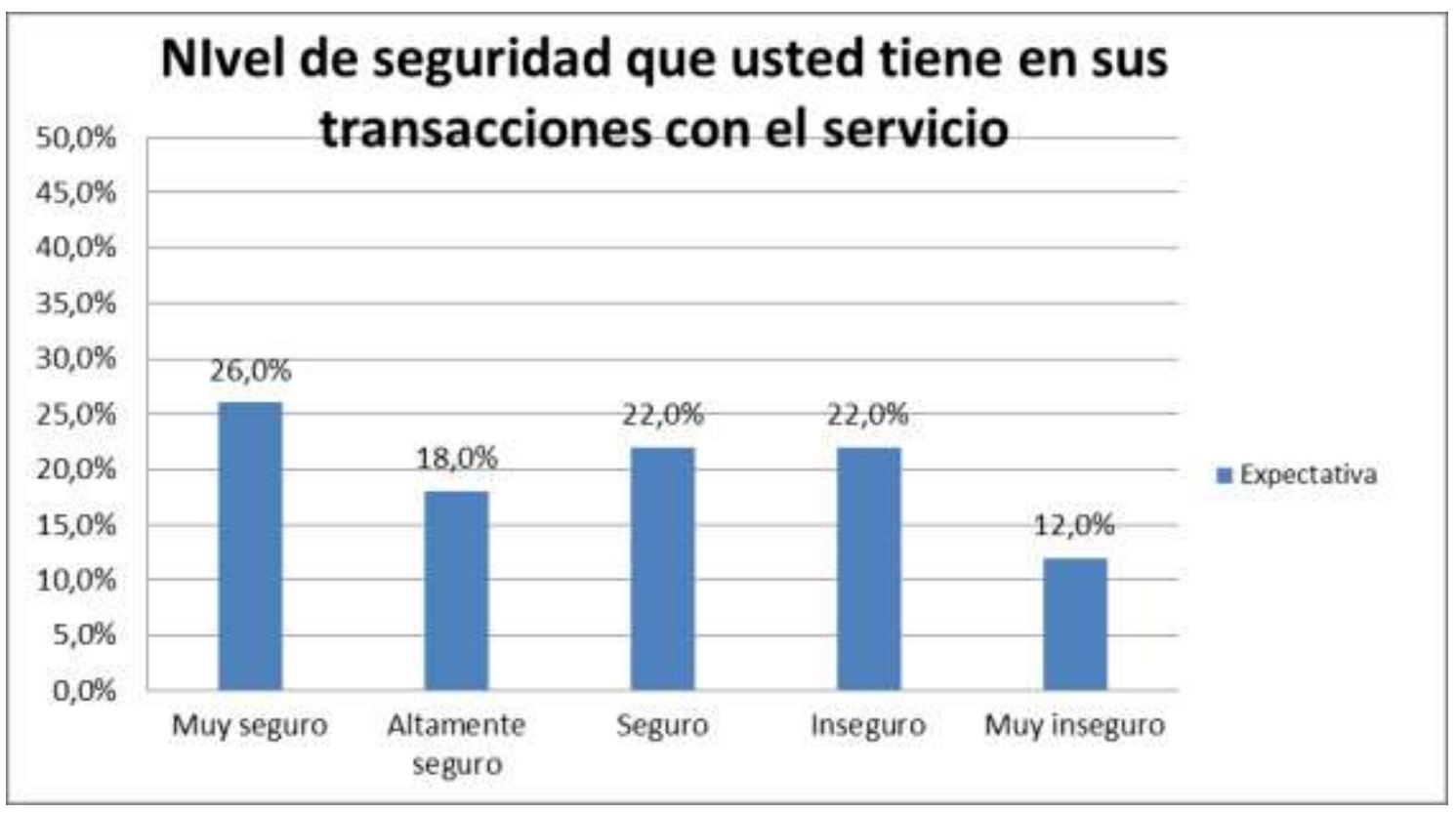

Saldo de respuesta: 2,76 "Seguro" con tendencia a "altamente seguro"

\subsubsection{Percepción}

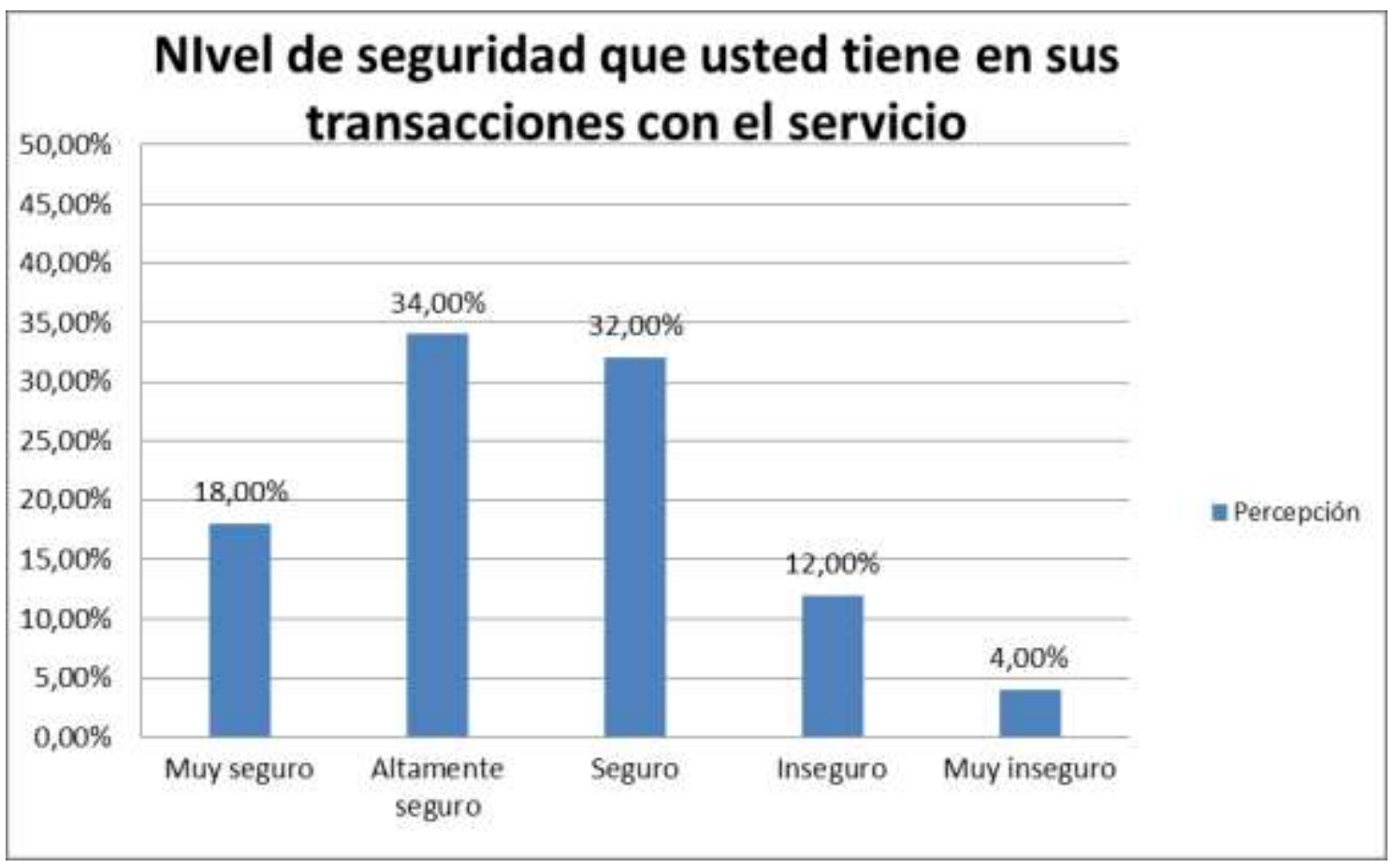

Saldo de respuesta: 2,50 "altamente seguro" con tendencia a "seguro". 


\subsubsection{Brecha}
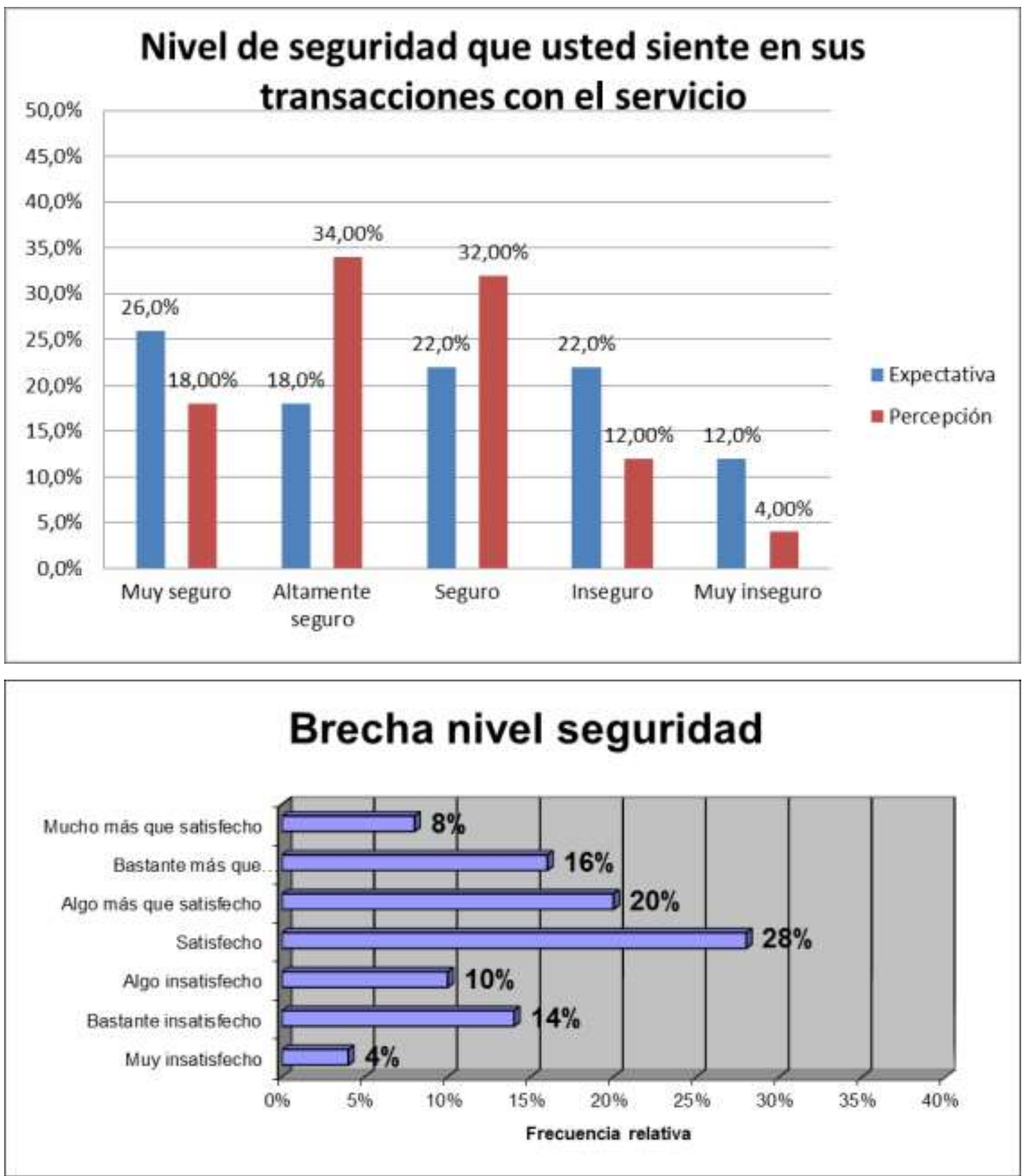

Saldo de respuesta: 0,26 "Satisfecho". 
7.6.3 Nivel de amabilidad que muestran los empleados del servicio

\subsubsection{Expectativa}

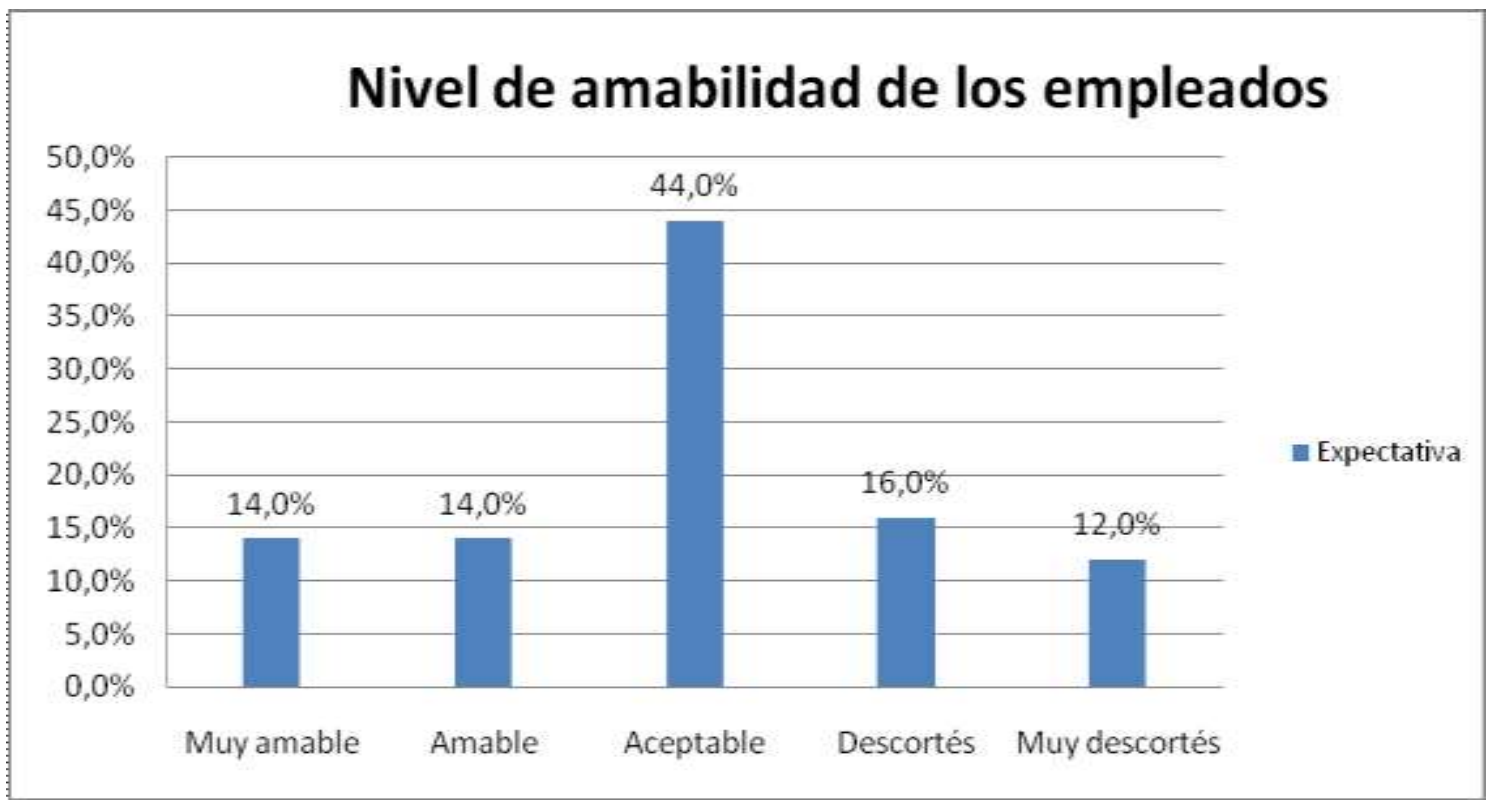

Saldo de respuesta: 2,98 "aceptable".

\subsubsection{Percepción}

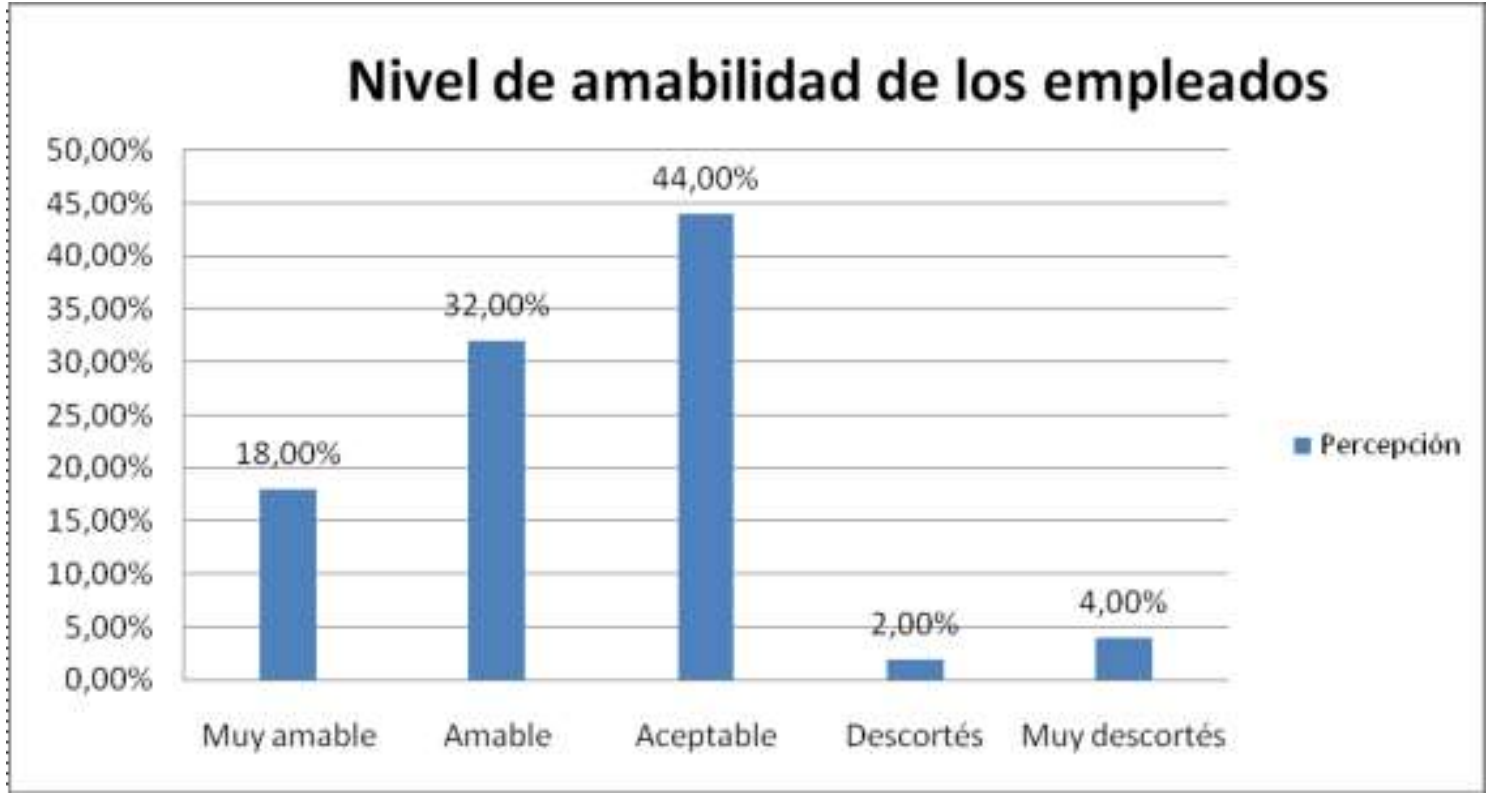

Saldo de respuesta: 2,42 "amable" con tendencia a "aceptable". 


\subsubsection{Brecha}
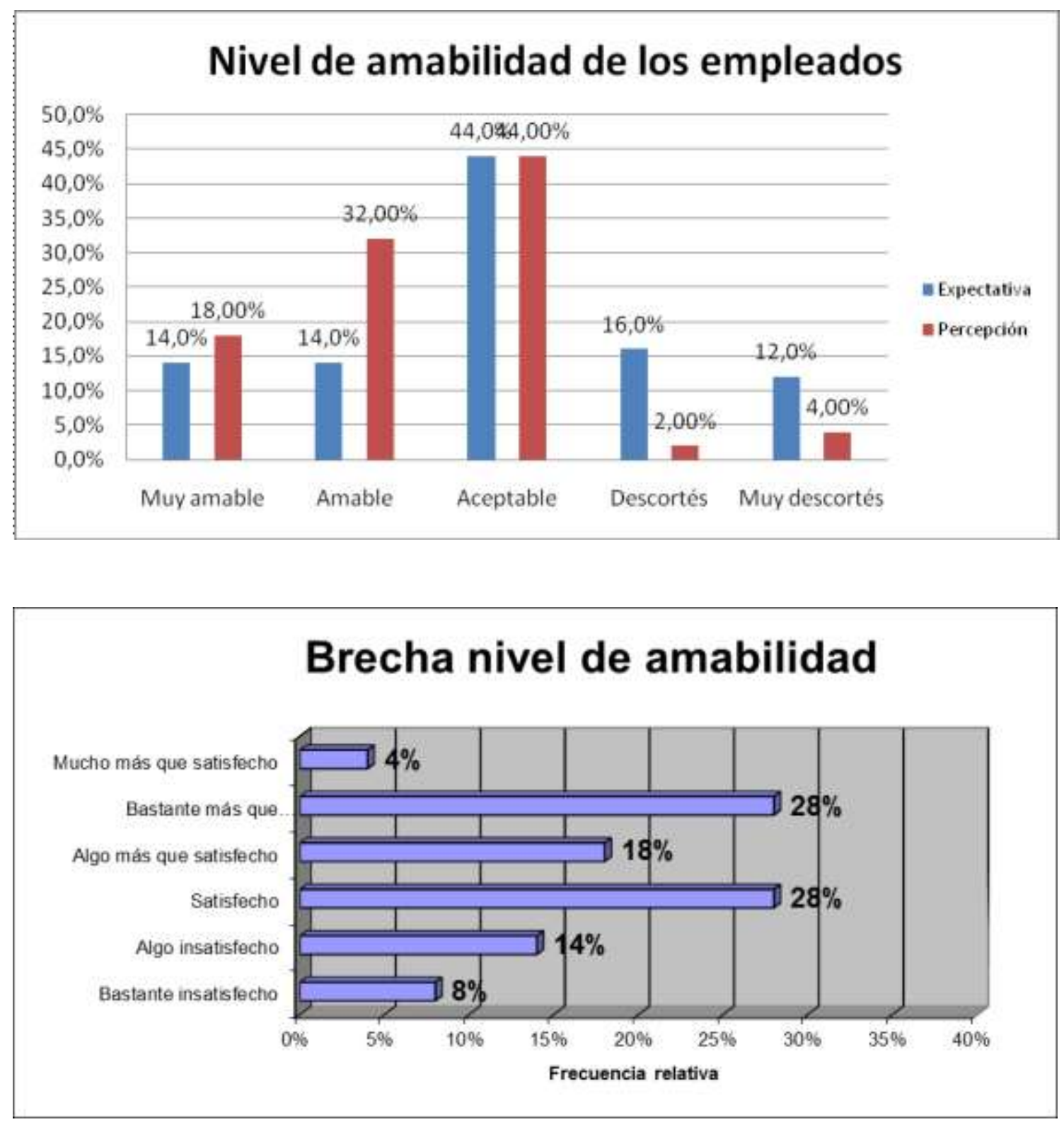

Saldo de respuesta: 0,56 "satisfecho" con tendencia a "algo mas que satisfecho". 
7.6.4 Grado de conocimiento que tienen los empleados para resolver las inquietudes de los usuarios

\subsubsection{Expectativa}

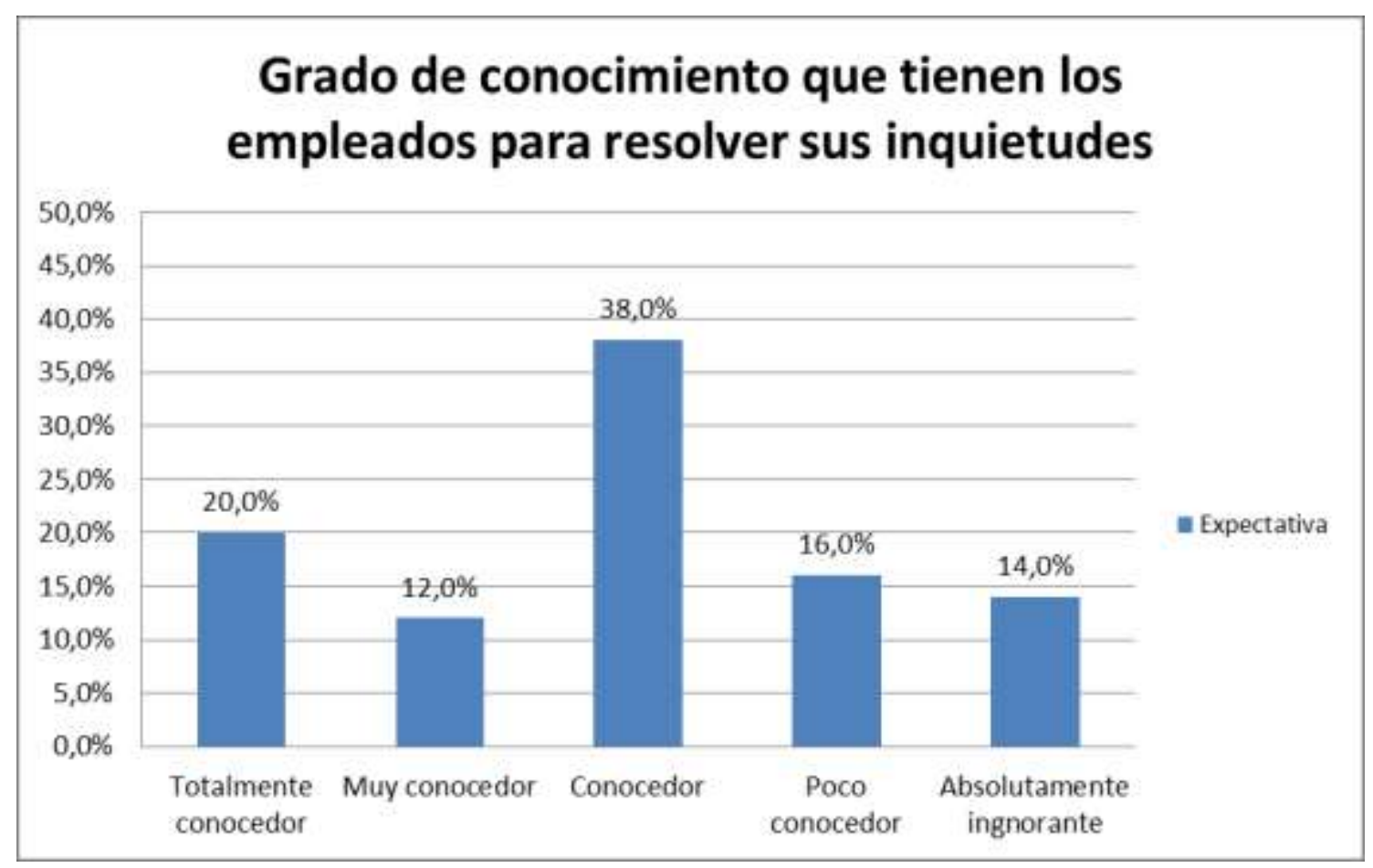

Saldo de respuesta: 2,92 "conocedor".

\subsubsection{Percepción}

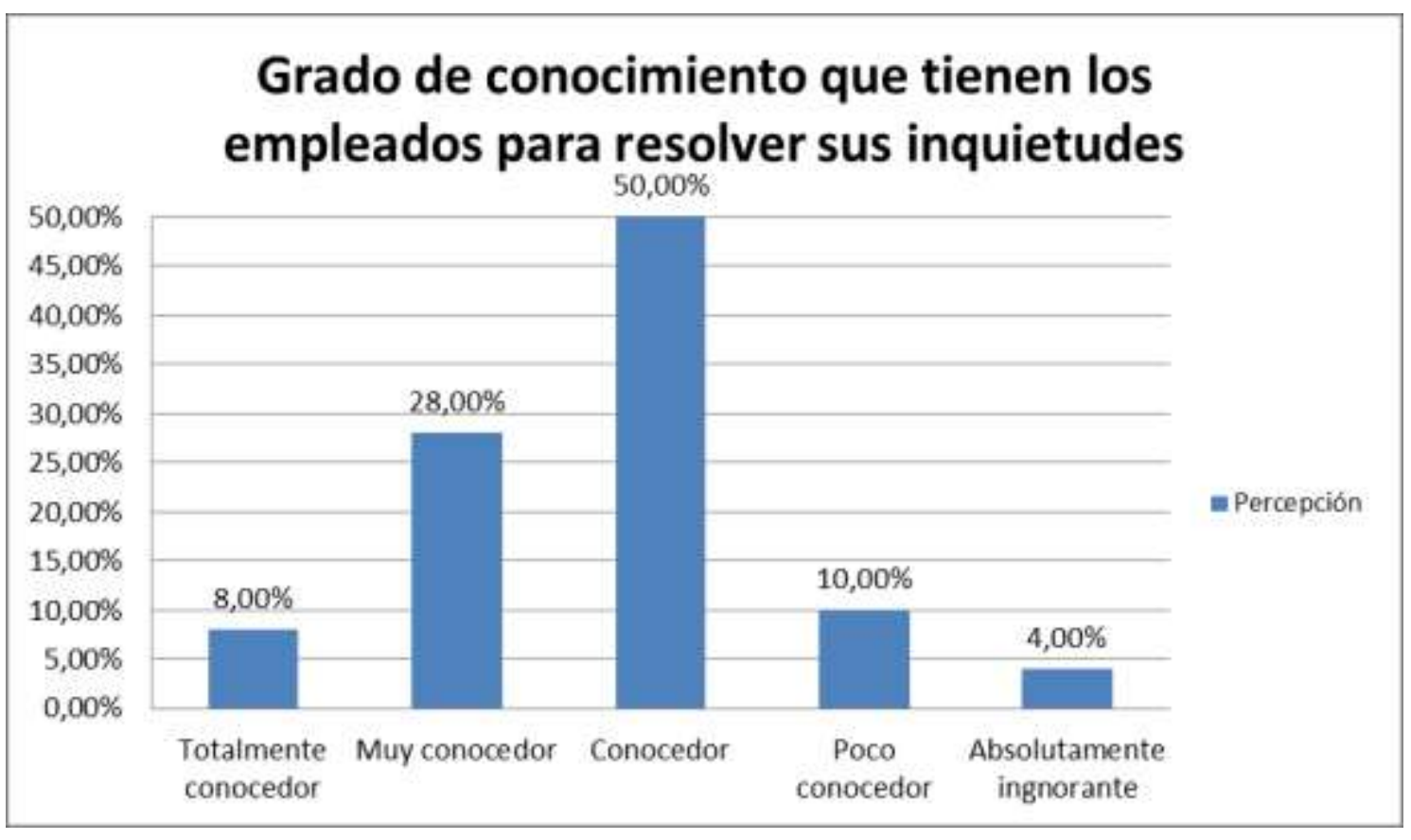

Saldo de respuesta: 2,74 "conocedor" con tendencia a "muy conocedor" 


\subsubsection{Brecha}
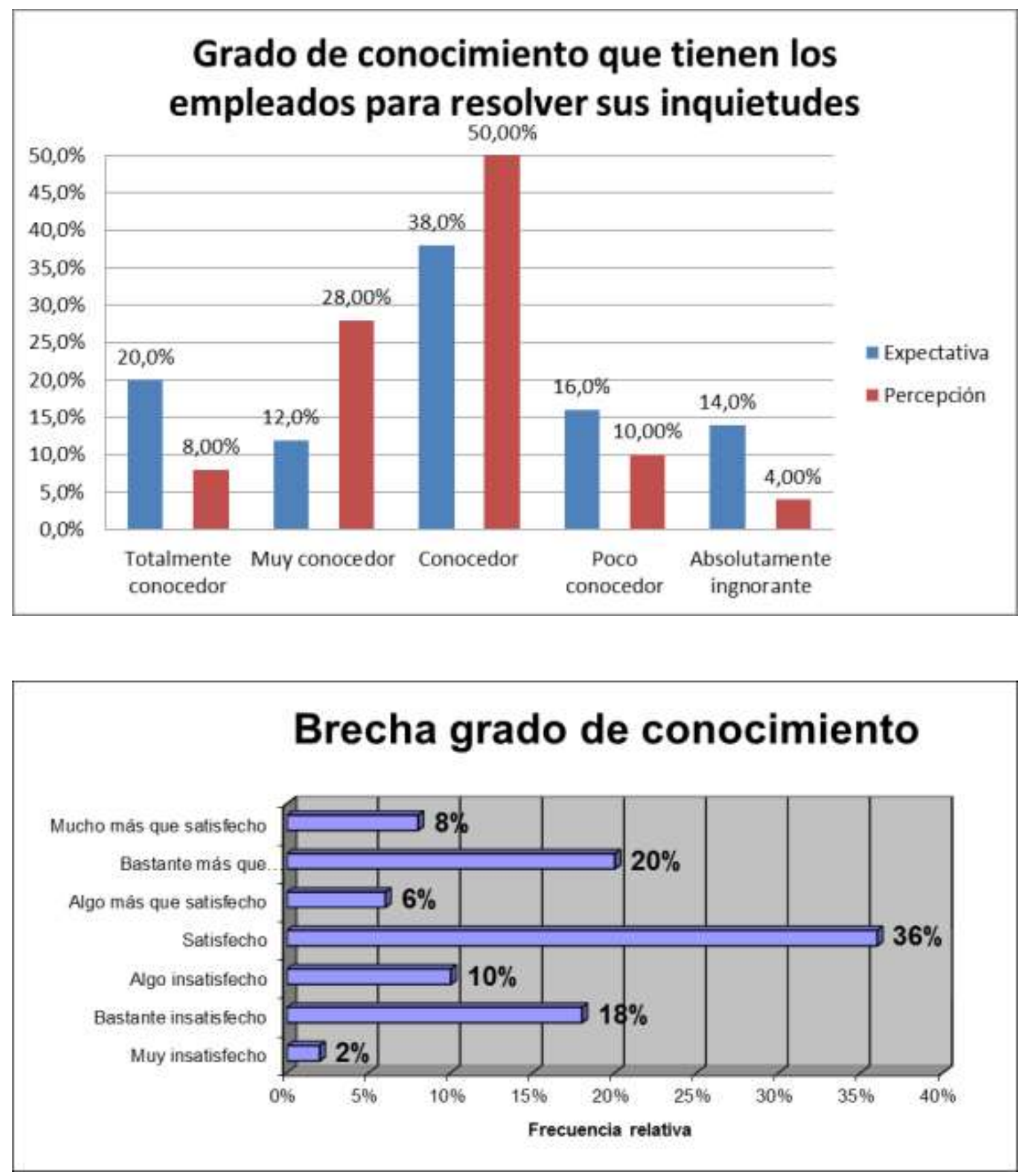

Saldo de respuesta: 0,18 "satisfecho"

7.7 Dimensión V: Empatía - Atención individualizada que ofrece la organización a los clientes

A continuación se exponen las expectativas y las percepciones de los usuarios respecto a la individualización, los horarios de trabajo, la personalización en la atención, la preocupación, y, la comprensión de sus necesidades. 
7.7.1 Nivel de individualización en la atención del servicio

\subsubsection{Expectativa}

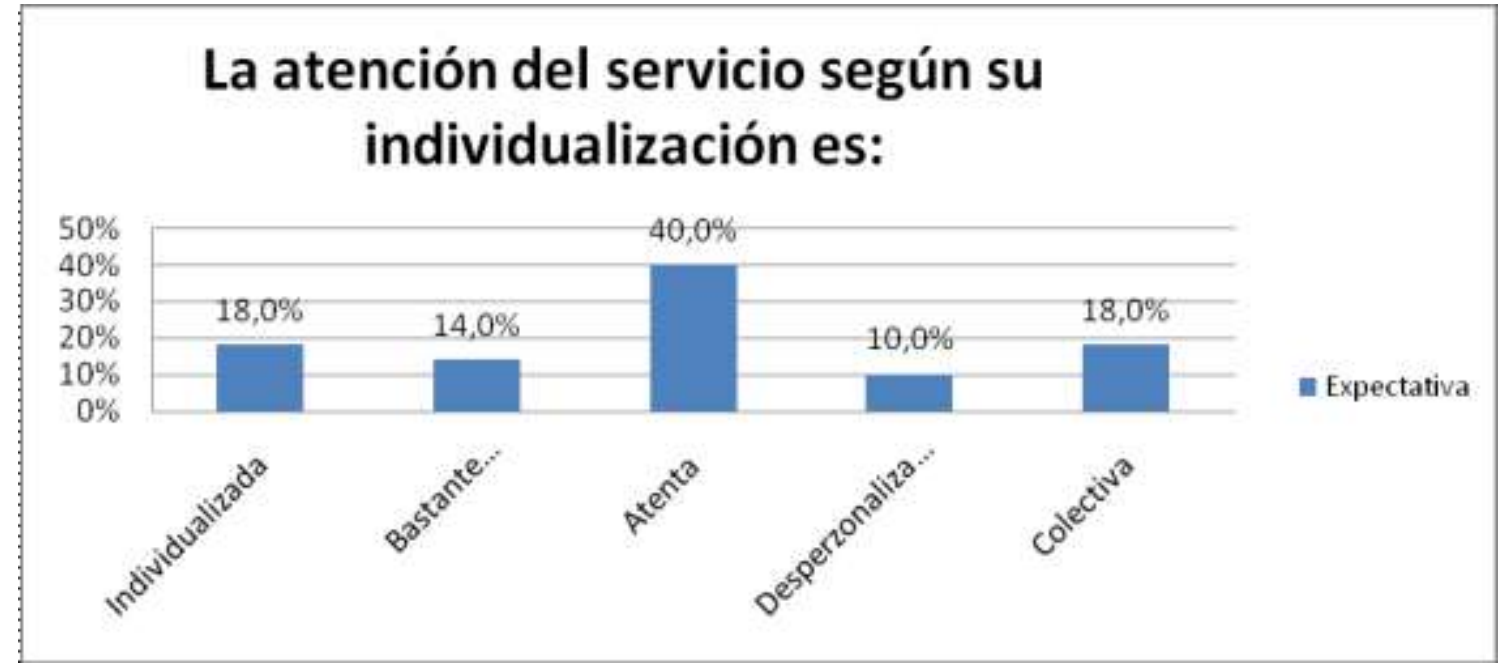

Saldo de respuesta: 2,96 "atenta"

\subsubsection{Percepción}

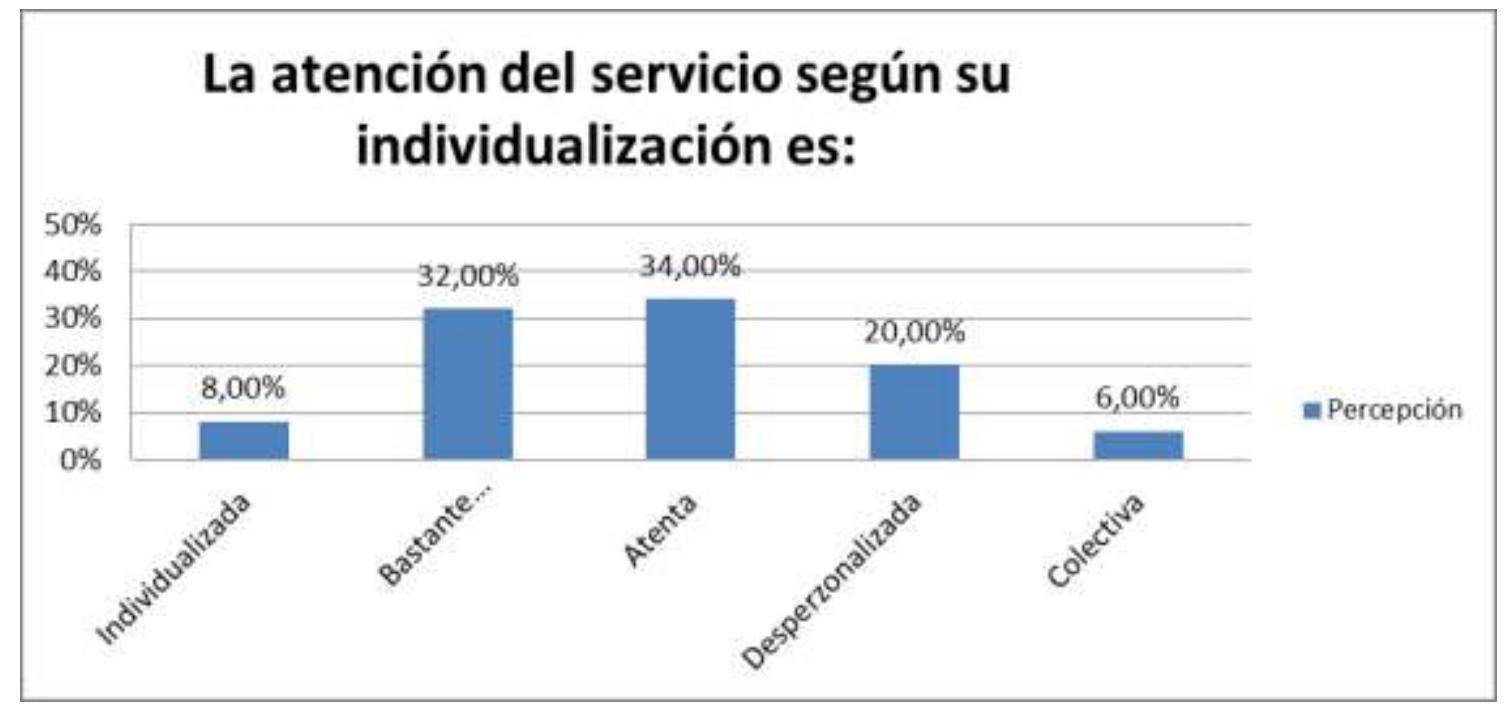

Saldo de respuesta: 2,84 "atenta" con tendencia a "bastante individualizada" 


\subsubsection{Brecha}

\section{La atención del servicio según su individualización es:}
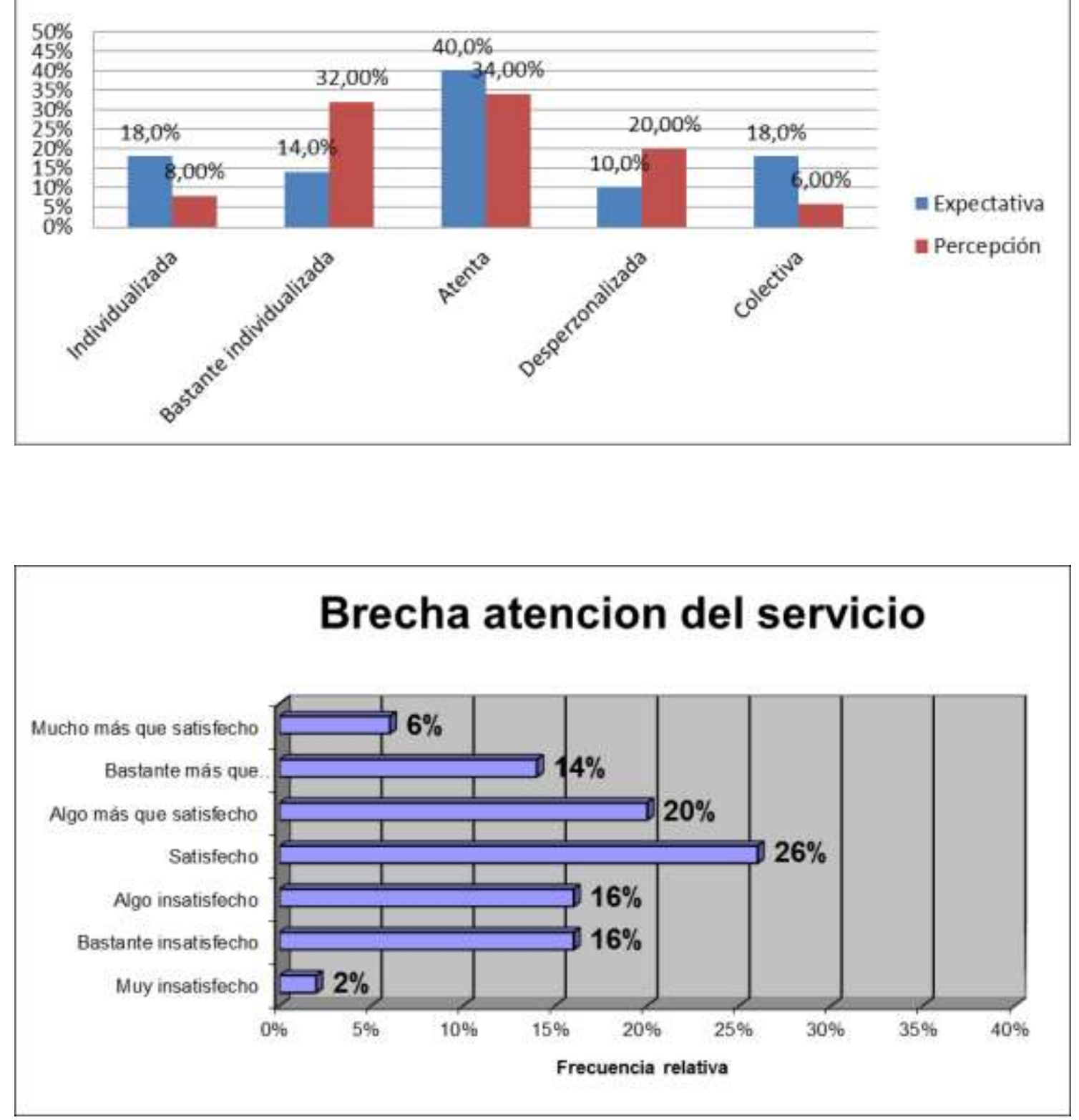

Saldo de respuesta: 0,12 "Satisfecho". 


\subsubsection{Conveniencia de los horarios de trabajo}

\subsubsection{Expectativa}

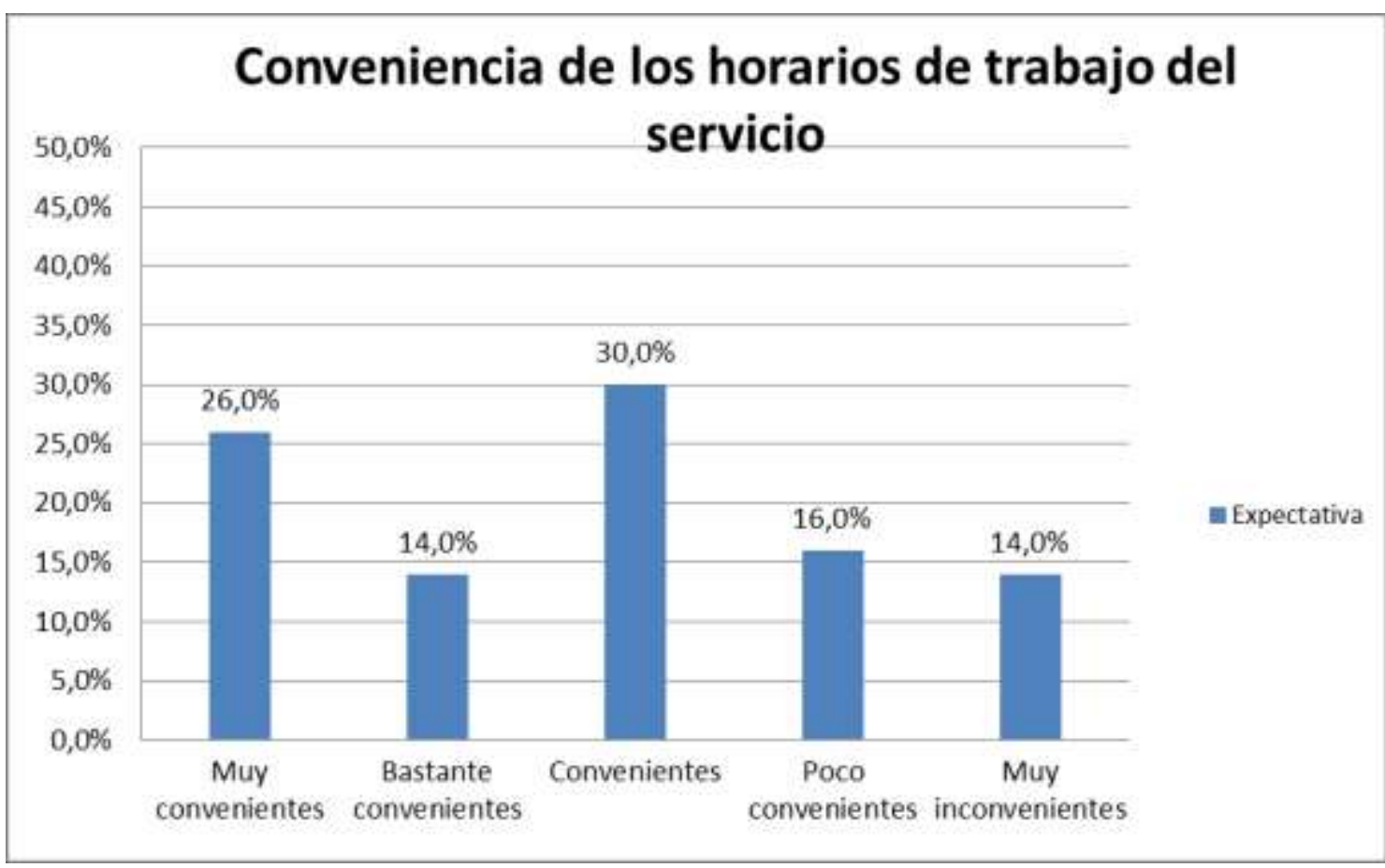

Saldo de respuesta: 2,78 "Bastante convenientes" con tendencia a "convenientes"

\subsubsection{Percepción}

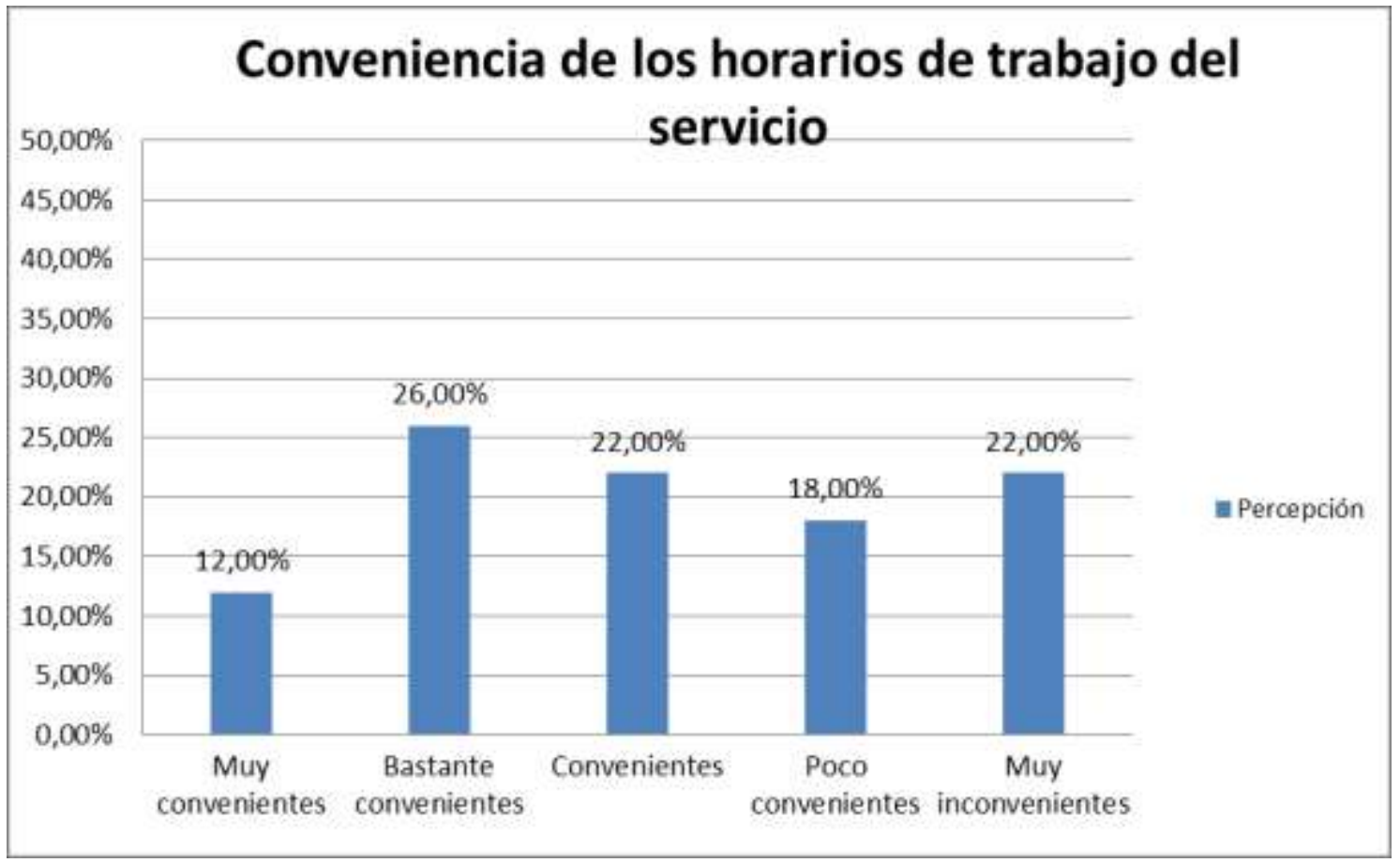


El Saldo de Respuesta de la conveniencia percibida en los horarios de trabajo del servicio es de 3,12 lo que implica que son Convenientes con una leve tendencia a Poco Convenientes.

\subsubsection{Brecha}
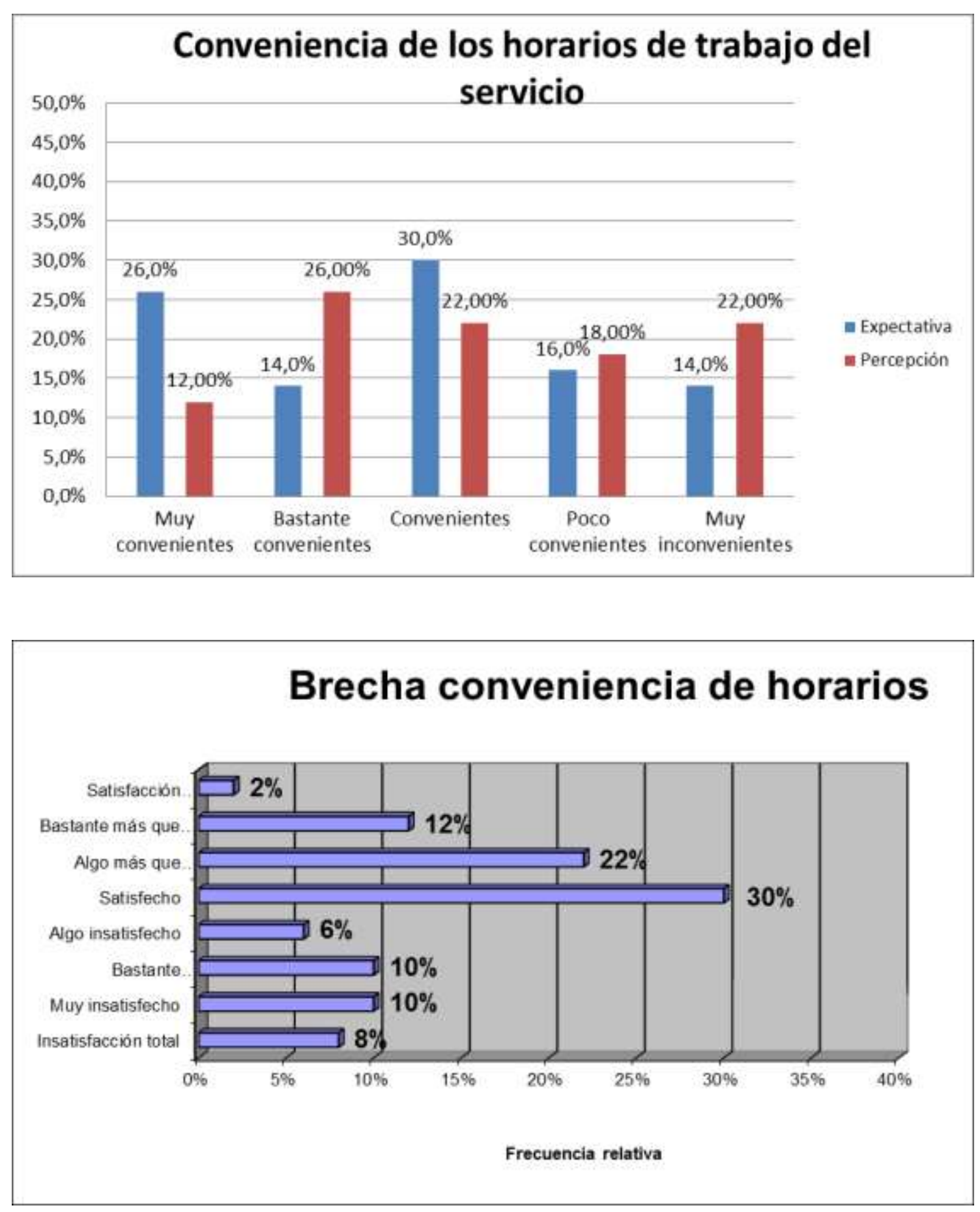

Saldo de respuesta: - 0,34 "algo insatisfecho" 


\subsubsection{Nivel de personalización en la atención del servicio}

\subsubsection{Expectativa}

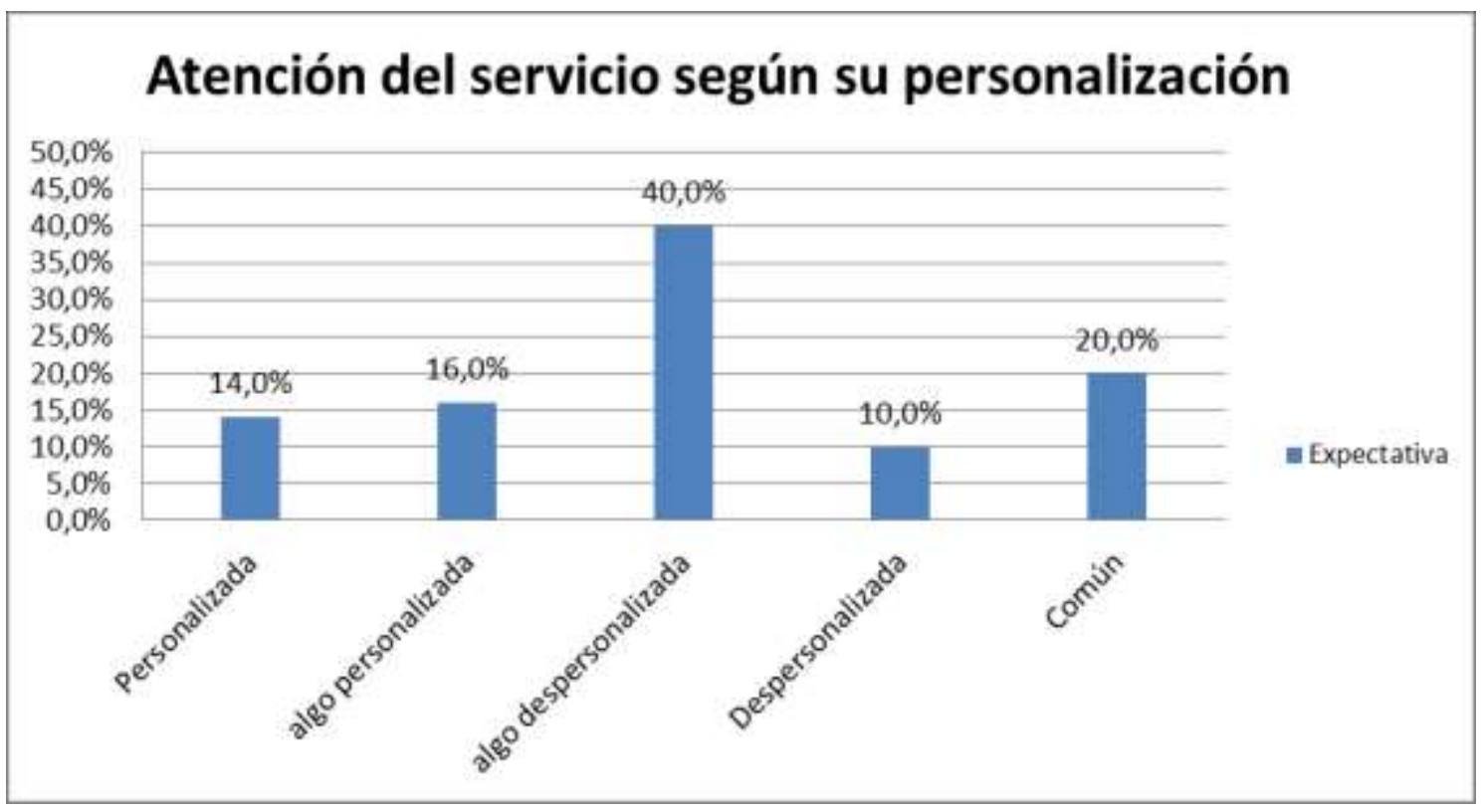

Saldo de respuesta: 3,06 "algo despersonalizada"

\subsubsection{Percepción}

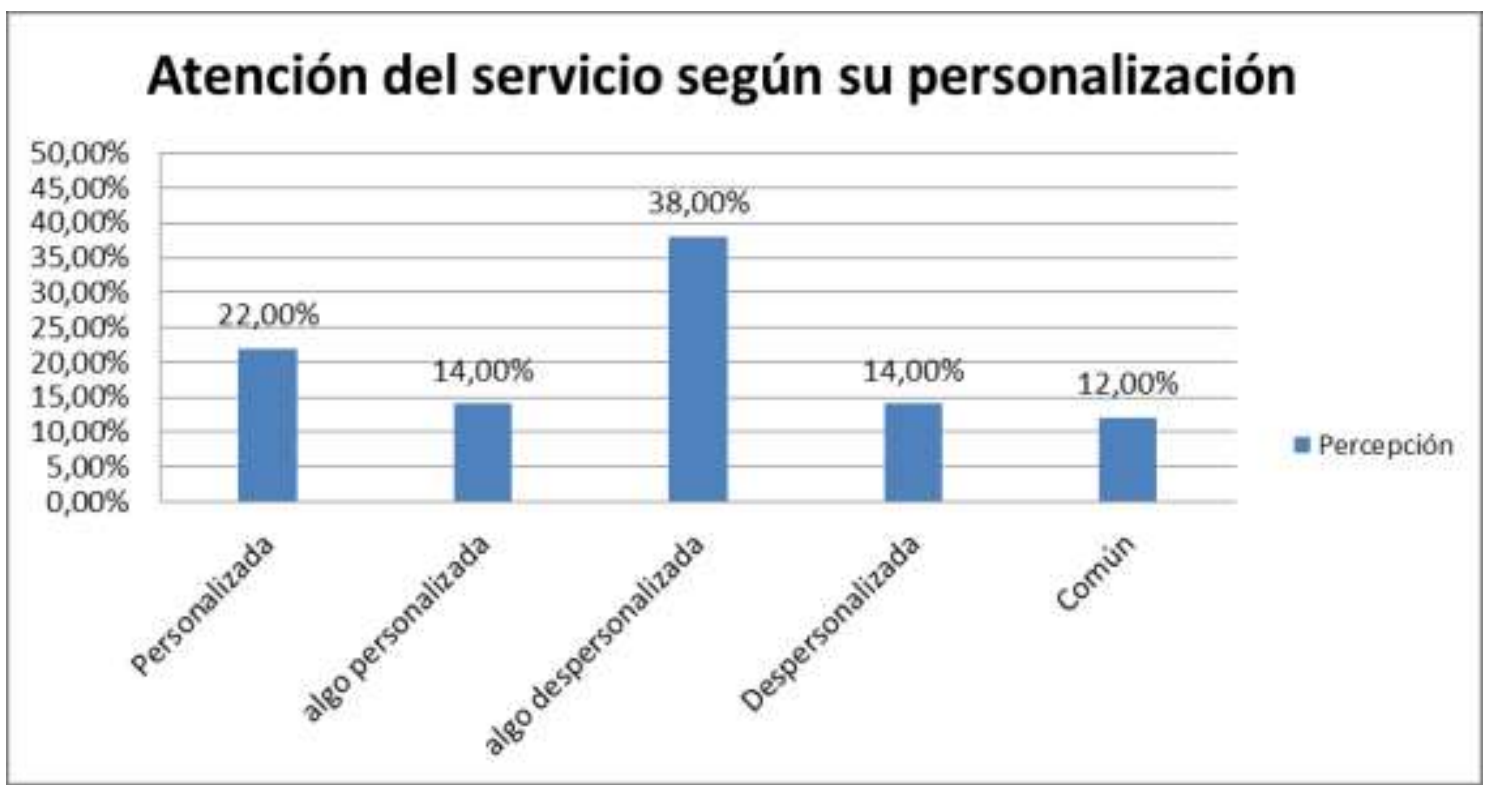

La calificación de la atención personalizada recibió una puntuación según el Saldo de Respuesta de 2,80 lo que implica que es "algo despersonalizada" con tendencia a "algo personalizada". 
A continuación se analiza la brecha entre las expectativas y las percepciones que se obtuvieron en la Dirección Operativa de Licencias de Conducir.

\subsubsection{Brecha}
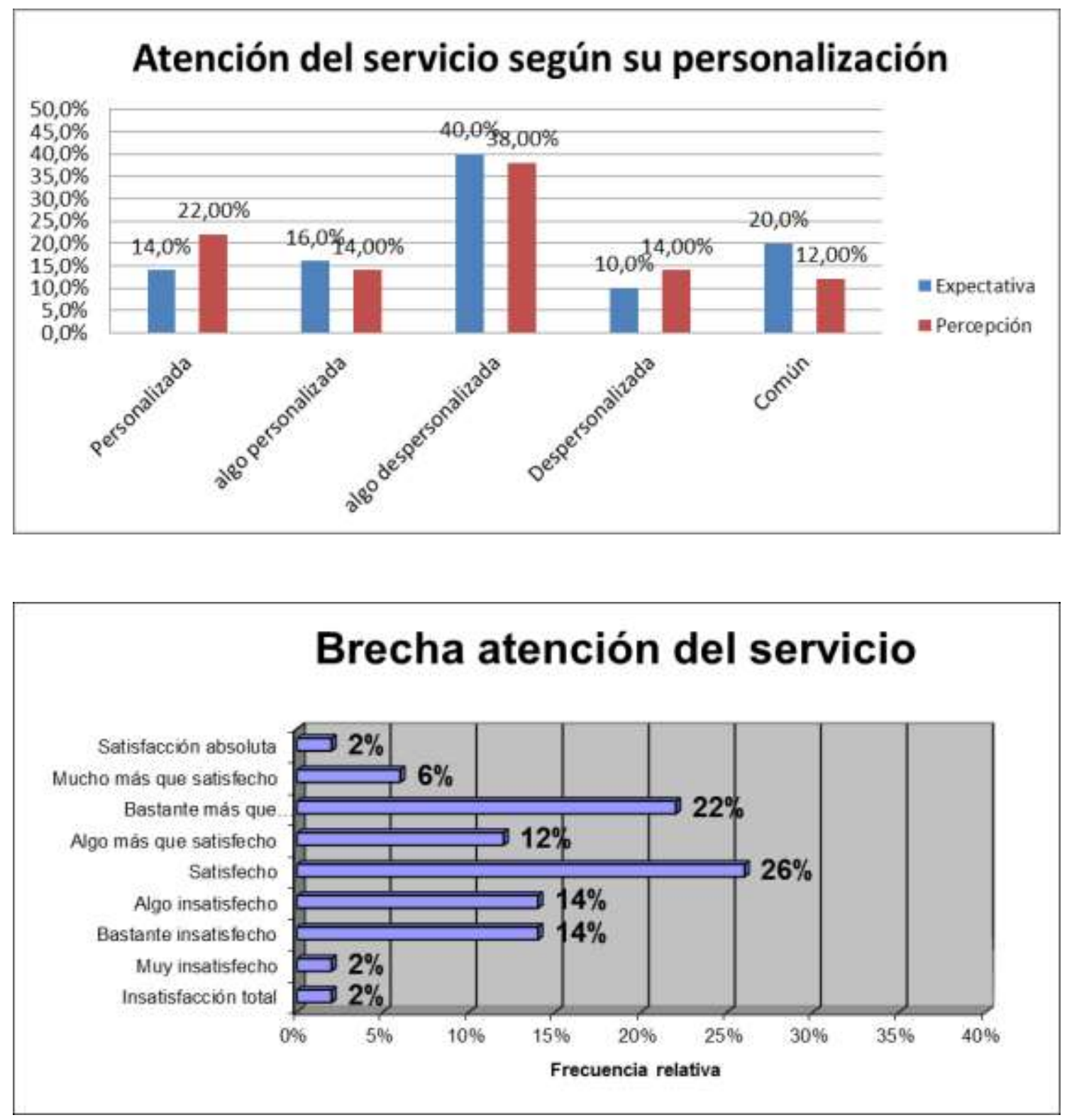

Saldo de respuesta: 0,26 "Satisfecho". 
7.7.4 Grado de preocupación que tienen los empleados por los intereses del cliente

\subsubsection{Expectativa}

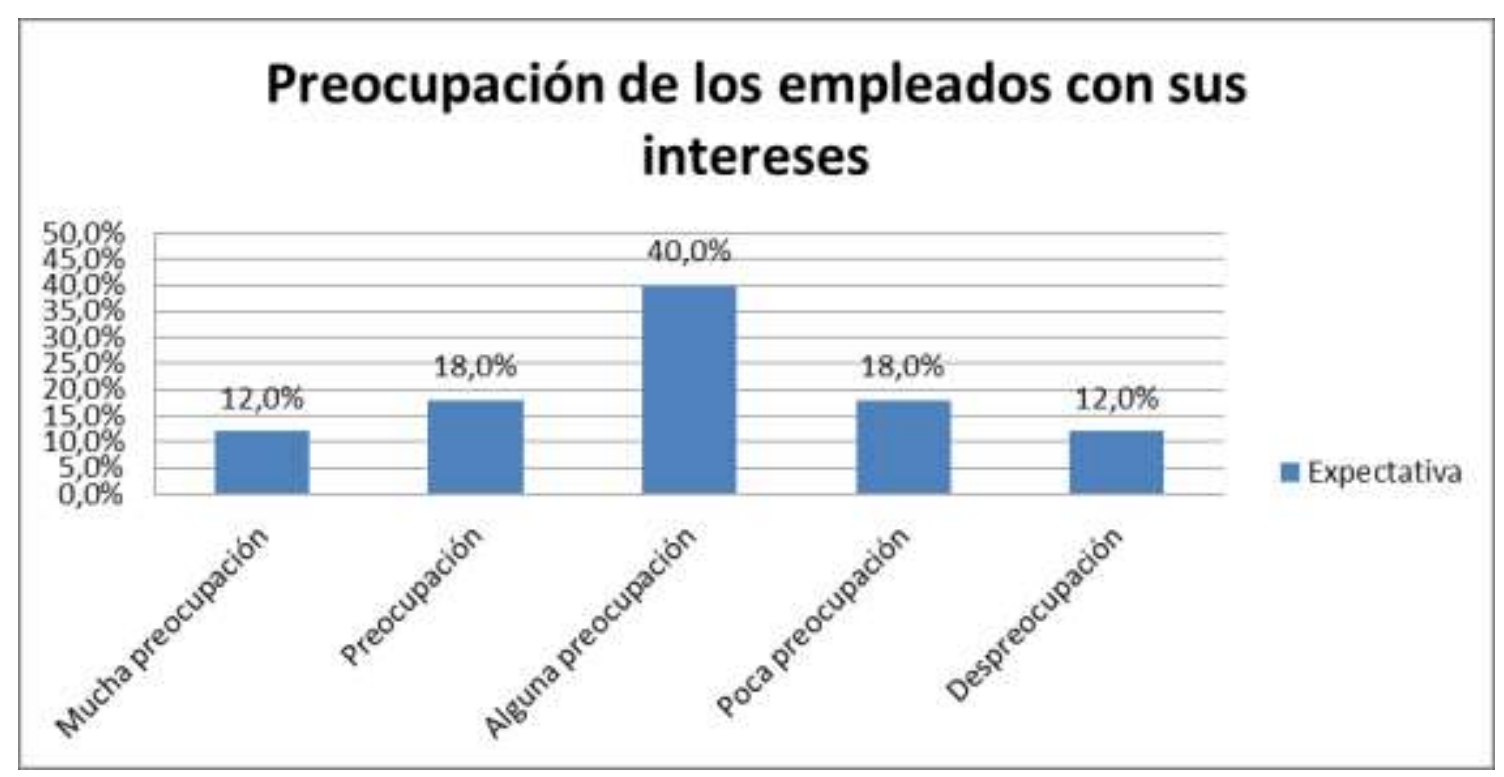

Saldo de respuesta: 3 "alguna preocupación"

\subsubsection{Percepción}

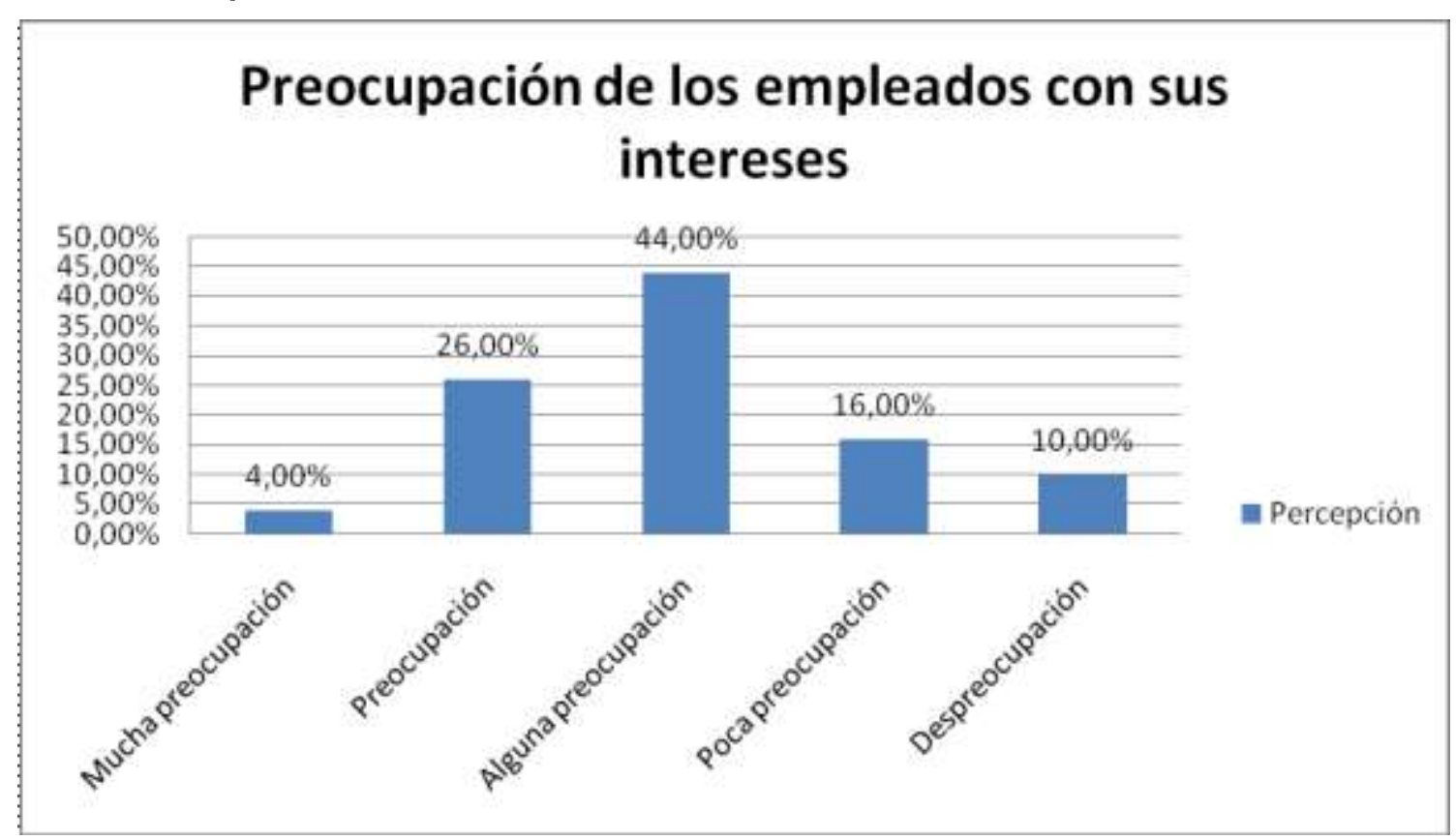

Con un Saldo de Respuesta de 3,02 perciben que los empleados muestran "alguna preocupación" por sus intereses. 


\subsubsection{Brecha}
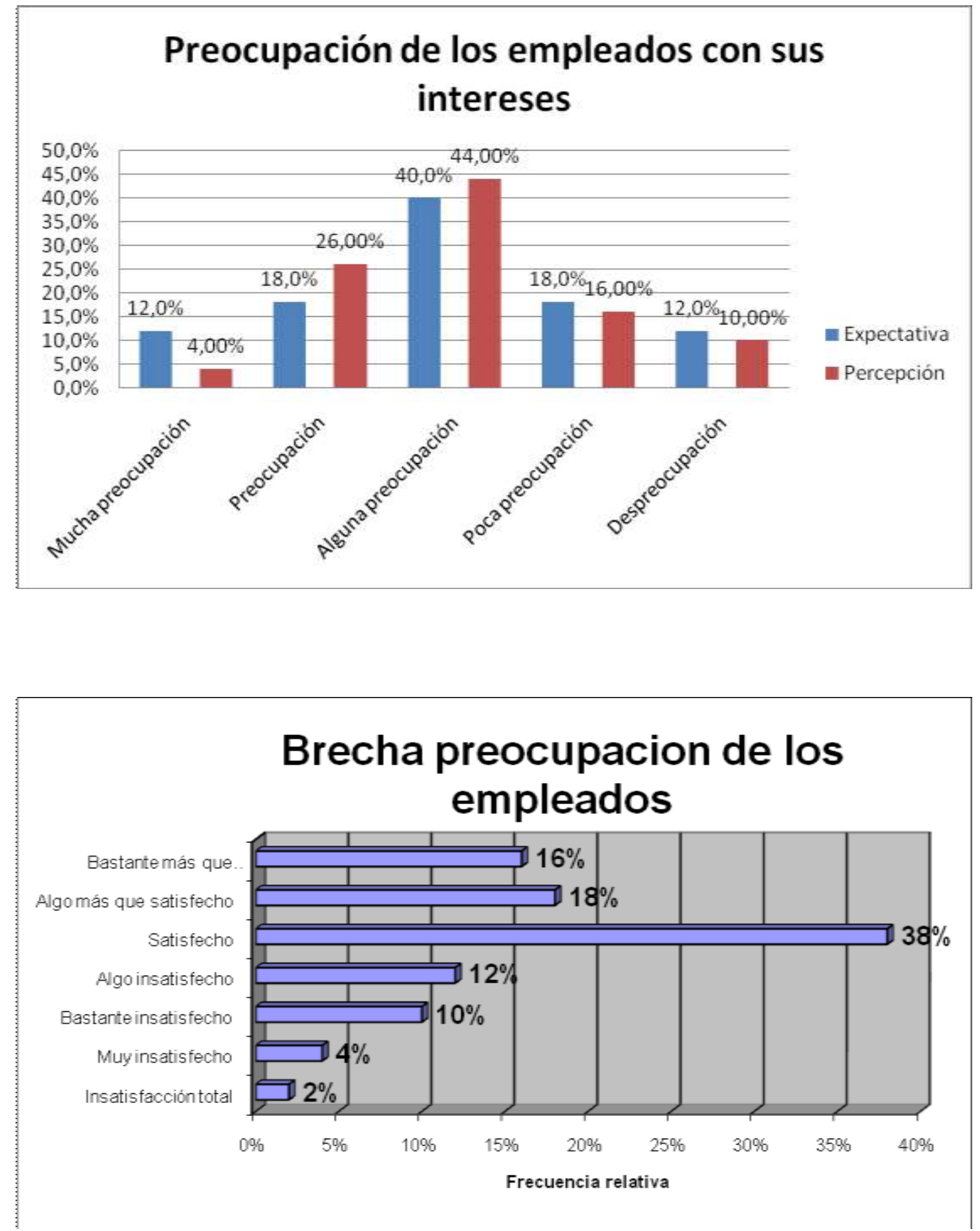

Saldo de respuesta: -0,02 "satisfecho" 
7.7.5 Grado en que el servicio comprende las necesidades específicas del cliente

\subsubsection{Expectativa}

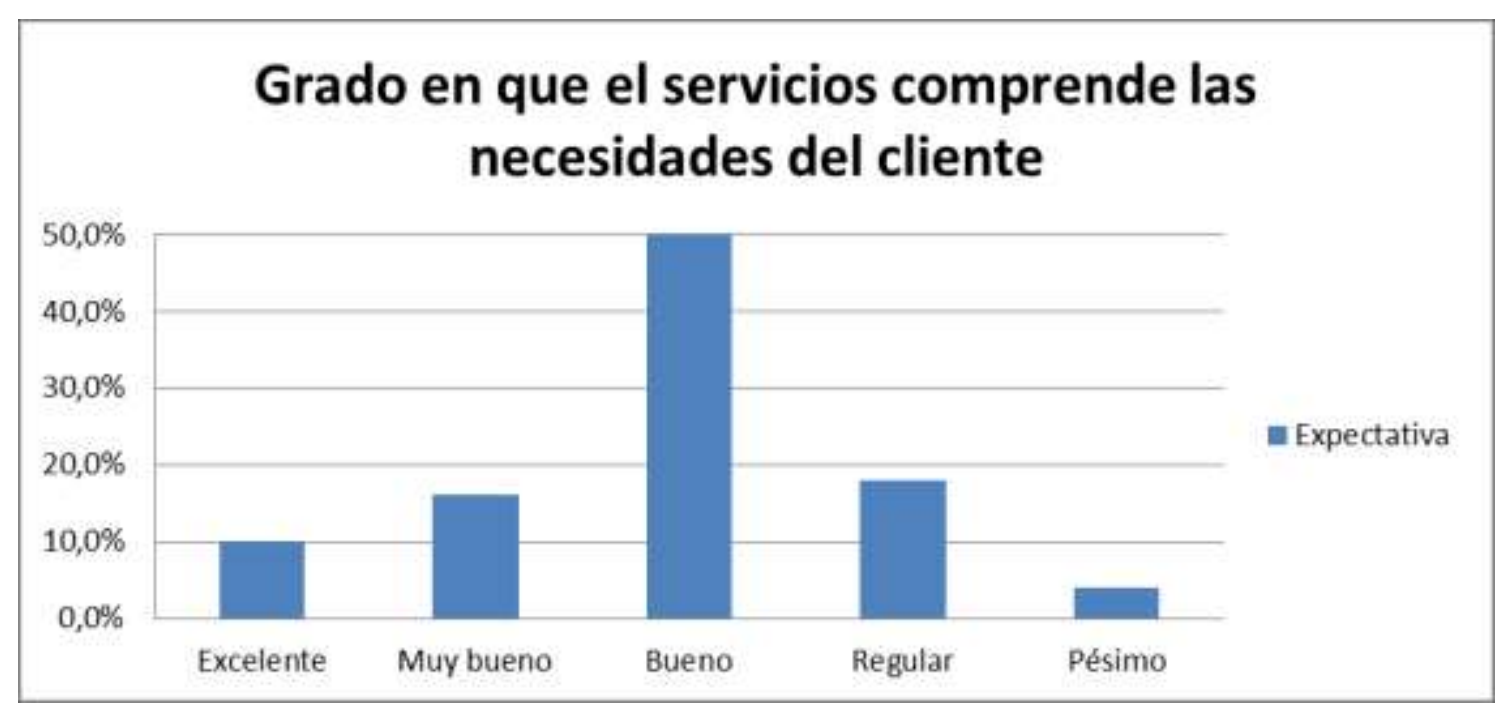

Saldo de respuesta: 2,90 "bueno" con tendencia a "muy bueno"

\subsubsection{Percepción}

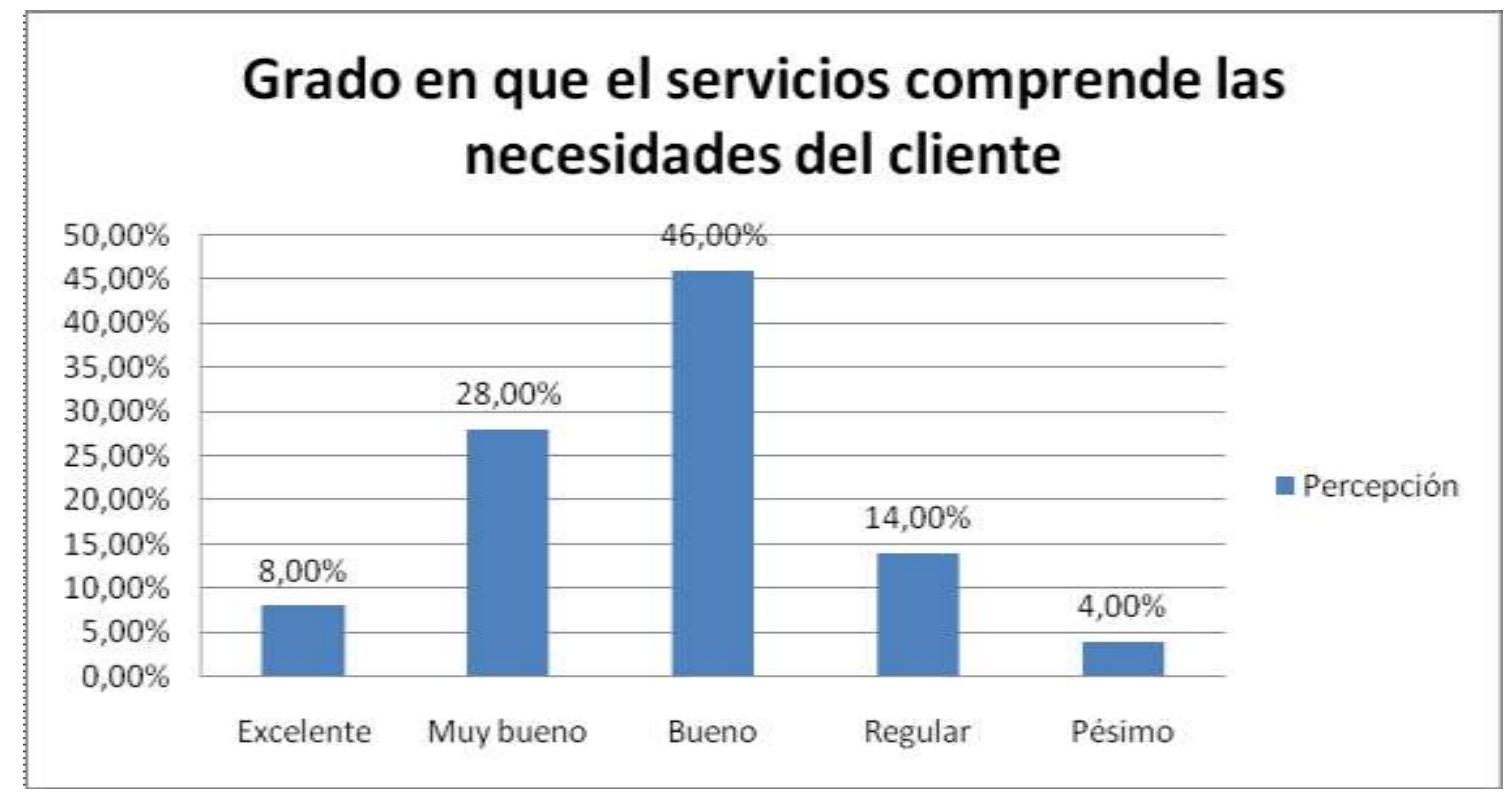

Con un Saldo de Respuesta de 2,78 se ha percibido que el grado de comprensión de las necesidades del cliente es Bueno con tendencia a Muy Bueno. 


\subsubsection{Brecha}
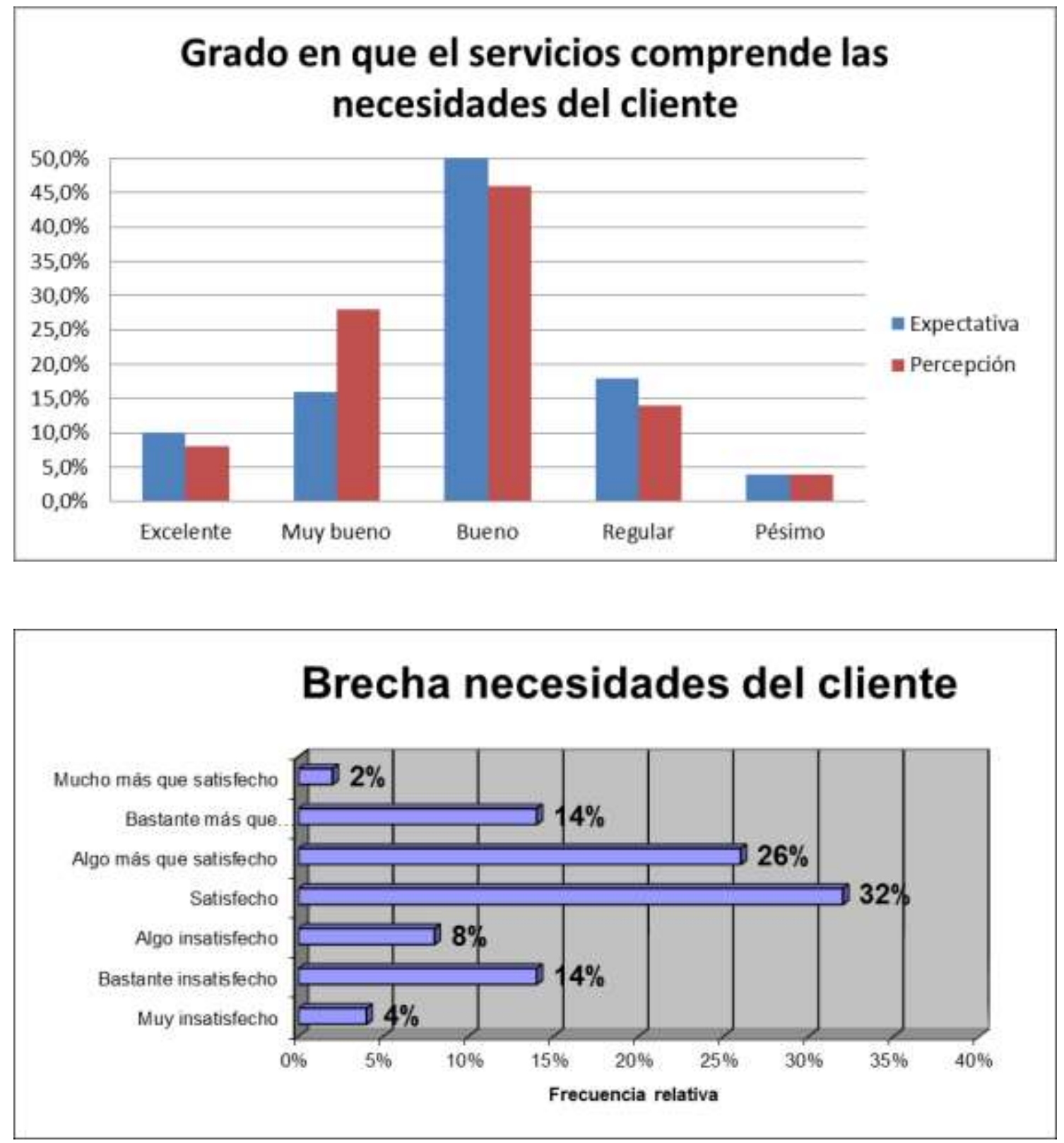

Saldo de respuesta: 0,12 "Satisfecho"

7.8 ¿Cuál es la dimensión más importante para el cliente de la Dirección Operativa de Licencias de Conducir?

La dimensión más importante para los usuarios del servicio de Licencias de Conducir es la Capacidad de Respuesta. Le sigue en importancia la dimensión IV, Seguridad, siendo la tercera La Confiabilidad, seguida en importancia por Elementos Tangibles y queda en último lugar la Dimensión $\mathrm{V}$ Empatía. 


\begin{tabular}{|l|r|r|}
\hline \multicolumn{1}{|c|}{ Dimensión } & \multicolumn{1}{c|}{ Valor } & Importancia \\
\hline Capacidad de respuesta & 2,34 & $1^{\circ}$ \\
\hline Seguridad & 2,59 & $2^{\circ}$ \\
\hline Confiabilidad & 2,85 & $3^{\circ}$ \\
\hline Elementos tangibles & 3,54 & $4^{\circ}$ \\
\hline Empatía & 5,00 & $5^{\circ}$ \\
\hline
\end{tabular}

7.9 Calificación global de la percepcion de los usuarios de la Dirección Operativa de Licencias de Conducir

\begin{tabular}{|l|r|r|}
\hline Calificación & Frecuencia & Calificación \\
\hline Excelente & 183 & $16,6 \%$ \\
\hline Bueno & 273 & $24,8 \%$ \\
\hline Regular & 384 & $34,9 \%$ \\
\hline Malo & 171 & $15,5 \%$ \\
\hline Pésimo & 89 & $8,1 \%$ \\
\hline \multicolumn{1}{|c|}{ Total } & 1.100 & \\
\hline
\end{tabular}

Con un Saldo de respuesta de 2,74 la calificación global es "Regular" (con tendencia a "Bueno").

7.9 Calificación global de la expectativa de los usuarios de la Dirección Operativa de Licencias de Conducir

\begin{tabular}{|l|r|r|}
\hline Calificación & Frecuencia & Calificación \\
\hline Excelente & 156 & $14,2 \%$ \\
\hline Bueno & 149 & $13,5 \%$ \\
\hline Regular & 402 & $36,5 \%$ \\
\hline Malo & 232 & $21,1 \%$ \\
\hline Pésimo & 161 & $14,6 \%$ \\
\hline \multicolumn{1}{|c|}{ Total } & 1.100 & \\
\hline
\end{tabular}

Con un Saldo de respuesta de 3,08 la calificación global es "Regular" (con tendencia a "malo"). 
7.10 Brecha global entre las expectativas y percepciones de los usuarios de la Dirección de Defensa del Consumidor.

\begin{tabular}{|c|c|c|c|}
\hline \multicolumn{2}{|r|}{ Calificación } & Frecuencia & Calificación \\
\hline-4 & Insatisfacción total & 7 & $0,6 \%$ \\
\hline-3 & Muy insatisfecho & 36 & $3,3 \%$ \\
\hline-2 & Bastante insatisfecho & 114 & $10,4 \%$ \\
\hline-1 & Algo insatisfecho & 141 & $12,8 \%$ \\
\hline 0 & Satisfecho & 294 & $26,7 \%$ \\
\hline 1 & Algo más que satisfecho & 225 & $20,5 \%$ \\
\hline 2 & Bastante más que satisfecho & 202 & $18,4 \%$ \\
\hline 3 & Mucho más que satisfecho & 65 & $5,9 \%$ \\
\hline 4 & Satisfacción absoluta & 16 & $1,5 \%$ \\
\hline & Total & 1100 & $100,0 \%$ \\
\hline
\end{tabular}

Con un Saldo de respuesta de 0,34 la calificación global es "Satisfecho".

7.11 Resumen de saldos de respuesta por genero de los usuarios de la Dirección de Defensa del Consumidor.

\begin{tabular}{|c|c|c|c|}
\hline Sexo & Expectativas & Percepciones & Brecha \\
\hline Mujeres & 2,773 & 3,172 & 0,399 \\
\hline Hombres & 2,716 & 3,036 & 0,320 \\
\hline
\end{tabular}

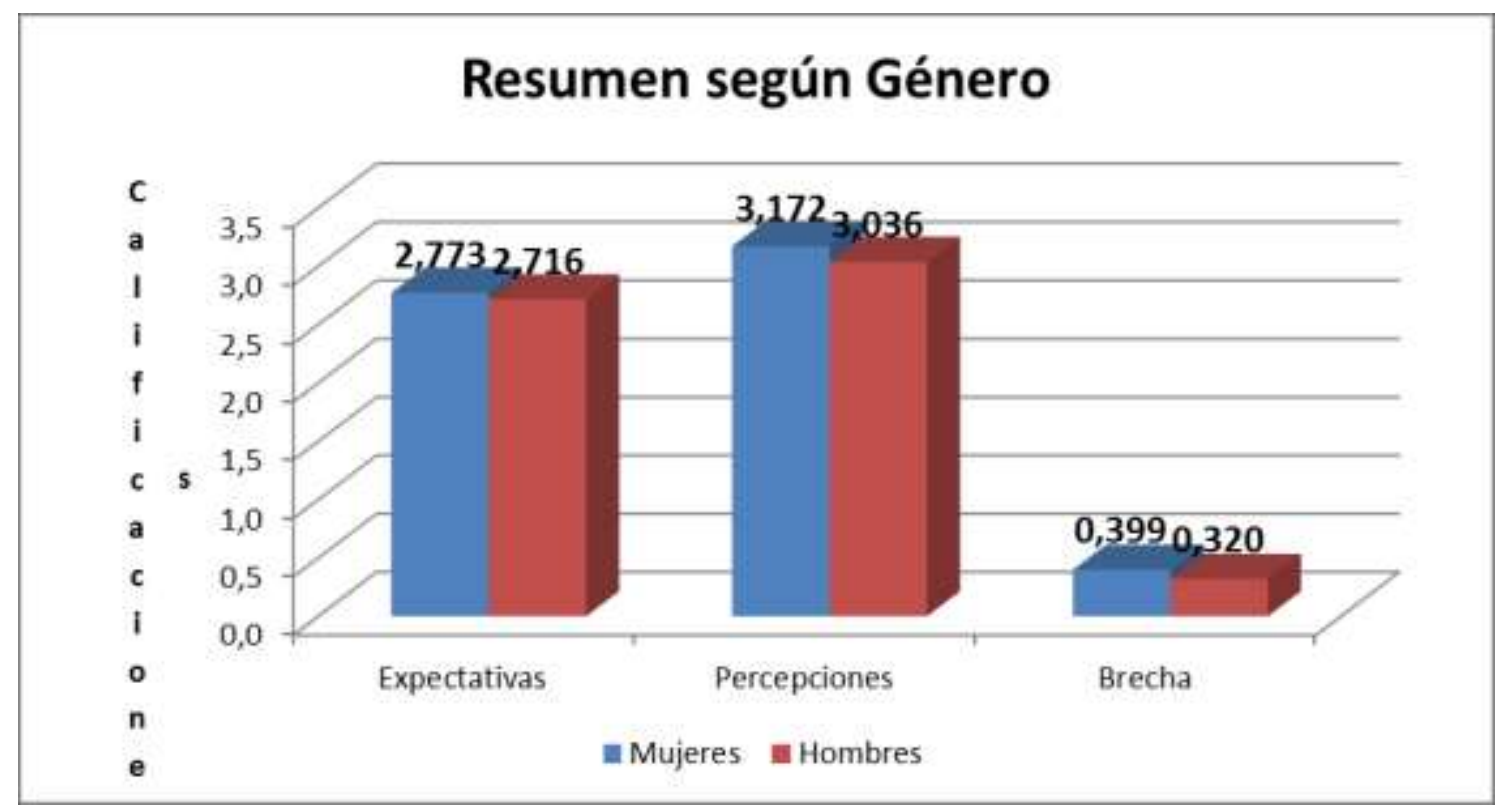


$\underline{7.12}$ Resumen de saldos de respuesta por edad de los usuarios de la Dirección de Defensa del Consumidor.

\begin{tabular}{|l|r|r|r|}
\hline \multicolumn{1}{|c|}{ Edad } & Expectativas & Percepciones & \multicolumn{1}{c|}{ Brecha } \\
\hline Hasta 20 años & 3,182 & 3,227 & 0,045 \\
\hline E/ 20 Y 30 años & 2,748 & 3,190 & 0,442 \\
\hline E/ 30 y 40 años & 2,682 & 3,277 & 0,595 \\
\hline E/ 40 y 50 años & 2,403 & 2,903 & 0,500 \\
\hline E/ 50 y 60 años & 3,173 & 3,027 & $-0,145$ \\
\hline Más de 60 años & 3,045 & 2,784 & $-0,261$ \\
\hline
\end{tabular}

\section{Conclusiones}

La calificación que le dan los usuarios a la organización del servicio en general es Regular.

Las mujeres son un poco más críticas que los hombres, concurren al servicio con unas expectativas levemente menores a las de los hombres y presentan mayor brecha.

En lo relativo a edades, las expectativas respecto de la calidad del servicio van en aumento con la edad hasta los 50 años y cae en los mayores. Los más críticos son los de la franja de entre 30 y 40 años y los menos críticos son los mayores de 60 años quienes, sin embargo, son los más insatisfechos (producto de una baja expectativa), seguidos por los de entre 50 y 60 años. Los más satisfechos son los que se hallan en la franja de 30 a 40 años (por bajas expectativas) y los que van por primera vez (menores de 20 años) ven cubiertas sus expectativas.

Al analizar los resultados en forma global de las expectativas y percepciones de los usuarios del servicio, se desprende que en la gran mayoría de las dimensiones, el servicio de Licencias de Conducir que brinda la Municipalidad de La Plata, alcanza las expectativas que los usuarios traían al solicitar el servicio. Sin embargo debe tenerse en cuenta que los usuarios llegan con 
bajas expectativas a realizar el trámite. Si a esto se le añade que los usuarios por las características del servicio: renovación de la licencia de conducir-en su mayoría ya han concurrido en otras oportunidades a realizar un trámite similar, y por lo cual ya están al tanto del servicio que van a recibir, esto indicaría cierta adecuación por parte de los usuarios al servicio que van a recibir y no esperan mejoría a lo ya obtenido en el pasado.

Acorde con Lovelock", "...cuando las expectativas del servicio son bajas y la prestación del servicio real es mejor que el deprimido nivel que se esperaba, difícilmente se puede hablar de la existencia de calidad en el servicio".

Es de destacar que los consultados definieron a la dimensión capacidad de respuesta como la más importante. Luego le siguen en valoración la seguridad, la confiabilidad, los elementos tangibles y finalmente a la empatía.

El orden del tratamiento de las dimensiones no se hace en función de como fueron relevadas en la encuesta sino por la importancia asignada por los usuarios.

En lo que respecta a la Capacidad de Respuesta, la subdimensión a priorizar -menor brecha entre expectativas y percepciones- es la de "Atención inmediata". Le sigue el "Nivel de comunicación de los empleados", la "Disponibilidad en la atención" y finalmente la "Velocidad del servicio". Cabe destacar que todas las brechas son positivas.

En lo relativo a la dimensión IV, Seguridad, la menor brecha es para grado de conocimiento de los empleados para resolver las inquietudes de los usuarios. Le siguen la seguridad en las transacciones del servicio, la amabilidad de los empleados $\mathrm{y}$, finalmente, la confianza en los empleados del servicio de Licencias de Conducir. También en esta dimensión todas las brechas son positivas.

${ }^{2}$ Lovelock, C. (1997). Mercadotecnia de servicios. Tercera Edición, Editorial Prentice Hall, México 
En lo referente a la Confiabilidad, los usuarios se mostraron levemente insatisfechos en lo que concierne al cumplimiento de los empleados. El resto de las subdimensiones, si bien presentan brechas positivas, son mínimas para Eficiencia y para Eficacia y un poco mayores para Interés de empleados y Tiempo.

Respecto de la dimensión I, los Elementos Tangibles, los usuarios se mostraron levemente insatisfechos en lo relativo a Equipos. El resto de las subdimensiones presenta brechas levemente positivas, en el siguiente orden de menor a mayor: Apariencia visual, Instalaciones físicas y Apariencia física.

Finalmente, la dimensión V Empatía, los usuarios se manifestaron algo insatisfechos con Horarios y Preocupación. El resto de las subdimensiones fueron levemente satisfactorias, en orden de menor a mayor: Individualización, Comprende necesidades y Personalización.

En síntesis, la Dirección de Licencias de Conducir de la Municipalidad de La Plata provoca usuarios algo insatisfechos con la calidad del servicio. Puntualmente presentan expectativas no satisfechas en lo que hace a la confiabilidad del servicio, elementos tangibles y empatía.

Por otra parte, los usuarios albergan bajas expectativas, lo cual permite concluir que la calidad del servicio de esta repartición tiene mucho por hacer. Acorde con la diferenciación entre las definiciones de "cliente" y "usuario" mencionadas en el acápite "Definición de términos básicos", en una repartición pública de estas características no tendría diferencias, ya que el usuario vuelve por el servicio, lo que lo transformaría en cliente, pero esto es cierto en la medida en que lo hace voluntariamente y porque tiene alternativas para elegir de a quien adquirir el producto o servicio, lo cual no es el caso por tratarse de un servicio monopólico. Por ello, el desafío para la Dirección de Licencias de Conducir de la Municipalidad de La Plata es que los "usuarios" se transformen en "clientes", es decir que cuando vuelvan -debido a las normativas que lo determinan- sea porque se dan las características tales que si fuera un servicio no monopólico, igual elegiría el ofrecido por la repartición de referencia. 


\section{Bibliografía}

- Álvarez, M. (1998): El liderazgo de la calidad total. Madrid: Editorial Escuela Española.

- Asensio, P. (2008). Marketing municipal. Madrid: Díaz de Santos.

- Badia A. (1999): Técnicas para la gestión de Calidad. Ed. Técnoc.

- Bernillon, A.; Cerutti, O. (1989): Implantar y gestionar la calidad total. Barcelona: Gestió 2.000.

- Cantú Delgado; Humberto -- Desarrollo de una cultura de calidad / rev. téc. Jesús Cantú Rodríguez-- Editorial McGraw-Hill, c2001.

- Deming WE. (1989): Calidad, productividad y competitividad. La salida de la crisis. Madrid: Díaz de Santos.

- Dona Bedian, a. (1991): " La calidad de la atención médica. Definición y métodos de evaluación", Méjico: La Prensa Médica Mexicana.

- Donnelly, M. \& Shiu, E. (1999). Assessing Service Quality and its Link with value for Money in a UK Local Authority's Housing Repairs Service Using the SERVQUAL Approach. Total Quality Management, 10(4/5), 498-506.

- Donnelly, M., Wisniewski, M., Dalrymple, J. F. \& Curry, A. C. (1995). Measuring Service Quality in Local Government: the Servqual Approach. International Journal of Public Sector Management, 8(7), 15-20

- Drummond, H. (1995): Qué es hoy la calidad total: el movimiento de la calidad. Bilbao: Deusto D.L.

- Feigenbaum; Armand V. tr. Ma. Ascención G. de la Campa Pérez - Control total de la calidad / -- Editorial CECSA, c1994 Título original: Total quality control.

- Fernández Barcalá, M. (2000). Validación de Servqual como instrumento de medida de la calidad de servicio bancario. Revista Europea de Dirección y Economía de la Empresa, 9(1), 57-70.

- Galgano, A. (1995): Los siete instrumentos de la calidad total: manual operativo. Madrid: Díaz de Santos.

- Gaster, L. (1996). Quality Services in Local Government: a Bottom-Up Approach. Journal of Management Development, 15(2), 80-96. 
- Gil, I. (1996). La evaluación de la calidad de servicio percibida y las limitaciones de la herramienta Servqual. Revista Europea de Dirección y Economía de la empresa, 5(2), 19-32.

- Gutiérrez, Mario (1989) Administrar para la calidad: conceptos administrativos del control total de calidad / -- Editorial Limusa.

- Gutiérrez, P. \& Jorge, M. (2008). El desarrollo de políticas públicas locales como garantes de la satisfacción de los ciudadanos. Madrid: Fundación Alternativas.

- Grima Cintas, P; Tort-Martorell, J (1995): Técnicas para la gestión de la calidad. Madrid: Díaz de Santos. Ishikawa K.

- J.M. Juran editor jefe, Frank M. Gryna editor asociado, tr. Josep María Vallhonrat Bou - Manual de control de calidad.-- Editorial McGraw-Hill, c1993.

- Kotler, P. \& Lee, N. (2007). Marketing en el sector público. Madrid: Prentice Hall. (Original en inglés, 2006).

- Méndez, J. M. (1996). Servicios municipales: análisis de situación y líneas de mejora sugeridas. Barcelona: Diputación de Barcelona, Papers de Formación Municipal, 25.

- Santesmases Mestre, M. (2007). Marketing: conceptos y estrategias. Madrid: Ediciones Pirámide.

- Sancho Royo, D. (1999). Gestión de servicios públicos: estrategias de marketing y calidad. Madrid: Ed. Tecnos.

- Scott, D. \& Shieff, D. (1993). Service Quality Components and Group Criteria in Local Government. International Journal of Service Industry Management, 4(4), 42-53.

- Senllé, A. (1996). Calidad total en los servicios y en la administración pública. Barcelona: Ed. Gestión 2000. 


\section{Referencias y Anexos}

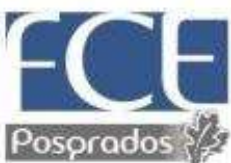

facultad de

Ciencias Económicas

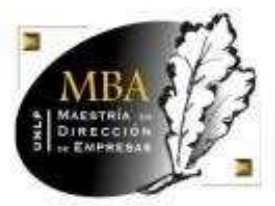

MAESTRIA EN

DIRECCIÓN DE EMPRESAS

Encuesta $\mathrm{N}^{\circ}$

Encuesta dirigida a clientes del servicio de Licencias de Conducir de la Municipalidad de La Plata.

\section{OBJETIVO}

Medir la satisfacción de los clientes del servicio de Licencias de Conducir de la Municipalidad de La Plata.

1.- ¿Con que frecuencia utiliza el servicio de Licencias de Conducir?

\begin{tabular}{|l|l|}
\hline 1) A diario & \\
\hline 2) Varias veces a la semana & \\
\hline 3) Una vez al mes & \\
\hline 4) Una vez cada seis meses & \\
\hline 5) Una vez al año & \\
\hline 6) Cada varios años & \\
\hline
\end{tabular}

2.- ¿Cómo calificaría la organización del servicio de Licencias de Conducir?

\begin{tabular}{|l|l|}
\hline 1) Excelente & \\
\hline 2) Bueno & \\
\hline 3) Regular & \\
\hline 4) Malo & \\
\hline 5) Pésimo & \\
\hline
\end{tabular}

3.- En las siguientes preguntas, califique de 1 a 5 según corresponda

Dimensión 1: Elementos Tangibles

\begin{tabular}{|l|l|l|}
\hline $\begin{array}{l}\text { Apariencia de las instalaciones físicas, equipos, personal y } \\
\text { materiales de comunicación }\end{array}$ & Expectativa & Percepción \\
\hline $\begin{array}{l}\text { Los equipos con que cuenta el servicio son... [1 = Modernos a } 5= \\
\text { Obsoletos] }\end{array}$ & & \\
\hline
\end{tabular}




\begin{tabular}{|l|l|l|l|}
\hline $\begin{array}{l}\text { Las instalaciones físicas del servicio son }[1=\text { Atractivas a } 5= \\
\text { Desagradables] }\end{array}$ & & \\
\hline $\begin{array}{l}\text { La apariencia física de los empleados es... [1 = Pulcra a } 5= \\
\text { Desaseada] }\end{array}$ & & \\
\hline $\begin{array}{l}\text { La apariencia visual de los elementos materiales de comunicación es... } \\
{[1=\text { Atractivos a } 5 \text { = Desagradables }]}\end{array}$ & & \\
\hline
\end{tabular}

\section{Dimensión 2: Confiabilidad}

\begin{tabular}{|c|c|c|}
\hline $\begin{array}{l}\text { Habilidad para ejecutar el servicio prometido de forma confiable y } \\
\text { cuidadosa }\end{array}$ & Expectativa & Percepción \\
\hline $\begin{array}{l}\text { Los empleados del servicio municipal cumplen lo que prometen... [1 = } \\
\text { Siempre Cumplen a } 5=\text { Nunca Cumplen] }\end{array}$ & & \\
\hline $\begin{array}{l}\text { El interés que tienen los empleados del servicio en solucionar los } \\
\text { problemas de los clientes es... }[1=\text { Total Interés a } 5=\text { Completo } \\
\text { Desinterés] }\end{array}$ & & \\
\hline $\begin{array}{l}\text { La eficacia del servicio municipal es... [1 = Realiza el trabajo bien a la } \\
\text { primera vez a } 5=\text { nunca lo hace bien] }\end{array}$ & & \\
\hline $\begin{array}{l}\text { El tiempo del cumplimiento del trabajo es... [1 = Siempre a tiempo a } 5 \\
\text { Nunca a tiempo] }\end{array}$ & & \\
\hline $\begin{array}{l}\text { El trabajo que el servicio mantiene según su eficiencia es... [1 = Exento } \\
\text { de errores a } 5=\text { Con serias deficiencias }]\end{array}$ & & \\
\hline
\end{tabular}

\section{Dimensión 3: Capacidad de Respuesta}

\begin{tabular}{|l|l|l|}
\hline $\begin{array}{l}\text { Disposición y voluntad de los empleados para ayudar al cliente y } \\
\text { proporcionar el servicio }\end{array}$ & Expectativa & Percepción \\
Ex nivel de comunicación que tiene con los empleados es... [1 = & & \\
\hline La velocidad del servicio es... [1 = Muy Rápido a 5 = Muy Lento] & & \\
\hline $\begin{array}{l}\text { El nivel de disponibilidad de atención es... [1 = Siempre Disponible a } 5= \\
\text { Nunca Disponible] }\end{array}$ & & \\
\hline El grado de disponibilidad para atención inmediata frente a otras & & \\
actividades es... [1 = Siempre disponible a $5=$ Nunca Disponible] & & \\
\hline
\end{tabular}

\section{Dimensión 4: Seguridad}

\begin{tabular}{|l|l|l|}
\hline $\begin{array}{l}\text { Conocimiento y atención mostrados por los empleados y sus } \\
\text { habilidades para inspirar credibilidad y confianza }\end{array}$ & Expectativa & Percepción \\
\hline $\begin{array}{l}\text { La confianza que brinda el comportamiento de los empleados es... [1 = } \\
\text { Completa Confianza a } 5 \text { = Absoluta Desconfianza] }\end{array}$ & & \\
\hline $\begin{array}{l}\text { El nivel de seguridad que usted siente en sus transacciones con el } \\
\text { servicio es... [1 } 1 \text { = Muy seguro a } 5=\text { Muy Inseguro] }\end{array}$ & & \\
\hline
\end{tabular}


El nivel de amabilidad que muestran los empleados del servicio es... [1 $=$ Muy Amable a 5 = Muy descortés $]$

El grado de conocimiento que tienen los empleados para resolver sus inquietudes es... [ $1=$ Totalmente Conocedor a 5 = Absolutamente Ignorante]

\section{Dimensión 5: Empatía}

\begin{tabular}{|l|l|l|}
\hline Atención individualizada que ofrece la organización a los clientes & Expectativa & Percepción \\
\hline $\begin{array}{l}\text { La atención del servicio según su individualización es... [1 = } \\
\text { Individualizada a } 5=\text { Colectiva] }\end{array}$ & \\
\hline $\begin{array}{l}\text { Los horarios de trabajo -por conveniencia- son... [1 = Muy } \\
\text { convenientes o } 5=\text { Muy Inconvenientes] }\end{array}$ & \\
\hline $\begin{array}{l}\text { La atención del servicio según su personalización es... [1 = } \\
\text { Personalizada a } 5=\text { Común] }\end{array}$ & \\
\hline $\begin{array}{l}\text { El grado de preocupación que tienen los empleados con sus intereses } \\
\text { es... }[1=\text { Mucha Preocupación a } 5=\text { Despreocupación] }\end{array}$ & \\
\hline $\begin{array}{l}\text { El grado en que el servicio comprende sus necesidades específicas } \\
\text { es... }[1=\text { Excelente a } 5=\text { Pésima] }\end{array}$ & & \\
\hline
\end{tabular}

\section{4.- Distribuya del 1 al 5 según el grado de importancia que las siguientes dimensiones} ocupan para usted en este servicio

\begin{tabular}{|l|l|}
\hline Elementos tangibles & \\
\hline Confiabilidad & \\
\hline Capacidad de respuesta & \\
\hline Seguridad & \\
\hline Empatía & \\
\hline
\end{tabular}

\section{5.- Perfil del encuestado}

Sexo $1 \square$ Hombre $2 \square$ Mujer

$$
\begin{aligned}
\text { Edad } & 1 \square \text { Hasta } 20 \text { años } \\
& 2 \square \text { Más de } 20 \text { y hasta } 30 \text { años } \\
& 3 \square \text { Más de } 30 \text { y hasta } 40 \text { años } \\
& 4 \square \text { Más de } 40 \text { y hasta } 50 \text { años } \\
& 5 \square \text { Más de } 50 \text { y hasta } 60 \text { años } \\
& 6 \square \text { Más de } 60 \text { años }
\end{aligned}
$$

$\begin{array}{ll}\text { Ocupación } \quad 1 \square \text { Independiente } \quad 2 \square \text { Empleado } 3 \square \text { Jubilado } \quad 4 \square \text { Desempleado } \\ & 5 \square \text { Otros (especifique): }\end{array}$ 
Resumen de Saldos de respuesta ordenados por importancia para el consumidor:

\begin{tabular}{|c|c|c|c|}
\hline Importancia & Dimensión & Subdimensión & Saldo de Respuesta \\
\hline \multirow{4}{*}{$1^{\circ}$} & \multirow{4}{*}{$\begin{array}{l}\text { Capacidad de } \\
\text { Respuesta }\end{array}$} & Atención inmediata & 0,38 \\
\hline & & Nivel de comunicación & 0,52 \\
\hline & & Disponibilidad & 0,72 \\
\hline & & Velocidad & 0,74 \\
\hline \multirow{4}{*}{$2^{\circ}$} & \multirow{4}{*}{ Seguridad } & Conocimiento & 0,18 \\
\hline & & Seguridad & 0,26 \\
\hline & & Amabilidad & 0,56 \\
\hline & & Confianza & 0,78 \\
\hline \multirow{5}{*}{$3^{\circ}$} & \multirow{5}{*}{ Confiabilidad } & Empleados cumplen & $-0,04$ \\
\hline & & Eficiencia & 0,04 \\
\hline & & Eficacia & 0,22 \\
\hline & & Interés de empleados & 1,00 \\
\hline & & Tiempo & 1,04 \\
\hline \multirow{4}{*}{$4^{\circ}$} & \multirow{4}{*}{ Elementos Tangibles } & Equipos & $-0,12$ \\
\hline & & Apariencia visual & 0,40 \\
\hline & & Instalaciones físicas & 0,78 \\
\hline & & Apariencia física & 0,78 \\
\hline \multirow{5}{*}{$5^{\circ}$} & \multirow{5}{*}{ Empatía } & Horarios & $-0,34$ \\
\hline & & Preocupación & $-0,02$ \\
\hline & & Individualización & 0,12 \\
\hline & & $\begin{array}{l}\text { Comprende } \\
\text { necesidades }\end{array}$ & 0,12 \\
\hline & & Personalización & 0,26 \\
\hline
\end{tabular}

